Florida International University FIU Digital Commons

$11-7-2011$

\title{
Voting with their Feet: Migration, Partisanship, and Party-Safe Elections in Florida
}

Rezwan Hussain

Florida International University, rhuss001@fiu.edu

DOI: $10.25148 /$ etd.FI11120616

Follow this and additional works at: https://digitalcommons.fiu.edu/etd

\section{Recommended Citation}

Hussain, Rezwan, "Voting with their Feet: Migration, Partisanship, and Party-Safe Elections in Florida" (2011). FIU Electronic Theses and Dissertations. 510.

https://digitalcommons.fiu.edu/etd/510 


\title{
FLORIDA INTERNATIONAL UNIVERSITY
}

Miami, Florida

\section{VOTING WITH THEIR FEET: MIGRATION, PARTISANSHIP, AND PARTY- SAFE ELECTIONS IN FLORIDA}

\author{
A dissertation submitted in partial fulfillment of \\ the requirements for the degree of \\ DOCTOR OF PHILOSOPHY \\ in \\ POLITICAL SCIENCE \\ by
}

Rezwan Hussain 
To: Dean Kenneth G. Furton

College of Arts and Sciences

This dissertation, written by Rezwan Hussain, and entitled Voting with Their Feet: Migration, Partisanship, and Party-Safe Elections in Florida, having been approved in respect to style and intellectual content, is referred to you for judgment.

We have read this dissertation and recommend that it be approved.

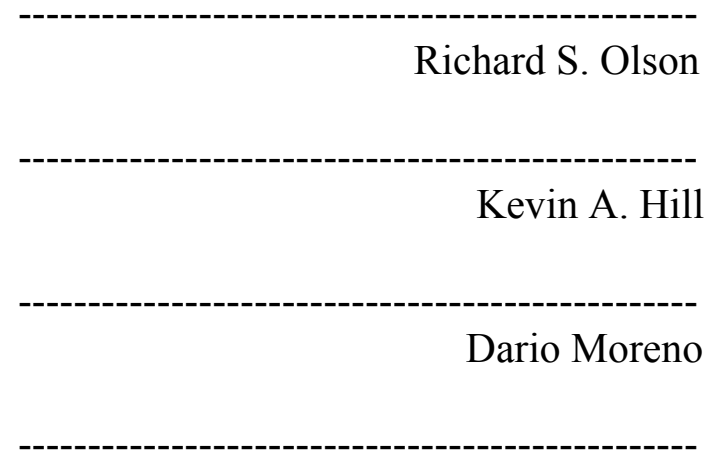

Abraham Lavender

Nicol C. Rae, Major Professor

Date of Defense: November 7, 2011

The dissertation of Rezwan Hussain is approved.

Dean Kenneth G. Furton College of Arts and Sciences

Dean Lakshmi N. Reddi University Graduate School

Florida International University, 2011 
ABSTRACT OF THE DISSERTATION

VOTING WITH THEIR FEET: MIGRATION, PARTISANSHIP, AND PARTY-

SAFE ELECTIONS IN FLORIDA

by

Rezwan Hussain

Florida International University, 2011

Miami, Florida

Professor Nicol C. Rae, Major Professor

Political scientists have long noted that Congressional elections are often uncompetitive, often extremely so. Many scholars argue that the cause lies in the partisan redistricting of Congressional districts, or "gerrymandering". Other scholars emphasize polarization created by a fragmented news media, or the candidate choices made by a more ideological primary electorate. All these explanations identify the cause of party-safe elections in institutions of various kinds.

This dissertation, by contrast, presents a structural explanation of uncompetitive elections. My theory is that population composition and patterns of migration are significant causes and predictors of election results in Florida. I test this theory empirically by comparing the predictions from four hypotheses against aggregate data, using the county as the unit of analysis.

The first hypothesis is that Florida can be divided into clearly distinguishable, persistent partisan sections. This hypothesis is confirmed. The second hypothesis is that Florida voters have become increasingly partisan over time. This hypothesis is confirmed. The third hypothesis is that the degree of migration into a county predicts 
how that county will vote. This hypothesis is partially confirmed, for the migration effect appears to have waned over time. The last hypothesis is that the degree of religiosity of a county population is a predictor of how that county will vote. This hypothesis is also supported by the results of statistical analysis.

By identifying the structural causes of party-safe elections, this dissertation not only broadens our understanding of elections in Florida, but also sheds light on the current polarization in American politics. 
TABLE OF CONTENTS

CHAPTER

PAGE

1 PARTISAN POLARIZATION AND PARTY-SAFE ELECTIONS .1

2 REVIEW OF THE LITERATURE .8

1: PARTISAN POLARIZATION AND THE AMERICAN

ELECTORATE. 9

2: PARTISAN POLARIZATION AND ELECTORAL

INSTITUTIONS .30

CONCLUSION.

3 A STRUCTURAL THEORY OF ELECTIONS .49

1: THE CONSTITUENCY BASIS OF POLITICS ...........................51

2: AMERICAN VOTERS AS STABLE PARTISANS......................54

3: COMPOSITION AND CONTEXT ..............................................59

4: MOVING AS POLITICAL BEHAVIOR .....................................65

5: SECTIONALISM IN FLORIDA....................................................71

6: FOUR HYPOTHESES ON FLORIDA ELECTIONS ...................78

CONCLUSION: A GENERAL THEORY OF ELECTIONS .............80

4 METHODOLOGY AND RESEARCH DESIGN ........................................8

1: QUALITATIVE AND QUANTITATIVE METHODS .................84

2: ANALYTIC METHOD .........................................................89

3: SOURCES AND TYPE OF DATA..........................................99

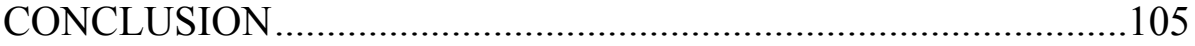

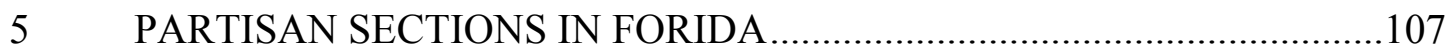

INTRODUCTION ..............................................................108

1: ELECTIONS IN FLORIDA: A COUNTY-LEVEL PERSPECTIVE

113

2: DO FLORIDA REGIONS FORM POLITICAL SECTIONS? .....130

3: PARTISANSHIP AND FLORIDA ELECTIONS .......................144

CONCLUSION ......................................................................156

$6 \quad$ EXPLAINING PARTISAN SECTIONS IN FLORIDA ............................158

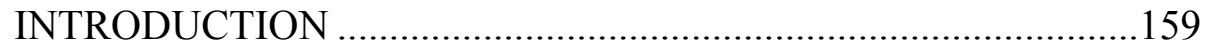

1: EXPLAINING PARTISAN SECTIONS WITH STATISTICS ....161

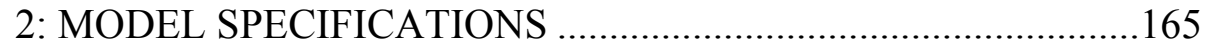

3: REGRESSION RESULTS .....................................................177

4: RELIGIOSITY AND PARTISAN SECTIONS ...........................197

CONCLUSION ........................................................................207

7 BUILDING A GENERAL THEORY OF ELECTIONS............................209

1: PARTISAN SECTIONS IN FLORIDA REVISITED.................210 
2: EXTENDING THE RESEARCH............................................217

3: A GENERAL EXPLANATION OF ELECTIONS .....................219

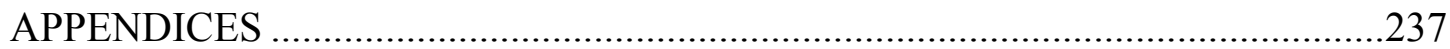

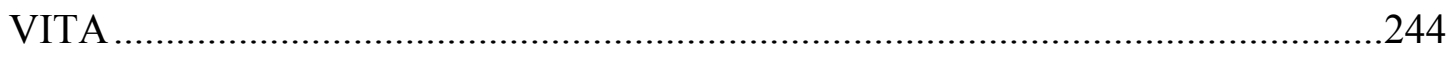




\section{LIST OF TABLES}

TABLE

PAGE

1: Methods in Scholarly Articles on American Politics, 1980-2000 .86

2: Republican Margin of Victory, 2004 U.S. Presidential Election, by Florida County

3: Republican Margin of Victory, 2006 U.S. House Elections in which Both Parties

Fielded a Candidate, by Florida County

4: Comparison of Republican Average Winning Margins, in U.S. Presidential

Elections in the 1980s, 1990s, and 2000s, by Florida Region

5: Comparison of Republican Average Winning Margins, in Successive U.S. House

Elections, in the 1990s and 2000s, by Florida region.

6: Republican Average Margin of Victory in U.S. House Elections, Only Elections in which Both Parties Fielded a Candidate, by Florida Region

7: Effect of Uncontested U.S. House Elections on Republican Average Winning Margins, by Florida Region

8: Residence of County Population, Five Years Earlier, as a Percentage of the County Population 5 yrs of Age and Older, in 1990

9: Control Variables Deployed in OLS Regression Models.

10: Results of OLS Regression of Republican Average Winning Margins from U.S.

Presidential Elections of 1988 and 1992, by 1990 U.S. Census Variables.

11: Results of OLS Regression of Republican Average Winning Margins from U.S.

Presidential Elections of 2000 and 2004, by 2000 U.S. Census Variables.

12: Correlations ( $\mathrm{r}$ ) between Republican Average Winning Margins from U.S. House

Elections of 1988 - 1992, and 1990 U.S. Census Variables

13: Results of OLS Regression of Republican Average Winning Margins from U.S. House Elections of 1988 - 1992, by 1990 U.S. Census Variables. 190

14: Correlations (r) Between Republican Average Winning Margins from U.S. House Elections of 1998 - 2002, and 2000 U.S. Census Variables

15: Results of OLS Regression of Republican Average Winning Margin from U.S. House Elections of 1998 - 2002, by 2000 U.S. Census Variables. 
16: Correlations (r) between Democratic Winning Margins from 2004 U.S.

Presidential Election, and 2006 American Community Survey Variables.....

17: Results of Simultaneous OLS Regression of Democratic Winning Margins from 2004 U.S. President Elections, by 2006 American Community Survey Variables ...203

18: Results of Hierarchical Regression of Democratic Winning Margins from 2004 U.S. Presidential Election, by 2006 American Community Survey Variables..........205

19: Results of Hierarchical Regression of Democratic Winning Margins from 2004 U.S. Presidential Election, by 2006 American Community Survey Variables..........207 


\section{LIST OF FIGURES}

FIGURE

PAGE

1: Winning Margins of the Two-Party Vote in 2004 U.S. Presidential Election, by

Florida County

2: Florida County Partisanship, using Average Winning Margin of the Two-Party

Vote in U.S. Presidential Elections of 2000 and 2004.

3: Winning Margins of the Two-Party Vote in 2006 U.S. House Elections, by Florida

County..... 125

4: Comparison of Average Winning Margins of the Two-Party Vote in U.S.

Presidential Elections in the 1980s, 1990s, and 2000s, by Florida Region

5: Average Winning Margins of the Two-Party Vote in U.S. Presidential Elections of 2000-2004, by Florida Region.

6: Comparison of Average Winning Margins of the Two-Party Vote in U.S. House Elections in the 1990s and 2000s, by Florida Region 138

7: Comparison of Average Winning Margins in U.S. House Elections in the 1990s and 2000s - Only Elections Contested by Both Parties, by Florida Region.

8: Graphs of Winning Margins in Elections for State and U.S. Federal Government Offices, Between 1980 and 2006, for Five Large Florida Counties 146

9: Graphs of Winning Margins in Elections for U.S. President, U.S. House, and Florida Agriculture Commissioner, Between 1980 and 2006, by Florida Region ...151

10: Florida's Partisan Sections, by Average Winning Margins from U.S. House Elections of 1992-1996

11: Florida's Partisan Sections, by Average Winning Margins from U.S. House

Elections of 2002-2006 


\section{CHAPTER 1}

PARTISAN POLARIZATION AND PARTY-SAFE ELECTIONS 
Over the last two decades, observers of American politics have noted that American politics has become more polarized, and that members of the U.S. Congress appear to engage in much more partisan bickering. Scholars have found that members of the two Congressional parties are more inclined to vote along party lines, and more inclined to vote along an ideological divide. Republican members of Congress have become more cohesive and conservative in their voting, while Democratic members have become more cohesive and liberal in their voting.

This increasing partisan polarization has become a cause for concern to many Americans. Many academics and members of the general American public worry that polarized politics will make America harder to govern, or even render American government ineffectual, as the affairs of state grind to a halt amidst partisan gridlock, and necessary legislation is passed only after partisan brinkmanship. Not surprisingly, scholars of American politics, as well as the media, have devoted considerable time and energy into describing, explaining, and theorizing about the causes and consequences of this polarization in American politics.

To explain this development, scholars have looked more closely at the institutions and processes of American elections. This focus is eminently sensible, because elections are how members of Congress are selected. Since elections involve voters, one possible cause of polarization in Congress is the attitudes and behavior of the American electorate. Have American voters become more polarized? This question 
has fomented a lively debate, as scholars argue over whether a "culture war" is underway, driven by emotive issues such as abortion or gay marriage.

Other scholars have looked to elites and institutions as likely causes of partisan polarization. These scholars are interested in investigating whether those who run for office, who emerge as candidates in American elections, have become more polarized - always assuming, of course, that previously moderate candidates do not suddenly change their stripes and become polarized ideologically after being sworn into office. Accordingly, some scholars have looked into the candidate selection process as the cause of polarization, and in particular, into primary elections. These elections, they argue, are dominated by ideologically polarized party activists, who select more polarizing candidates to run in the general election.

Other scholars have examined the structural features of the general election itself, and in particular the uncompetitive nature of many of these Congressional elections. This focus on elections also makes sense, since if elections are uncompetitive, there is little reason for an incumbent to spend time or effort appealing to voters who did not vote for him or her; the incumbent can safely ignore these voters, and concentrate on tending to those the voters who have already voted for him or her. According to this line of thinking, uncompetitive elections contribute to polarization because incumbents generally ignore the median, or moderate, voter, and concentrate on appealing to the more polarized party base. 
Originally, this incumbency advantage was thought to derive from advantages inherent in the office of U.S. Representative, such as the resources and visibility afforded to the incumbent, These strategic incumbents, scholars argued, learned how to please their constituents with the votes they cast in Congress, and their style of communicating at home in the districts, and deterred high quality challengers by raising large amounts of campaign funds - an activity aided by their incumbency status. The result was to make elections safe for incumbents, and, by extension, the incumbent's party.

In recent years, however, scholars have begun to rethink incumbency advantage. They noticed, for instance, that when an incumbent retired, the seat almost always remained in the hands of the party of the departing incumbent. So did the incumbent hold that seat because of the advantages of incumbency, or because of the advantages of being identified with the right party? In other words, was the incumbency advantage personal, or partisan? It was a puzzle, because challenges are rarely successful, and the number of competitive districts continued to decline, into the first decade of the twenty-first century.

If Congressional elections are uncompetitive because one or other party enjoys the support of a clear majority in the district, election after election, what could account for this partisan incumbency advantage? Many scholars identified the cause in redistricting: the practice of redesigning districts after the decennial Census to account for population changes and make electoral districts more equitable in 
population size, pursuant to Federal law and Supreme Court ruling. The process of redesigning districts, these scholars argued, was being conducted for partisan advantage: the partisan political elites who controlled the process were "gerrymandering" districts in order to pack those likely to vote for the opposite party into a limited number of districts, leaving more districts that are safe for the candidates of their own party.

The redistricting explanation is enormously popular, among both scholars and media outlets, often appearing in the media and popular discourse whenever the topic turns to Congressional elections. Unfortunately, as often happens with such nostrums, the partisan redistricting explanation of party-safe Congressional elections is not clearcut: elections in districts that have not been redesigned display many of the same trends as districts that have, and the U.S. Senate has become almost as polarized as the U.S. House of Representatives, and many Senate elections have become just as party-safe.

But even if redistricting is not the reason why many Congressional districts display a persistent partisan advantage, the way voters are distributed may still confer an electoral advantage to a specific party. In other words, it may not be because district boundary lines are being moved by legislators, commissions and judges, but because voters are moving themselves, from one place to another. Are American voters, who live in a famously mobile society, making residential choices that are creating electoral districts with distinct and persistent partisan profiles? 
In this dissertation, I will construct and test the prime hypothesis that the distribution of voters is the cause of party-safe elections, using Florida as a test case. I will examine whether the American political landscape displays distinct partisan sections - geographical areas where one party has an embedded and persistent advantage and whether this sectionalism can be linked to Congressional election outcomes, and party-safe elections in particular. My argument is that to understand American Congressional elections, we must understand American voters, and the way they are distributed across the political landscape, within the nation and within individual states. My argument identifies the behavior and attributes of the American voter as the cause of party-safe elections.

My objective is not to supplant existing explanations of party-safe elections, explanations that emphasize elites and institutions as the causal variables, but to complement them. If we can better understand the causes of uncompetitive elections, we gain a better understand of increasing partisan polarization, which, I believe, is a consequence of party-safe elections. As such, this study not only contributes to the scholarly literature on Congressional elections and American electoral behavior, but also contributes to our real world understanding of American politics.

In the next chapter, I will review the scholarly literature on district competitiveness and polarization in elections for the U.S. House, and elaborate on the some of the points made in this introduction. In chapter 3, I will specify my explanation of partysafe elections, one that takes the form of an empirical theory. In chapter 4, I discuss 
various elements of my research design and method, such as my choice of units of analysis, and the observations that constitute my data sets. In chapters 5 and 6 , I discuss my findings: in chapter $5 \mathrm{I}$ describe the partisan sections that emerge in Florida, and in chapter 6 I build explanatory models of these partisan sections. I conclude with an overview of what I have done in this study, and describe one way to develop and extend it. 


\section{CHAPTER 2:}

REVIEW OF THE LITERATURE 
In this chapter, I will review what scholars have said about partisan polarization and electoral competitiveness in American politics. Both polarization and electoral competitiveness are multidimensional phenomena, involving institutions, elite behavior, and structural factors such as public opinion. For analytic and organizational purposes, I will first discuss voter behavior, which is central to public opinion literature, and then I will discuss the literature on elites and institutions. Regardless of the order of discussion, the central question remains the link between elites and the mass public. The question of representation has been a central concern in the study of American politics; I do not expect to resolve any major controversy here. My objective is to review the relevant literature that can help us understand America's polarized politics.

I begin, in the next section, with a brief synthesis of what political scientists have said about American electoral behavior over the last three or four decades. I will paint a picture with very broad strokes. My goal in Section I is to introduce the topic of American elections and American political parties, and contextualize my research question.

\section{PARTISAN POLARIZATION AND THE AMERICAN ELECTORATE}

The scholarly explanation of elections and partisan polarization encompasses various processes: a realignment of the balance of electoral support for the two major parties 
in the American political system, the behavior of elites as cause and effect of these changes, institutional factors such as Congressional reforms, primary elections, and the "redistricting revolution." In short, the panoply of variables political scientists often summarize as "structure and agency.",

Scholars often describe the landscape of contemporary American electoral politics as the outcome of a process that began with the defection of conservative white Southerners from the Democratic Party to the Republican Party over differences regarding the Civil Rights agenda. They go on to argue that this shift in electoral politics, typically referred to as the "Southern realignment," made the two parties more ideologically coherent entities, more clearly differentiated from one another along ideological and policy profiles, as opposed to geography (Carmines and Stimson 1989; Black and Black 2002). According to the literature, this realignment was a two-stage process.

First, Southern whites began voting Republican, initially in presidential elections (in the 1960s), and then in Congressional elections (in the 1980s), transforming ("realigning") the American South from a Democratic into a Republican Party stronghold by the 1990s. The Southern realignment was reinforced by the migration of many middle-class whites from the Northeast and Midwest to the Sunbelt (Black and Black 1987), a process partly motivated by technology and infrastructure, such as air conditioning and the interstate highway system (Polsby 2004). The realignment

\footnotetext{
${ }^{1}$ This phrase, popular with many scholars, conflates structure with institutions. Since this distinction is central to my analysis, I will not employ this phrase again.
} 
not only re-shaped the nation's political geography, but also led to the rise of a new generation of national political leaders from the South, such as Newt Gingrich (Kruse 2006).

This realignment of the electorate led to changes in the two parties in Congress. Over several election cycles, conservative white Southern Democrats became less important in the House and Senate, and were increasingly replaced by Republican and Democratic African American members. The new Democrat cohorts replaced a personalistic, committee-based chamber dominated by seniority and a bipartisan "conservative coalition" into a more partisan, majoritarian chamber dominated by party leaders and whips (Rohde 1991, Polsby 2004). The transformation of Congress did not happen overnight: it took two waves of reforms, in the 1970s, under Democratic leadership, and in the 1990s, under Republican leadership (Sinclair 1995; Rae 1998). Rank-and-file members, for their part, gave Congressional party leaders the power to make these changes because they trusted the latter to serve party ideology, rather than sectional or constituency interests (Sinclair 1995). The outcome was a more polarized, partisan institution, characterized by greater party-line roll-call voting (Poole and Rosenthal 1997), gridlock (Brady and Volden 2006), polarizing leaders (Sinclair 1995) and increased partisan rancor in general (Jacobson 2004).

The partisan polarization within Congress cued ideological polarization within the American electorate (Abramowitz and Saunders 1998; Jacobson 2000a; Black and Black 2007). Increasing ideological coherence within the Congressional parties - 
with liberals aligned with the Democratic Party, and conservatives aligned with the Republican Party, taught voters that party labels meant something - that they indicated and predicted how representatives would vote or act once in office (Jacobson 2000a), and encouraged voters to align their party identification with their preferences on various issues (Abramowitz and Saunders 1998; Carmines and Layman 1997). Whether described as "ideological realignment" (Abramowitz and Saunders 1998), "sorting” (Fiorina and Levendusky 2006), or just "polarization", the result was greater ideological coherence and party loyalty within the American electorate (Jacobson 2000b), which became increasingly divided politically, along regional, racial, religious, ethnic, income, gender and cultural lines (Carmines and Stimson 1989, Layman 2001, Brewer and Stonecash 2007, Black and Black 2007, Bartels 2008).

Scholars found evidence of this increasing division in various domains, and among various groups. There are three such groups that, for many political scientists, matter most for electoral politics: members of Congress, party activists, and voters.

The most compelling evidence of polarization is probably in the U.S. Congress. The Republican and Democratic parties in Congress appear more solidly opposed to one another, more cohesive, and more ideologically distinct from each other. Measures such as party votes, where a majority of Republicans oppose a majority of Democrats, and party unity scores, which measure how often a member of Congress votes with his or her party, indicate that Republicans and Democrats in Congress began voting 
more along party lines in the 1980s (Rohde 1991). Other measures, such as interest group scores of individual members (Fleisher and Bond 2000), or the DW-Nominate scores calculated by Poole and Rosenthal, which capture the ideological distance between members using all roll call votes (Poole and Rosenthal 1984, 1997), indicate that members of Congress have become more ideologically polarized. In short, both Republican and Democratic members more become partisan and more ideological; the two parties have become more cohesive.

The polarization appears to extend to party activists. Some scholars argue that ideological differentiation, or the distance between Republicans and Democratic activists on economic and social issues, has increased (Aldrich 1995; Layman 2001; Fiorina 2002). Such polarized activists contribute to party polarization, according to these scholars, by virtue of the influence they exert over the candidate selection process, one that throws up more polarized candidates for the general election, and sends more polarized office-holders to Congress (Burden 2001; Fiorina et al. 2006; Brady and Han 2007; Masket 2009).

And finally, polarization appears to extend to the electorate. Scholars first noticed increasing partisanship in presidential voting in the 1980s (Miller 1991; Bartels 1992), and subsequently in Congressional voting (Bartels 2000). Measures of public attitudes toward the parties, such as the "feeling thermometer" in NES surveys, also indicate that voters became more partisan beginning in the 1980s (Hetherington 2001), and the proportion of voters who self-identified as independents - a measure 
that some consider to be the most revealing measure of aggregate partisanship - fell (Bartels 2000). At the same time, ticket splitting, or voting for different parties for president and Congress, declined (Hetherington 2001; Stonecash 2006). The increasingly partisan behavior, according to some scholars, is evidence of a polarized electorate, as voters increasingly align their partisanship with their preferences on various social and political issues (Jacobson 2000b).

Political scientists, however, are as contentious as any group of scholars, and many of the observations offered in this capsule summary have been simply grist to the mill for scholarly argumentation and debate. Scholars argue over whether the electorate is actually polarized, or whether only elites are polarized, over what causes polarization, and, as always, over what links elites to the mass public - the central question in the public opinion literature for decades (Converse 1964; Delli Carpini and Keeter 1996). These issues dominate the scholarly literature on American public opinion and the American party system, and the remainder of this chapter is devoted to these debates.

To organize the discussion conceptually, I will conceptualize the electoral arena using three constituent elements: voters, the elites who seek to influence or earn those votes, and the electoral institutions through which elites act. I have presented polarization as an outcome of electoral politics; consequently, I will conceive of polarization as a product of the interaction and mutual reinforcement between voters, elites, and institutions, which refer to both elections and political parties (Jacobson 2000a). 
I begin by discussing the electorate. The logical way to do so is by reviewing the theoretical framework political scientists have used for decades when thinking about American elections, political parties and even political change in general: realignment theory. Then, I will focus on the link between elites and voting behavior. I will end the section with a discussion of the so-called "culture war," which can be thought of simply the latest version or iteration of the complex and never-ending interaction between elites and voters.

\subsection{Realignment and Partisan Polarization}

In the original formulation of this theory, realignment occurs when stable patterns of partisan alignment and electoral coalitions are sundered by a powerful, polarizing issue, one that displaces the existing conflict, cuts across pre-existing political cleavages, and realigns the electoral coalitions of the two parties (Key 1955). Key first proposed that realignments occurred convulsively, in a "critical election", such as those of 1860,1896 , or 1932 (Key 1955), but later expanded the concept to include longer "secular realignments" that take place over several election cycles (Key 1959). The literature has grown enormously since then, but realignment theory still refers to one of two processes: the rise of a new issue around which political coalitions divide, or the rearrangement of partisanship within the electorate (Stonecash, Brewer and Mariani 2003). 
As with many ubiquitous concepts, however, scholars are divided over different aspects of the concept, such as how long realignment takes, whether the cause is conversion or mobilization, whether the cleavages are societal or issue-based, whether cleavages displace each other, or accumulate, and whether realignments are national or sectional phenomena (Petrocik 1981, Carmines and Stimson 1989; Dalton et al. 1984; Bensel 1984). For the purpose of my research question, in which the link between voters and elites is a central concern, three popular accounts of how and why realignment occurs are worth noting.

\section{Issue Evolution}

In classical realignment theory, as Sundquist (1983) remind us, party elites are the first to respond when a polarizing issue emerges; their actions motivate voters to do one of two things: review their own stance on the issue, and change their party alignment (conversion), or, if they are independents, to choose a party (mobilization).

Carmines and Stimson argue, however, that the Southern realignment was not a function of conversion or mobilization, but of generational replacement - the entry of younger voters into the electorate with different attitudes (Carmines and Stimson 1989). They suggest that this "issue evolution" began in the South in 1964, as disagreements regarding Civil Rights and racial integration pushed Southern whites out of the Democratic and into the Republican Party, simultaneously motivating newly empowered black voters to identify with the Democratic Party. 


\section{Ideological Realignment}

According to Abramowitz (1994), this "issue evolution" explanation confuses correlation with causation. $\mathrm{He}$ argues that racial attitudes are really a correlate of ideology - the broad set of attitudes toward the proper role of the state in providing welfare and national security. Ideology drives partisanship and partisan realignment, not race. These two issues first became salient in the 1964 presidential election, and have driven partisanship ever since (ibid.). As in classical realignment, Abramowitz acknowledges that party leaders act as catalysts, but he attributes more agency to voters, who contribute to polarization by realign themselves in two ways: first, by matching their self-identification as liberals or conservatives (their ideology) with preferences over a range of issues, and then by matching that ideology with a specific party (Abramowitz and Saunders 1998, 2008).

\section{Conflict Extension}

In a more recent approach, Layman and Carsey (2002) take issue with "ideological realignment" for exaggerating the ability of an electorate that is essentially ideologically incoherent to mimic the ideological coherence of elites. They also take issue with the central classical realignment concept of "conflict displacement," that realignment occurs when a new, polarizing issue displaces an older issue. Conflict displacement, the authors argue, may describe how voters respond to new issues, but elites do not displace conflict, but extend it - they polarize on several issues simultaneously. The consequence of this "conflict extension" is to heighten political 
polarization, as one polarizing issue is piled on top of another, reinforcing the previous cleavage, rather than displacing it or cutting across it (ibid.).

The realignment literature thus offers different interpretations on the link between voters and elites. The debate continues because, whereas most political scientists accept that political office-holders and activists appear to possesses a set of coherent beliefs about politics, and can be placed along a liberal-conservative ideological continuum (Poole and Rosenthal 1984, 1997), the voting public is an entirely different matter. Ever since Converse (1964) first reported that American voters were generally ill-informed about political issues, and, with the exception of selected groups ("issue publics"), who took an interest in specific issues but did not possess any coherent set of political beliefs, scholars have been bedeviled by the question of whether or not voters possess any coherent understanding or conception of politics, or ideology (Lewis Beck et al. 2008).

\subsection{Is the Electorate Polarized?}

Those who argue that voters have become more polarized take one of two approaches, which I will refer to as participatory and informational. The first approach builds on the concept of political participation, a very broad term that encompasses not just voting but also a host of behaviors that typically attend elections. These behaviors can be cognitive, such as being aware of candidates and 
issues, and being able to distinguish between parties, affective, such as taking an interest in the election outcome, or actual political activity, where activity is typically defined as engaging in at least one act beyond voting, such as volunteering, or helping to raise campaign funds. Abramowitz points to greater levels of these types of political participation to support his claim that the contemporary electorate is more ideological than the one Converse encountered in the 1960s (Abramowitz 2006). Looking at the National Election Studies (NES) data for the 2004 general election, he concluded that levels of politically activity, awareness of differences between the parties, and interest in the election outcome were all at record levels (Abramowitz and Saunders 2008). Political participation, in this approach, takes the form of a proxy measure for ideology.

The most popular approach taken by those arguing that the electorate is more polarized is one that I have labeled "informational". If the electorate is more polarized today, these scholars maintain, it is because voters are taking their cue for how to think or behave politically from signals they receive from political elites - if those signals are sufficiently clear and strong (Brody 1991; Page and Shapiro 1992; Zaller 1992). Scholars who make this argument usually add that these signals are typically reinforced by media references to polarized politics (since voters typically obtain information from politics from the mass media); the result is greater ideological awareness and coherence within the electorate. This "cue-taking" hypothesis is really the theoretical core of the various realignment theories just discussed - even Abramowitz's conception of ideological realignment. 
Unfortunately, it is not at all clear that voters do indeed respond to elite cues, for the simple reason that they do not pay enough attention to politics (Converse 1964; Delli Carpini and Keeter 1996). The exception is the minority of voters who are politically informed, the so-called "strong party identifiers" (Zaller 1992). According to Layman and Carsey (2002), these strong party identifiers respond to elite cues on an issue in one of two ways, depending on how much the issue matters to them, or the "saliency". If the issue is important, these partisans may defect to another party. This

process is consistent with classical realignment theory, where "cross-cutting cleavages" motivate voters to cross party lines; this response creates a ceiling, or cap, on partisan polarization (Sundquist 1983). But if the issue is not salient, partisans will modify their preference on that issue to better align it with their party's platform. This process extends political conflict, rather than displacing it; it encourages party elites to move even farther apart, and heightens partisan polarization (Layman and Carsey 2002).

\section{Do Voters take Cues?}

The "elite cuing" idea appears plausible. Nevertheless, it is not entirely consistent with some empirical observations about mass political behavior. For instance, repeated surveys conducted every decade since the 1970s in the World Values Survey project, administered by the University of Michigan, describe a mass public in the U.S. that is increasingly individualistic, non-hierarchical and elite-challenging in their political style and behavior (Inglehart 1997, 2005). According to Inglehart, this "expressive politics" is manifest at the individual-level in petition signing, recall and 
ballot initiatives, and the increasing emphasis on post-material issues, such as the environment (ibid.). The expressive politics hypothesis dovetailed neatly with inquiry into partisan de-alignment, which dominated the scholarly agenda during the 1970s through the 1990s, but it does not fit so neatly with the hypothesis that the public is following the lead of elites. So do Americans favor elite-challenging expressive politics, or are they taking their cues from polarized partisan political elites, such as activists and party leaders? Logically, it is one or the other. In short, the World Values Survey findings are at odds with the idea of an electorate increasingly polarized by elites.

The elite-cueing explanation is also problematic if we consider the behavior of elites - the party activists, the candidates for elected office, and the professional political class hired to help them do so. If the electorate follows cues from these elites, why do contemporary political campaigns expend vast resources gathering and analyzing data on every conceivable aspect of voters' lives? Why do candidates spend everincreasing amounts on "micro-targeting" potential voters (Baker 2008)? The critical importance of demographic research and grass-roots organizations in contemporary elections, not to mention the obsessive attention to opinion polling, is not consistent with the "elite-cueing" hypothesis. These practices imply that it is elites who are looking to the mass public for cues.

These features of the voter-based, or public opinion, perspective on polarization is amply illustrated in the debate that has raged over what many consider the dominant 
cleavage in contemporary American politics: the increased salience of cultural issues, and the so-called "culture war". Is this an example of political conflict being extended, rather than displaced? It is worth taking a closer look at this debate, for it illustrates the strengths and weaknesses of the argument that contemporary polarized politics stems from a polarized American electorate.

\subsection{The “Culture War" Hypothesis}

There are two elements to the culture war hypothesis. The first is that there is a religious divide in the American public. Unlike the religious cleavage of a century ago, defined by the Protestant - Catholic divide, (Sundquist 1983; Brewer and Stonecash 2006), the contemporary religious divide is not between denominations, but within them. It is one that pits religious traditionalists, or "orthodox" in Hunter's terminology, against modernists, or "progressives" (Hunter 1991). The former, associated with evangelical Christians, consider the Bible to be authoritative; the latter, associated with mainline churches, consider the Bible to be a social artifact, and consider political institutions, embedded in distinct cultural contexts, to be authoritative (Wuthnow 1988; Hunter 1991; Layman and Carmines 1997; Layman 2001).

\footnotetext{
2 The sociologist John Davison Hunter is credited with coining the term (1991); Pat Buchanan introduced the term to mainstream America in his speech at the 1992 Republican National Convention.
} 
The second element to the culture war hypothesis is that this religious conflict has spilled over from the religious realm to the political realm, and religious beliefs now influence not only personal issues (family, gender and sexuality) but also a range of attitudes regarding the proper role of government in society, or ideology (Wuthnow 1988; Hunter 1991). This spillover into politics, which Hunter (1991) refers to as “isomorphism", has two consequences: (i) it creates an ideological electorate and (ii) it is creates particularly intractable political attitudes, since religious beliefs tend to be incommensurable. The result is that, instead of negotiation and compromise over differences, political discourse becomes an unyielding struggle, or war (ibid.).

Layman and Carmines (1997) examined NES data, and, consistent with this perspective, concluded that traditional religious values were the strongest predictor of the presidential vote - a measure often taken as a proxy for ideology. Researchers analyzing the World Values Survey have concluded that church attendance is the strongest predictor of ideology, with greater attendance being positively correlated with politically conservative attitudes - not only in the U.S., but also throughout the industrialized world (Norris and Inglehart 2004).

As with the accounts of polarization in general, political activists are identified as the prime catalysts of this culture war. In one influential work in this school of thought, Layman (2001) argued that it was activists and party leaders who turned the religious divide into one that extended into partisan politics. In this argument, conservative activists felt threatened by the changes promoted by "post-materialists" and other 
secular groups in contemporary society, and pressed party leaders to exploit the "great divide" between religious traditionalists and secularists in order to mobilize conservative voters. Party leaders obliged, and voters, taking their cues from family, friends, and community, re-aligned their support for the two parties: traditionalists aligned with the Republican Party, and more secular voters with the Democratic Party (ibid.).

\subsection{Is There a Culture War?}

How does this culture war hypothesis stack up against empirical evidence? DiMaggio and his collaborators scoured two decades worth of survey responses in the General Social Survey (GSS) and NES data and found that, contrary to the culture war predictions, the public's opinions on social issues were converging, rather than polarizing (DiMaggio, Evans and Bryson 1996; Evans, Bryson and DiMaggio 2001). The one exception appeared to be abortion - although Mouw and Sobel (2001) dismissed even that seeming evidence of polarization as basically measurement error. Davis and Robinson (1996) for their part, found that religiosity correlated with family and gender-related issue attitudes, but not political attitudes. Instead, as predicted by classical realignment theory, they found cross-cutting cleavages - attitudes that cut across party lines; they found that religious traditionalists were just as likely to be economically conservative as they were to be economically liberal. The authors do find that religious elites were more doctrinaire than rank and file congregations, just 
as political elites were more ideological than the mass public, but that, on the whole, religious conservatives in the U.S. resemble the electorate at large: divided along race, sex, class and age, with no consistent issue attitudes (Davis and Robinson 1996).

Partly inspired by these findings, Fiorina published arguably the most influential and widely-read critique of the culture war thesis in 2005. According to Fiorina, the distribution of opinion within the electorate (polarization) has been unchanged for decades: the relative proportion of liberals, conservative, or moderates within the electorate has remained steady since the 1950s (Fiorina et al. 2005). And moreover, the American public remains much as Converse depicted it in 1964 - ill-informed about political issues in general, divided over specific issues, and lacking in any coherent ideology - religious or otherwise (Fiorina et al. 2006; Fiorina and Levendusky 2006).

What has changed, according to Fiorina, is the behavior of party leaders, candidates and activists, behavior that can be explained by the process by which such elites are selected: primary elections dominated by ideological party activists (Fiorina 2002, Fiorina et al. 2006). Since voters are restricted to the choice of elites who emerge from these primaries structure the vote choice, they end up having to choose between party candidates with polarized positions on issues that primary activists hold dear, such as abortion, gay marriage, or gun control. In short, the electorate is "sorted" along partisan lines, and this sorting creates the misleading impression that the electorate is polarized (Fiorina et al. 2006, Levendusky 2009). 
While scholars such as Abramowitz and Fiorina focus on indicators such as political participation or the distribution of attitudes, and seek to explain political behavior in terms of political orientations, a burgeoning literature in political science investigates whether political behavior can be explained by psychological attributes, such as personality. One recent study examined links between parenting values or family structure and partisanship or vote choice. Using a parenting scale developed from a series of questions in the NES about childrearing, Hetherington and Weiler (2005) test the hypothesis that the American electorate can be sorted by a "strict parent/nurturing parent" binary. They find a clear correlation between strict fathers and Republican partisanship, and between nurturing parents and Democratic partisanship (Hetherington and Weiler 2005). I will revisit this interesting new line of research into the electorate in the concluding chapter.

The culture war controversy notwithstanding, most scholars acknowledge that religion has long been a source of political cleavage in American politics (Sundquist 1983). The question is whether, after being quiescent for a period of time, religion has resurged as a factor in American politics, and if so, how it contributes to partisan polarization. But why did the religious divide subside in the first place? 


\subsection{Income and Partisan Polarization}

According to some scholars, the religious divide was displaced in the twentieth century by a new, overriding cleavage in American politics: economic class (Glaeser and Bryce 2006). Economic class as the dominant cleavage in American politics is typically attributed to the Great Depression and the ensuing "New Deal realignment" of American politics, in which the working and lower middle-classes aligned with the Democratic Party of FDR, and the upper middle and upper classes aligned with the Republican Party (ibid.). This New Deal alignment is familiar to most Americans in the commonplace stereotype of Republicans as the party of the rich, and Democrats as the party of "the little guy."

I will not belabor this point, partly because, unlike the difficulties associated with measuring ideology, which relies on subjective responses to survey questions, not to mention the continuing debate about whether ideology actually matters to American voters, there is less controversy about whether class is a factor in electoral politics, if only because class can be measured using more objective criteria. In fact, there is a range of criteria for scholars to choose from since class is a multidimensional concept, and can be defined using income, education, or occupation as indicators. Nevertheless, much of the literature has traditionally defined class in terms of income. Bartels, for instance, finds that whereas class defined by college education has become less relevant as a factor in voting over the past half-century, class defined by income has become more relevant (Bartels 2008). 
Class-oriented scholars argue that partisan polarization stems not from attitudes toward race or culture, but from differences in (income-based) class (McCarty, Poole and Rosenthal 2006; Bartels 2006, Gelman 2008). McCarty et al., for instance, argue that racial attitudes in the South cannot explain polarization in Congress, since the demise of liberal Republican members outside the South is clearly observable beginning in the 1970s (ibid.). The "Southern realignment," in their view, was simply an extrapolation of an income-based polarization that was already underway nationally. According to their analysis, polarization in the South actually trailed the rest of the nation (ibid.). To explain the observation that voting in the U.S. House of Representatives since the 1970s clearly maps onto a liberal-conservative dimension, they identify personal income within a district as the cause: the wealthier the district, the more the Representative in Congress hews to the Republican Party line (McCarty et al. 2006).

Scholars who emphasize class rather than ideology argue that the influence of economic class, or income, on election outcomes has been increasing in recent decades, and that the correlation between class and voting behavior is now considerably higher than in the 1950s (Brewer and Stonecash 2006; Bartels 2006). These scholars point to polling evidence that income is a strong predictor of Republican partisanship, and that the New Deal alignment is very much intact: poorer whites tend to vote Democrat, whereas middle and upper income voters have become ever more Republican (Bartels 2006, Gelman 2008, McCarty et al. 2006). To the extent that white voters without college degrees have become more Republican over 
past half-century- a proposition seized upon by some popular writers, who wonder "what the matter is with Kansas" (Franks 2005) - these class-oriented political scientists respond that this trend is largely restricted to the South (Bartels 2008).

A variation on this literature is that income and cultural attitudes combine to make politics more polarized (Brewer and Stonecash 2006). One influential study in this vein seeks to explain American voting behavior as an interaction between economic and cultural motivations. Gelman (2008) argues that the distinctive "red and blue" presidential map that the media generates after presidential elections stems from cross-cutting cleavages: the combination of liberal cultural and social values and higher income mean many upper-income voters in coastal states override their economic interests and align with the Democratic Party, turning wealthy coastal states "blue".

I will return to this idea of red and blue partisan sections in the next chapter. But now I must continue my review of the scholarly literature and discuss a different approach to explaining partisan polarization and election outcomes, one that looks to elites and institutions, rather than voters. 
In this section, I will first discuss primary elections, an institution that many scholars identify as the source of polarized representatives in Congress and polarized politics. Then I consider an institution that is believed to create party-safe districts, whence come representatives who do not have to reach out to moderate voters, but foment partisan polarization. Finally, I will consider the incumbency advantage hypothesis, which has preoccupied scholars of Congressional elections for decades.

\subsection{Primary Elections}

As we have seen, primary elections have been a popular target of scholarly attention in the literature on polarization. They are viewed as vehicles driven by the "issue activists" - ideologues who hold intense and polarizing views on issues and wield disproportionate influence in candidate selection by striving to help candidates who reflect that intensity and polarity win primary elections (Fiorina 2002, 2006; Brady and Hahn 2007). If these committed partisans, by dominating the primary electorate, succeed in helping such candidates win primaries, then, contrary to pluralist theory, the candidates chosen to compete in the general election will represent the ideology of the median party activist in the district, rather than the ideology of the median voter in the district (Brunell 2008). In this way, the primaries are responsible for the emergence of polarizing representatives in Congress. 
Brady and Hahn (2007) argue that primary electorates are indeed more ideologically polarized than the general electorate, and that incumbents do move closer to the primary electorate to deter primary challengers. But Ansolabehere et al. (2006) note that House primary elections are typically as uncompetitive as general elections. They pose a different question: are primaries uncompetitive because incumbents are skillful at deterring quality challengers, or are they uncompetitive because they are simply not politically significant? King (2003) suggests that it is low turnout that produces a homogenous electorate, and it is this homogeneity, rather than activist influence, that produces more polarized candidates. Unfortunately, since there is no longitudinal survey of primary elections to examine, such as the NES for general elections, this hypothesis is difficult to test.

Gerber and Morton (1998), however, offer a testable hypothesis about primaries predicated on whether they are open or closed primaries. If primaries are polarizing, then states with closed primaries, in which only registered partisans can vote, should produce demonstrably more polarizing candidates for Congress than open primaries, with unrestricted access. If closed primaries do throw up more polarizing candidates for general election, then these more polarizing candidates should appear as more polarizing representatives in Congress. Looking at data from the NOMINATE database, McCarty, Poole and Rosenthal (2006) find that this prediction holds for House Democrats from closed primary states, but not for Republican members, or for members of the U.S. Senate. There is some evidence that primaries produced polarizing representatives, they conclude, but it is thin. 
Given the popularity of the primary election explanation of polarization, there is surprising little evidence linking primaries directly to polarization. The explanation is intuitively appealing, for who has not seen media images of vocal issue activists stalking the highways and byways of electoral campaigns? But unfortunately, intuition does not always provide sound empirical support. As McCarty et al. point out, primaries were introduced at the turn of the twentieth century - a period associated with diminishing partisan polarization (ibid.).

If scholars favor the "primary activists" explanation of polarization, another explanation focuses on the general election, and whether the election is competitive or safe The reasoning is that uncompetitive elections could contribute to polarization by producing elected representatives who have no incentive to appeal to moderates, but can play to their party base, safe in the knowledge that they will win re-election. Uncompetitive Congressional elections have become ever more pervasive since the 1970s, and especially so since the 1990s. Scholars estimate that U.S. House elections in the early twenty-first century have been among the least competitive in electoral history (Abramowitz, Alexander and Gunning 2006). Whether measured using reelection rates or the proportion of close contests (usually defined as decided by less than ten percent) the 2002 and 2004 House elections were the least competitive in the postwar era (Abramowitz et al. 2006).

If uncompetitive electoral districts are the cause of polarization, then I need to review what scholars have to say about them. The most popular explanation is redistricting, 
the notion that electoral districts are drawn with the goal of making the district safe for one party or the other. This explanation for uncompetitive elections has assumed the status of conventional wisdom, so it will be important to review it with a critical eye.

\section{$2.2 \quad$ Redistricting}

According to the literature, redistricting takes one of three forms: partisan, bipartisan, and racial gerrymandering (Cain, MacDonald and McDonald 2005). First, in state legislatures controlled by one party, the majority party can attempt a partisan redistricting, or partisan "gerrymander", referring to districts being re-drawn to reapportion voters so as to benefit a party or to better protect an incumbent in an election (Mann 2006). Self-interested political actors who have control over the process are assumed to "pack" likely voters of the opposite party into a limited number of districts, thus wasting their votes, and leaving more districts that are safe for their own party incumbents or candidates (ibid.).

In the second form, in states with divided government, legislatures may attempt a bipartisan gerrymander, geared to protect incumbents of both parties (Mann 2006). In the third form, re-districting may be pursued to create minority districts, in response to the Federal mandates and Court rulings regarding equal representation. Since minorities, if they vote, tend to be part of the Democratic Party coalition in most 
regions of the U.S., gerrymandering to create majority-minority districts is often tantamount to a partisan gerrymander (Cain et al. 2005).

Redistricting as the cause of party-safe House elections has become almost the default explanation. But as often occurs with such nostrums, reality is far more complex. In fact, redistricting and reapportionment is a puzzling phenomenon - theoretically, historically, and empirically - and its consequences are far from obvious. Is the objective to create party-safe districts? Or is it to maximize the number of seats in play for the party controlling the process? If the goal is seat maximization, distributing partisans more efficiently will expose some seats to more, not less, competition (Cain 1984). Nineteenth century partisan gerrymanders, for instance, created districts that were more competitive, not less so (Carson et al. 2006).

The central question, however, is whether a systematic relationship exists between redistricting and district competitiveness. Unfortunately, contemporary exercises in reapportionment and redistricting offer no conclusive answer. Incumbents in House districts that have been redesigned are no more likely to be re-elected than incumbents from districts that have not been redesigned (Oppenheimer 2005). Moreover, scholars find that, contrary to expectations from partisan gerrymandering, in districts that have been re-designed, the portion of the vote that can attributed to incumbency alone - the so-called "personal vote" - may increase or decrease; there is no systematic effect from redistricting (Desposato and Petrocik 2003). 
Other empirical observations cast doubt on whether a direct relationship exists between redistricting and district competition. If redistricting leads to party-safe districts, then this should be evident in Congressional elections immediately after districts are redrawn. Since most redistricting takes place the year after the decennial census, the election returns from the House elections following redistricting - in 1982, 1992, and 2002 - should exhibit a marked decline in competitiveness. What Abramowitz finds, however, is that the most significant changes in the number of competitive House seats occurred not in these three post-redistricting years, but between redistricting cycles (Abramowitz et al. 2006).

If redistricting does not affect district competitiveness directly, perhaps it does so indirectly. Cox and Katz (2002), for instance, argue that redistricting depresses competition indirectly, in the form of strategic behavior by candidates. Incumbents who are pessimistic about their prospects of re-election will retire rather than expend the effort required on reelection, a calculation that can be reinforced by the strategic entry of high-quality challengers, who sense an opportunity. But despite being intuitively appealing, this explanation, like the primary election explanation, leaves scholars struggling to account for the magnitude of the incumbency advantage using the strategic retirement explanation (Ansolabehere and Snyder 2002).

Finally, is there a link between redistricting and polarized politics? Again, the evidence is inconclusive, for polarization seems to be unrelated to electoral district design. Redistricting, as Oppenheimer (2005) points out, can hardly account for the 
appearance of highly partisan House members from states with one Congressional district, which are obviously never redesigned, or the appearance of partisan polarization in the U.S. Senate, where constituencies (state populations) are obviously not reapportioned. Senate roll-call voting is just as polarized as in the House (McCarty, Poole and Rosenthal 2006), and Senate voting patterns appear to move almost in tandem with the votes in the House on much legislation (Sinclair 2005). Concurrent polarized politics in both chambers of the U.S. Congress casts significant doubt on the redistricting explanation for partisan polarization.

\subsection{The Incumbency Advantage}

If redistricting is the most popular explanation of party-safe elections, incumbency advantage is perhaps a close second. The post-war "Michigan model" of elections treated Congressional elections as essentially party-line, low-salience affairs, where ideology was largely absent, and issues and candidates mattered even less than in presidential elections (Campbell et al. 1960). But after Erikson and Mayhew pointed out that marginal districts were vanishing (Erikson 1972; Mayhew 1973), scholars began a reappraisal of Congressional elections. "Vanishing marginals" inspired a new "candidate-centered politics" model of Congressional elections, one that placed far more emphasis on candidates and candidate behavior. 
These revisionist scholars discovered that incumbent candidates enjoyed distinct advantages over opponents, making elections safe for themselves, and, by extension, the incumbent's party. One advantage was access to ex-officio resources that, if used strategically, boosted incumbent visibility and popularity among constituents (Mayhew 1974; Fenno 1978). Another incumbent advantage was the ability to deter and discourage high quality challengers by raising significant campaign funds, as well as exploiting greater experience accrued from holding office (Jacobson and Kernell 1983; Jacobson 1989). Scholars also found that successful incumbents were adept at personalizing elections, at distancing themselves from the national politics, the national parties, and partisanship in general (Fiorina 1977; 2005).

Researchers calculated that this incumbency advantage surged in the late 1960s, increased more gradually through the 1970s and 1980s, and peaked in 1988, when a record 98\% of incumbents won re-election (Gelman and King 1990; Levitt and Wolfram 1997). Then, in the 1990s, the incumbency advantage began to recede (Fiorina 2005; Oppenheimer 2005). What caused this recession? The literature offers two potential answers: (i) increasing congruity between House and presidential voting, in other words, increasing partisanship in the electorate (Jacobson 2000a), and (ii) resurgent national party organizations, dominated by issue activists (again!) who got involved in elections not to seek patronage, but to promote an ideology, and had the means to nationalize what where hitherto local affairs dominated by the candidate (Brady, D’Onofrio and Fiorina 2000; Jacobson 2009). I have already discussed 
ideology in the electorate in the previous section; here I will comment on the nationalization of electoral politics.

Scholars noted that the demise of the incumbency advantage in the 1990s coincided with increasing nationalization of House elections. National parties and national interest groups formed political action committees, collecting and disbursing money in elections around the country as they saw fit. Meanwhile, political elites used the mass media to frame hot-button issues and policy debates, and mobilized voters through sophisticated get-out-the-vote (GOTV) campaigns, all financed by party organization and donors at the national level (Jacobson 2000, Fiorina 2005). In this new electoral environment, in this "independent expenditure campaign" (Fiorina 2005), candidates still mattered - a good candidate was critical for deterring quality challengers - but they no longer dominated affairs; elections were now a collaboration between local candidates and national-level actors and realities, such as parties or the state of the economy (Jacobson 2000a, 2007). When these national forces, or tides, are both strong and unfavorable to the incumbent's party, better quality challengers emerge, and more House seats change hands - as occurred in 1994 and 2006 (Jacobson 2009).

In the new, partisan model of elections the characteristic feature is perhaps the decline in "split outcomes," with fewer and fewer votes cast "against the partisan grain," such as victory for a Democratic House candidate in a district where the Republican candidate won the presidential vote, and vice versa (Jacobson 2006, 2009). Jacobson 
argues that this decline in split-ticket voting contributed to declining district competitiveness, a trend that was magnified by the Republican advantage in the distribution of partisans: more Democratic voters were concentrated around urban centers, leaving more districts (outside of the urban centers) that are Republican leaning. Jacobson calculates that this structural advantage began in 1964, so redistricting is not the cause. Rather, the cause is a combination of strategic elite behavior and the distribution of the electorate: Republican elites have an incentive to polarize politics, since they only need win favorable seats to control the House. In support of this hypothesis, Jacobson points out that fewer Democrats have been winning unfavorable seats since the 1980s (Jacobson 2006).

\subsection{The Underlying District Partisanship}

If politics has become more nationalized, as the incumbency advantage has declined, it would be logical to expect to see more competitive Congressional elections. Instead, the number of competitive districts has continued to decline, and challengers are rarely successful, even in marginal districts (Abramowitz et al. 2006). To dig deeper into this puzzling trend, it is useful to make two distinctions.

First, there is the incumbency advantage that derives from ex-officio resources and activities (Mayhew (1974), as opposed to the incumbency advantage that derives from campaign financing, whether from incumbent quality (Jacobson 1978), to 
challenger inexperience (Sorauf 1992). One hypothesis proposed by scholars is that the ex-officio advantages of incumbency became less important by the 1980s (Fiorina 2005; Abramowitz et al. 2006), at the same that campaign financing advantage became more important, as the cost of running a viable House campaign has soared (Abramowitz et al. 2006). So if incumbents enjoy an ever-expanding fund-raising advantage, simply by virtue of being office-holders (Ansolabehere and Snyder 2000), then electoral competitiveness will continue to decline, a trend reinforced by the nationalization of elections, which brings cash-rich national party organizations and interest groups to district elections, thus reinforcing inequality in campaign finances. Second, there is personal incumbency advantage, accrued by the individual member from constituency service, versus partisan incumbency advantage, vested in the district, and the underlying structural (demographic) composition there. Scholars measure underlying district partisanship using partisan registration (if available), vote totals for statewide offices, or the most popular measure, the normalized presidential vote result (MacDonald 2006; Abramowitz, Alexander and Gunning 2006; Jacobson 2006). Of course, this vote varies from one election to another, so scholars often select a "typical" year as index.

Oppenheimer (2005) finds that in U.S. House elections between 1992 and 2000, the personal incumbency advantage declined, but the partisan incumbency advantage advanced. He also found that the more competitive the district, the greater was the incumbent's own vote margin relative to the presidential candidate's vote margin - a discrepancy that grew larger the more the unfavorable the district (i.e. the larger the 
victory for the presidential candidate from the other party). Conversely, he finds that the less competitive the district, the more the incumbent's own vote margin matched the presidential result. Oppenheimer suggests that this inverse relationship emerges because, in the more competitive districts, incumbents work harder to exploit their personal incumbency advantage to win re-election (ibid.).

In short, by re-conceptualizing incumbency advantage in terms of district partisanship, rather than the behavior of the candidate or the party, political scientists have offered one explanation for the persistence of uncompetitive elections. This theoretical maneuver implies that the source of district competitiveness lies in the electorate, rather than in electoral institutions, and suggests a link between district competition and partisan polarization.

\subsection{District Competitiveness and Partisan Polarization}

Incumbency advantage as a function of underlying district composition implies that, in a district where the partisan balance is close, the election will be competitive. The winner in such a district is likely to be a candidate who considers the median voter in the district to be his or her most important constituency (for re-election), and is likely to vote and behave as a moderate member of Congress (Mann 2006). On the other hand, in a district where the underlying partisan competition heavily favors one party, the election will be uncompetitive. Here the winner is likely to be a candidate who 
considers the party base to be the important reelection constituency (ibid.), and has far less incentive to be a moderate member of Congress.

Thus the underlying basis of incumbency matters for partisan polarization. Diminished district competitiveness and party-safe districts produce representatives who can ignore the views of the minority within their district without fear of electoral repercussion; he or she will have license to take polarizing positions on a range of issues. Is there evidence to support this kind of linkage between underlying district partisanship and partisan polarization?

Mann (2006) takes the Poole/Rosenthal ideological scores, calculated from roll-call voting by members of the 108th Congress, and compares the score for a member against that members' margin of victory in their district, which is assumed to be a proxy for the personal incumbency advantage. He finds no significant relationship. But when he compares the same score against the presidential margin of victory in the member's district, which is assumed to be a proxy for the partisan incumbency advantage, he finds a linear positive relationship: Democratic members of Congress representing districts that $\mathrm{Al}$ Gore won in 2000 by a large margin were demonstrably more liberal in their Congressional voting record, and vice versa (ibid.). In other words, the ideological polarization of members of Congress is positively correlated with district electoral competitiveness. 
If ideologically polarized representatives emerge from districts that are party-safe, as this finding suggests, then whatever shapes district partisanship also contributes to partisan polarization. If the cause of district partisanship is not electoral institutions such as redistricting or primary elections, then Mann's research suggests that the electorate, the district constituency, is a prime suspect. Given that ideology among the electorate is hard to detect, and hard to link to polarization, this also suggests that American are partisan, regardless of whether they can be described as ideological. If so, how or why do these partisans converge or concentrate in certain electoral districts?

Oppenheimer (2005) offers one answer. He suggests that there may be no direct, individual level link between a polarized public and polarized elites that can be found, because American voters are creating party-safe districts - not directly, by purposefully changing their party alignment or taking polarized positions on issues but indirectly, by making residential decisions that are correlated with their partisanship. One analysis of county-level data suggests this demographic "sorting" is visible along the population density dimension: counties that voted for Bush in 2000 and 2004 averaged one eighth the number of inhabitants per square mile as did counties that voted for Gore and Kerry (Bishop 2008). 


\section{CONCLUSION}

How do scholars explain the current partisan polarization in American politics? If polarization is a product of the electoral universe, then the same factors that influence American elections should influence partisan polarization. I have conceptualized American Congressional elections as an interaction between an electorate that supplies votes, the elites (candidates and activists) who seek to influence where those votes go, and the electoral institutions that bring voters and elites together. It follows that partisan polarization is likely to be a product of the interaction between elites, the voting public, and the institutions that link them.

Scholars have sought to find the source of polarized politics in polarized attitudes in the electorate. Some believe that economic class, associated with the New Deal alignment of American politics, is the societal cleavage that makes voters polarized. Others argue that newer, cultural issues have driven voters apart. The findings from individual level surveys, however, have been inconclusive: much of the electorate appears to be as innocent of ideology, of a coherent set of preferences regarding the appropriate role of government, as it did five decades ago, when such surveys were first conducted. American public opinion offers no clear explanation for the current polarization in Congress.

Others have turned their attention to elites, and the electoral institutions through which activists and representatives pursue their objectives. Since elite agency relies 
on these institutions, for analytic purposes we can think of elites and institutions as one and the same set of factors. Three institutions have attracted the most attention from scholars: primary elections, redistricting, and the incumbency advantage.

The first explanation states that polarized politics originates in the candidate selection process, primary elections purportedly dominated by ideologically polarized issue activists. These elections reward candidates who play to these activists, rather than the electorate at large. Again, the findings are inconclusive. History and evidence do not indicate that any correlation exists between primaries and unusual levels of polarization, or that specific systematic differences exist between open and closed primaries. In addition, contemporary general elections are often as party-safe as primary elections. In short, the specific links between activists, the electorate, and polarized representatives are unclear.

The second institutional explanation states that polarization stems from uncompetitive, party-safe elections. These elections produce office-holders who only play to their party base, rather than the median voter in the electorate. But again, the empirical support is inconclusive. Many elections are party-safe or produced ideologically polarizing representatives without having undergone any redesign; Senate elections are party-safe and many Senators are polarizing. In addition, many districts do not become more party-safe right after redistricting, as the explanation predicts, but several years later. Finally, the redistricting explanation assumes partisan 
elites in charge of redistricting want to create party-safe districts, rather than to maximize the number of districts that their party might secure in the state.

A third institutional explanation emphasizes incumbency, and the electoral advantages that accrues to being the incumbent. There are two possible sources of this incumbency advantage. Personal incumbency advantage flows from the resources that inhere in office, which incumbents can use to make a favorable impression on constituents, and to deter potential challengers. The evidence, however, indicates that this personal incumbency advantage has been on the wane, even as party-safe districts have become more pervasive. The second possible source of incumbency advantage, partisan incumbency advantage, flows not from the office, but the underlying partisan composition of the district electorate, a measure of how much the district voters are pre-disposed to identify with one party, regardless of the incumbent. Research indicates that representatives from districts that are party-safe, as measured by the presidential vote margin, are more ideologically polarized in Congress.

Partisan incumbency advantage, vested in the underlying partisan composition of the district electorate, shifts the focus from the elites and institutions to voters, for incumbency is an institutional feature of elections (you could eliminate incumbents simply by creating a new rule: one-term limit), but the underlying partisan composition is an attribute of the electorate.

Analyzing the electorate is problematic, as public opinion scholars have found in their decades-long search for evidence of coherent ideology in the electorate. This problem 
may be a function of measurement error, or simply the limitations of survey research. Or it may be because the aggregate measures that have been used, such as the distribution of opinion, do not contain needed information. Brewer and Stonecash (2006), for instance, contend that aggregated measures that are typically calculated from survey data, such as distribution of opinion or the balance of partisans, may remain unchanged even as voters become more partisan.

The problems involved in measuring attitudes suggest that researchers may profit from considering other theoretical and methodological approaches. One option is to shift the focus from attitudes to partisanship. If we make some assumptions, we can consider vote totals to be a proxy for partisanship. This maneuver has the empirical advantage that, whereas it is hard to count attitudes, we do count votes. Another theoretical maneuver is to examine the distribution of voters, rather than the distribution of opinions. This maneuver has the virtue of not having to rely on individual level survey data to measure attitudes, given how indeterminate that approach can be. Rather, we can observe actions, rather than attitudes.

In the next chapter, I will discuss both these theoretical moves, in the context of my research design. The main goal of the chapter is to construct an explanation of partysafe elections that emphasizes where voters live, and how they vote, rather than their attitudes or opinions, or electoral institutions. It is an explanation of district competitiveness that identifies the underlying partisan composition as the cause, one 
that uses aggregate data to explain aggregate outcomes. The explanation will constitute a structural, rather than an institutional, theory of party-safe elections. 
CHAPTER 3:

A STRUCTURAL THEORY OF ELECTIONS 
In the previous chapter, I looked at what scholars have said about various features of U.S. Congressional elections that might explain the increasing partisan polarization in American politics. Of particular interest were possible causes of party-safe elections, as these uncompetitive elections are a plausible source of polarized members of Congress. After surveying the literature, I concluded that the concept of the underlying partisan composition was particularly promising in this regard.

In this chapter, I will build a theory of party safe elections centering on this concept of the underlying partisan composition. By theory, I mean a set of statements assumptions, definitions and hypotheses - that cohere to form an explanation of an outcome of interest. By explanation, I mean an account of the outcome of interest, that seeks to identify or specify the conditions, or causes, that lead to the outcome of interest. Such an explanation, of party-safe elections, is the purpose of the dissertation as whole.

I begin by distinguishing between "top-down" and "bottom-up" approaches to Congressional elections. This distinction, which follows from the literature reviewed in the previous chapter, informs and contextualizes my "constituency-based" theory of party-safe Congressional elections, one that emphasizes the composition of the electorate as the key independent variable. In sections 2 and 3, I analyze and define the concept of "underlying partisan composition"; in sections 4 and 5 I discuss the causes and consequences of the concept. I end with some broader epistemological 
observations and implications of my theory in sections 6 and 7, the better to frame the methodological discussion that follows in chapter 3.

\section{THE CONSTITUENCY BASIS OF POLITICS}

Much of the scholarly literature on American elections that I reviewed in the last chapter emphasizes elite agency. For instance, the candidate-centered model focused on the actions and calculations of candidates for office, ostensibly motivated by their desire to win reelection. The partisan model is also elite-oriented, although it conceives of elites in broader terms, as political activists, and campaign professionals, as well as candidates, the class of people who orbit the election campaign and its main offshoot, the political party (Aldrich 1995). The emphasis on elites is also evident in institutional explanations of electoral polarization, such as the "primary activists" explanation, and in institutional explanations of electoral competitiveness, such as the "partisan gerrymandering" explanation.

The focus on elites and the institutions that they design or control reflects an approach to the study of politics that emphasizes the arenas in which elites make political decisions and conduct the affairs of state. Much of the political science literature, such as the literature on American elections, is concerned with the operations of these 
arenas, and with those who hold office within them. ${ }^{3}$ In other words, it is a "topdown" vision of electoral politics. Some of this doubtless reflects scholarly fashion, such as the popularity of rational choice institutionalism in the study of American politics in recent years. But the emphasis on elites has likely also been influenced by decades of the survey research that, as I have noted, portrays Americans as uninformed and lacking in stable political attitudes or ideologies (Converse 1966, Lewis-Beck et al. 2008).

Nevertheless, as I also noted earlier, I consider the "top down" accounts of elections and partisan polarization to be unsatisfactory and incomplete. I ended the last chapter with the observation that the incumbency advantage explanation of elections has been reformulated, from one in which the advantages are thought to accrue from the incumbent's office, to one in which the advantages are thought to accrue from incumbent's constituency, or electorate.

I take this revised formulation of the incumbency advantage explanation as my cue to revisit the constituency basis of Congressional elections. For sure, there exists an extensive political science literature regarding the mass public, with particular focus on the determinants of the vote, (Campbell et al. 1960) and political participation (Verba et al. 1995, Campbell 2006), with the study of representation, indelibly associated with Fenno (1978), serving as the connective tissue between the mass public and elites. It remains true, however, that in recent decades, American politics

\footnotetext{
${ }^{3}$ This reference comes from Stoker and Marsh's (2010) discussion of the "arena" and "process" distinction in the approach to studying politics.
} 
scholars have focused more on institutions rather than the mass public, especially given the influence of the rational choice paradigm.

In this dissertation, by contrast, I shift the focus back to the American public, and to the constituency basis of American elections. I also conceive of politics in a broad manner, as phenomena inherent in social processes, not just in the formal arenas of public decision-making. In this "process" approach, to use Stoker and Marsh's term, scholars consider the realm of the political to encompass the choices that private individuals, households, and groups make within society, rather than simply the choices made by elites within the political arena. The result is what I refer to as a "bottom-up" view of politics.

My focus on the electorate is motivated by the link scholars have made between incumbency advantage and the underlying partisan composition of the electoral district, but my approach departs from the approach that scholars typically employ in the public opinion and elections literature. For my interest is less in who votes, or whether voters are ideologically polarized regarding specific issues, than in how voters are distributed. The distribution of voters matters because elections take place within clearly defined and bounded geographical areas, or sections, such as Congressional districts, counties, and states, and if the choices voters make regarding where to live are correlated with voting preferences, then these geographic sections will take the form of partisan sections: geographic areas with a distinctive, persistent, and predictable preference for one specific political party. 
So to the extent that voters make residential choices that result in social compaction, and to the extent this compaction is correlated with politically salient attributes, elections are not simply about who turns out to vote, or who is ideologically polarized, but also about what residential choices voters make. These millions of household residential choices distribute the American electorate in ways that lead to partisan sections. This sectionalism is the basis of the underlying partisan composition of electoral districts, the variable responsible for incumbency advantage, and party-safe elections. This, in a nutshell, is my argument, one that I will develop and support in the rest of this dissertation.

In the remainder of this chapter, I will specify the theory that I propose in support of this explanation - where by theory I mean the assumptions, propositions and hypotheses that together form a coherent explanatory framework. To support these theoretical statements, I will rely on scholarship, logic, and empirical observations and experience. I begin by elaborating on three concepts that are central planks of my theory: partisanship, composition, and migration. I begin with partisanship.

\section{AMERICAN VOTERS AS STABLE PARTISANS}

My theory is built on the premise that voters are partisans, meaning they identify with one or other party, and vote according to party cues. If voters switched from the candidate of one party or another from one election to the next, we would not see 
persistent patterns of voting in discrete electoral districts. If we did not see such persistent or stable voting, would hardly expect to see party-safe elections. Thus my theory of party-safe elections has a necessary condition: voting in Congressional elections is characterized by stability. Identifying the cause of this stability is the focus of this section.

To clarify this stability premise, I start by distinguishing between short term and long term factors that attend elections. Short-term factors include individual candidate quality, campaign effects, or which issue happens to be salient that year (Petrocik 1981, Jamieson 2000). These short-term factors are most useful in explaining the variability of election returns, such as difference in successive elections.

Long-term factors that scholars identify include ideology, or the attitude toward politics broadly conceived, and partisanship, or the degree to which an individual identifies with a party. These long-term factors are most useful in explaining the stability of election returns, such as similar outcomes from successive elections, or, at the individual level, similar voting behavior over time. Given that my outcome of interest is party-safe elections, it follows that some long-term factor must be in play, one that produces stable, rather than variable, election results. I identify that factor to be partisanship.

In the last decade, the concept of partisanship has become central to the study of elections. Scholars have found that partisanship is not only the strongest predictor of 
the vote choice (Lewis-Beck et al. 2008), but that partisanship and the partisan balance within the electorate show remarkable stability over decades (Bartels 2000, Green et al. 2002). For whether or not the electorate is ideological, it appears that they never really stopped identifying with political parties (Bartels 2000, Hetherington 2001). Of course, it is not uncommon for voters in House districts to vote for one party for Congress, and the other party for President, creating so-called split tickets. Nevertheless, scholars find that when the incumbent in these split House seats retires, the Congressional vote typically reverts to the party of the president back to party voting (Green et al. 2002). But what exactly is "partisanship"?

\subsection{Partisanship as a Social Identity}

Scholars take one of two broad approaches in conceptualizing partisanship. In the rational-ideological approach, voters evaluate the candidates, policies, and past performances of the two parties, and then pick the party that they believe will better manage the nation's affairs (Fiorina 1981), or better fits their own issue attitudes and preferences (Abramowitz 1994). In the social-psychological approach, voters form party affiliations from social cues they receive from their social environments and networks, rather than through rationalist calculations. In the classic "Michigan School" version of this approach, partisanship is conceived as a "perceptual filter" learned through childhood socialization within the nuclear family (Campbell et al. 1960); in the contemporary version, partisanship is conceived as a core "social 
identity," learned from social identification with a discernible group within society (Green et al. 2002).

In this social identity approach, partisanship develops in a two-step process. First, voters associate parties with certain social groups. Then, voters choose the party that appears to best fit the social group(s) that they themselves identify with. As Green puts it, the process is tantamount to voters asking themselves: Which party do people most like me vote for (Green et al. 2002)? Or alternatively, as Akerloff and Kranton (2010) put it, voters assign an identity to their selves, and then align that identity with the social category "Democrat" or "Republican." Regardless of what steps come first in the psychological process, the social identity approach states that the political party is simply another social group that Americans identify with.

The relationship between partisanship and social categories is nothing new, of course. The first generation of election scholars, in the post-war era, identified group traits such as ethnicity, class, religion and region as correlates of voting behavior (Lazarsfeld et al. 1948, Key 1955). But the Michigan School scholars who came on their heels shifted the emphasis from group psychology to individual psychology (Campbell et al. 1960). The social identity approach shifts the focus back to the social group as the link to partisan identification.

Partisanship is central to my theory for two reasons. First, unlike issue or ideological voting, which appears to be practiced by only a minority of the electorate, voting 
influenced by party identification appears to be pervasive across a large swathe of the electorate (Greet et al. 2002; Lewis-Beck et al. 2008). Second, my theory presupposes a stable two-party system, in which the two-party vote, meaning the vote for the Republican and Democratic Party candidates, effectively describes and encapsulates the vast majority of American election results.

Of course, there are instances where a third party candidate influences the outcome, in presidential elections and in Congressional elections, but on the whole, American electoral politics has been structured by a stable two-party system that is nigh on one hundred and fifty years old. The stable two-party system is the foundation for my stability premise: stable partisan identities influences American electoral outcomes.

In my theoretical framework, "party" refers not to the party defined by rational choice theory - an organizational vehicle for elites and political entrepreneurs to pursue their ambitions for office (Aldrich 1995) - but party more in the classical pluralist sense, as a proxy for a variety of preferences (Campbell 2006). By "preferences" I am referring to the choices individuals make in those social dimensions where they have an option, such as how to make a living, whom to marry, where to live, and whom to vote for. The political party as proxy for social preferences implies that party identification and these various social preferences are correlated. Just as voters may decide where to live because they have adopted or acquired certain social identities, so will they choose a political party because of the social categories they assign themselves - or their social identities (Akerloff and Kranton 2010). 
In short, partisanship derives from social identity, one that influences a variety of social preferences, including the choice of residence, as well as a political party to identify with and support. Since social identity tends to be stable, party identification and voting behavior is likely to be stable at the individual level - as scholars have found. And if residential choice is a function of social identity, correlated with partisanship, then we should also see stable patterns of voting at the aggregate level. The aggregate level manifestation of stable partisanship and correlated residential choices would take the form of geographic places or regions that display distinct and stable partisan voting patterns, or partisan sections. These sections account for the underlying partisan composition of electoral districts, which in turn determines whether the election will be competitive or party-safe, election after election.

To develop the idea of partisanship as an attribute of a place, I need to elaborate on this link between the individual and the aggregate, between individual partisanship and the underlying partisan composition of a place. As part of this elaboration, I need to define and describe the concept of "underlying partisan composition."

\section{COMPOSITION AND CONTEXT}

Scholars typically conceive of partisanship as an individual level variable, often measured by asking voters if they are strong partisans, weak partisans, or independents. My theory, on the other hand, takes and aggregate level approach. 
Consequently, I need to identify and define the concept of partisanship as an aggregate level phenomenon, if I can. I do this by conceiving of partisanship as an attribute of a place, as opposed to an attribute of an individual.

To reformulate partisanship in this way, I turn to the distinction that political geographers make between two mechanisms or processes by which a place can be said to acquire an identity, such as partisanship, the distinction between context and composition. ${ }^{4}$ I will employ this binary to specify and define what I mean by the "underlying partisanship" of an electoral district or region.

In the contextual approach, a place, or community, has characteristic features that inmigrants encounter, contextual features that predate the arrival of these migrants, and subsequently influence the behavior of newcomers. This influence can take the form of social sanctions that enforce pre-existing norms, such as those associated with the social capital concept, that I will discuss shortly, or the influence can take the form of communications networks that structure the exchange of information, political or otherwise (Fenton 1966). Whatever the mechanism, these different dimensions of context - social, cultural, legal, or institutional - shape preferences, including political preference such as partisanship and vote choice (Gimpel and Schuknecht 2004). This is what we typically refer to using the generic term "socialization".

\footnotetext{
${ }^{4}$ See, inter alia, Gimpel and Shucknecht 2002.
} 
In the compositional approach, on the other hand, place has no exogenous influence on behavior, no pre-existing structures that shape behavior. Any characteristic behavior associated with a place is simply an aggregation of the behavior and influences of the individuals and groups who reside there, or have moved there (Gimpel and Schuknecht 2004). People in a specific community or place behave the way that they do, including the way they vote, because of who they are, their identities - in whatever manner these identities were formed. In other words, people shape places; places do not shape people. And the more members of certain social categories, or identities, cluster in proximity, the more that place will exhibit identifiable and persistent patterns of behavior, including voting behavior. This persistent, predictable voting behavior defines the concept of "the underlying partisan composition."

So my prime hypothesis presumes that places are shaped by composition rather than context. One reason for my choice is that the contextual approach simply does not comport with the finding that individual level partisanship remains stable over time, a finding that can be traced to the validity of the theoretical underpinning of the contextual approach: the contact hypothesis.

The contact hypothesis states that new arrivals into a community will be socialized into the new in-group norms, while, at the same time, defecting from their group of origin (Bishop and Cushing 2008). But this hypothesis is inconsistent with the finding that party identification in the American electorate is remarkably stable over time. To 
put it another way, if defection from in-group norms is pervasive, why would party identification be so persistent, so "sticky", as reported by scholars from Key (1955) to Green (2002)?

The contact hypothesis is also difficult to reconcile with stable partisanship when we consider that Americans are unusually mobile (as we will see in the next section). Thus these migratory Americans should be constantly susceptible to defection, as they enter and encounter new communities. Moreover, if Americans change their social and political preferences after contact with others, then we should observe Americans switching parties much more as they go through the life-cycle, since we are likely to come into contact with more people, the longer we live. In short, the contact hypothesis is inconsistent with stable party identification.

A second problem with the contextual approach is that a place may have a partisan profile or identity, but context may not be the cause. For instance, observers of the 2004 presidential election, in both media and academic circles, found that lower density environments - rural counties and suburbs on the metropolitan fringe, or “exurbs" - were Republican strongholds (Lang and Sanchez 2008). But what is it about low density that causes such pronounced Republican Party identification?

The contextual explanation would be that low density shapes the information environment and social networks such that Republican Party identification increases, and newcomers are socialized into this Republican Party identification in some way. 
The compositional argument is much more straightforward: low-density environments attract the type of migrants and residents (those with the social preferences) who are likely to vote Republican or identify with the Republican Party. The first explanation is complex: what is the process by which places ostensibly influence political behavior and political change? The second, compositional argument is simpler. Following Occam's Razor (choose the simple explanation unless there is good reason to do otherwise) I choose the compositional approach.

There is also a practical reason for favoring the compositional approach. If we describe a place by reference to social and demographic composition, then we can employ aggregate level data census and population data to analyze it - data that are typically collected and archived by government agencies. The researcher therefore has recourse to publicly available secondary data that he or she can collect and organize in order to measure aggregate features of population composition, or to use in support of an argument. The methods I adopt to do this are discussed in the next chapter.

The concept of composition I have presented here is not a novelty in structural explanations of politics; it is a staple feature of them. One explanation of House elections, for instance, identifies the racial mix in the district as the explanatory variable: the percent non-white predicts whether the Democratic or the Republican candidate succeeds (Stonecash, Brewer and Mariani 2003). Other structural/compositional variables that also typically matter in such explanations 
include income, urbanization, or population density - although they may be conceived as proxies for the variable of interest (in this instance, the minority share of the population).

The premise of arguments such as these is ideological realignment (non-whites are more politically liberal than whites, and accordingly they vote Democrat), but the core explanatory logic is structural: as the non-white population increases, the underlying composition of dense, urban districts become more politically liberal and Democratic party-safe. Rural districts, by contrast, with far smaller non-white share of the population, appear as conservative and Republican party-safe.

Of course, structural/compositional explanations are not always so straightforward; rather, it depends on whether the explanatory variable has a constant effect. If the explanatory variable is the share of the population that is black, then we are likely to find consistent partisan effects, since black Americans have been stable Democratic identifiers for many decades (the consequence of the Southern realignment). A different variable, however, may not produce such predictable or persistent effects.

For instance, if the researcher adopts income as the explanatory variable, he or she may find that the explanation is not straightforward, for the income effect is not constant: whereas income does correlate positively with Republican voting in general, the relationship breaks down at the state level. Gelman and his collaborators find that in the poorer states in the interior of the country, the wealthier tend to vote for the 
Republican Party in elections, but in the richer, coastal states, the wealthier tend to vote Democrat (Gelman et al. 2008). Why such a breakdown in the income effect in the coastal states? Gelman argues that the effect is suppressed by the influence of culture and values on partisanship: upper income voters in the coasts prefer the party that better fits their socially liberal values (ibid.).

But why is the income effect confounded in coastal "blue" states in this way? Do blue states turn people into Democratic partisans, or do Democratic partisans move to blue states? In other words, is it context or composition? Gelman suggests that it is composition, and that geographic mobility is the cause of this type of distinct red/blue partisan composition. He does not elaborate on this suggestion, but this "mobility hypothesis" is a core proposition of my constituency-based theory of party-safe elections. I turn to this next.

\section{MOVING AS POLITICAL BEHAVIOR}

If the income effect is shaped by geographic mobility, then geographic mobility obviously matters for election outcomes. But this "mobility effect", for its part, does not require the existence of partisan polarization at the mass level, or politically divisive actions by elites. Instead, mobility will influence electoral outcomes as long as it is non-random, and as long as voters are partisan, and do not defect when they move from one place of residence to another. The result of non-random migration of 
partisans will be the emergence of partisan sections, regardless of whether voters are "ideologically polarized", how elites behave, or how districts are designed - although it does not exclude any of these possibilities. But the basic point is that the mobility effect is exogenous.

Mobility is unrelated to ideological polarization in the electorate because if voters were distributed in a non-random manner across geographic space, the result would be polarized politics, and party-safe elections, even if most voters were politically moderate. Such sectionalism would emerge if, as I have postulated, partisanship is a social identity correlated with other social preferences such as residential choice. In such a scenario, voters will be distributed in such a way as to endow different regions or counties with distinctive partisan preferences, creating partisan sections. These sections would be revealed during elections, as the predictable voting preferences that define the underlying partisan composition of various electoral districts.

Why is the mobility effect potentially consequential? Mobility matters in American politics because Americans are unusually mobile. The U.S. Census Bureau calculates that, on average, Americans change residence every five years (Schachter 2002). Others calculate that one hundred million Americans moved from one U.S. county to another in the decade of the 1990s (Bishop and Cushing 2008), while another finds that forty-eight percent of Americans moved between 1995 and 2000 (Gelman et al. 2008). Such mobility, assuming it involved stable Democrat or Republican partisans, would shape the underlying partisan composition of all those places experiencing in- 
and-out-migration. In these places, the changing composition of the balance of partisans would influence election outcomes, as opposed to simply the aggregate preferences of existing voters, as in "static" models of elections such as the classical pluralist or rationalist models, which do not take into account the consequences of self-selected migration.

So it matters where voters live and how mobile they are, since migration is not likely to be politically neutral in its electoral consequences. If households who planned to move simply threw darts at a map to decide where to go, or if migrants were composed solely of "median voters" or independents located in the middle of the ideological and partisan spectrum, then their relocation would likely not affect the underlying partisan the underlying composition or partisan balance of the places they left or entered. Neither scenario is plausible. It is much more likely that those who move do not throw darts at a map in choosing where to live, and that they differ from those who are remain rooted.

For instance, demographers find that internal migrants in the U.S. are younger and have more education than the general population (Schachter 2002), while urban economists find that knowledge workers (typically defined as those with higher education), tend to cluster in certain places, on account of the uneven manner in which economic development distributes high-growth industries across the economic landscape, concentrating these skilled workers in certain areas, and, by subtraction, depopulating others of these same demographic groups (Florida 2002). If these 
knowledge workers have social preferences that correlate with party identification, then their employment-based clustering will consolidate partisan sections. In short, economic geography will contribute to a partisan political geography.

Of course, much of the American population lives in the same neighborhood or metropolitan areas, one generation after another. Those who marry and start families at a younger age are more likely to be rooted, as are those who are less educated (Schachter 2002). But a significant portion of the American population is evidently mobile, and my contention is that this mobility affects the partisan composition of different regions and areas of the country. Where in-migrants reinforce the existing partisan composition, they are likely to contribute to political sections, and to make elections less competitive. Where in-migrants muddy the existing partisan composition, they are likely to make elections more competitive.

Does this mean Americans move because of their self-identified partisanship, with Republicans seeking out other Republicans, and Democrats seeking out other Democrats to live near? There is no evidence to indicate that this motivation or decision rule prevails in the American electorate (although that does not exclude it, obviously). But such a decision rule is not necessary for migration to have partisan consequences. Rather, as Oppenheimer (2005) suggests, all that is required for partysafe sections to emerge is the less restrictive condition that residential choices are a function of preferences that are correlated with partisanship. But what might these correlated migration choices look like? 


\subsection{Migration: Three Processes}

As with most aggregate outcomes, migration should be reducible to plausible individual and group level preferences and actions (Geddes 2003). As with any complex social process, there are likely to be a variety of processes - including institutional, rational, and psychological factors - that contribute to migration choices. Here, I suggest three processes of migration that have a structural logic, consistent with the structural bent of my overall argument - processes that plausibly contribute to political sections.

First, there is the income effect. Since moving requires resources, those with more income are more likely to consider moving, in search of economic or social opportunities. And since income is correlated with Republican Party identification, it follows that migrants are more likely to be Republican Party identifiers (Gimpel 1999). Using the terminology employed by geographers, the income effect is a "pull" factor, one that is biased to one specific party.

Second, there is the effect of immigration, as many native-born white residents are likely to leave a neighborhood where there is substantial non-white immigration (Frey 1996, Gimpel 1999). Assuming an ideological alignment in which minority immigrants are more likely to be Democratic Party identifiers, it follows that these immigrant enclaves become Democratic Party strongholds, wrought by the dual 
process of subtraction (of native-born whites), and addition (of non-white immigrants). Using terminology from geography, immigration is a "push" factor.

A third possibility is that native-born whites make migration choices not because of income or immigration, but because of cultural and lifestyle preferences. As noted in the previous chapter, scholars have noted that religiosity, typically defined as regular attendance at a place of worship, has emerged as an important variable in American politics in the last two decades. ${ }^{5}$ Empirically, scholars have identified with religiosity specific sub-groups, particularly evangelical Protestants, and, to a lesser extent, Catholics. According to the "culture war" hypothesis, religiosity is positively correlated with Republican Party identification.

It is important to note that migration is shaped not only by obvious individual level factors such as education and income, but also by the diversity of residential choices available to the American electorate. Such expanded choice is made possible by liberal and permissive land-use regulations and practices that favor developers and new home construction, and gives internal migrants more scope to sort themselves according to economic, social and cultural preferences (Teaford 1996, 2006).

In sum, it matters where people live because those aggregate choices determine the distribution of voters. This distribution is neither random nor politically neutral, since those who move are self-selected, and the choice of new residence reflects

\footnotetext{
${ }^{5}$ See, inter alia, Layman (1997).
} 
preferences that may be correlated with party identification. If these preferences promote social compaction - the clustering of Americans according to demographic attributes - as opposed to social fragmentation, then the way voters distribute themselves will lead to partisan sections, which become evident during elections as the underlying partisan composition of counties and electoral districts. The more evenly divided this underlying partisan balance, the greater the migration effect will be on the underlying partisan composition. Thus geographic mobility will cause the underlying partisan composition to evolve over time, as evident from election results: some places are likely to become more party-safe, whereas other places may become more competitive.

\section{SECTIONALISM IN FLORIDA}

The idea of sectionalism in American politics is now familiar to even casual observers of American politics, from the "red and blue map" that has been produced by the media every four years since the 2000 Presidential election, showing the country divided into red (Republican) and blue (Democrat) states, depending on which party won that state's electoral college votes. ${ }^{6}$ This "red and blue" map reveals a country carved into distinct partisan regions: the Northeastern and the Pacific Coast states tend to be reliably Democratic in presidential voting, from one election to the

\footnotetext{
${ }^{6}$ Black and Black (2007) have divided the country into five regions: two are Democratic, two are Republican, and the fifth, the Midwest, is the one fought over fiercely every four years.
} 
next; the South, the Mountain West, and Great Plains states tend to be reliably Republican, whereas the Midwestern states define a region that is neither reliably Democrat nor Republican, but "purple.,7

My contention is that this sectionalism does not just exist nationally, and that just as the nation is divided into regions that favor one or other party in presidential elections, so are the states themselves divided into partisan sections. The distribution of voters into partisan sections within states is something campaign strategists have long analyzed and exploited in campaigns for state legislature and the U.S. Congress. But sub-national sectionalism has garnered less attention from scholars. Those few scholars who have devoted attention to the topic have argued for its importance. Gimpel and Schuknecht (2004) believe sub-state sectionalism to be more important than sectionalism at the national level, for while the distribution of voters within the nation matters for presidential election outcomes, the distribution of voters within the state matters for both state and national elections

To flesh out my theory that the distribution of voters accounts for election outcomes, I need a reason why individual level choices lead to sectionalism. What are the individual level motivations or decisions that could lead to voters creating party-safe, red and blue electoral districts?

\footnotetext{
${ }^{7}$ There are exceptions to this pattern, notably Colorado, which is no longer reliably Republican, and New Hampshire, which is not solidly Democrat.
} 


\subsection{Individual Preferences and Aggregate Segregation}

If political sections are a function of residential decisions that not only lead to social compaction, but also correlate with similar preferences such as party identification, does this mean that Americans are choosing segregation? Not necessarily. In fact, social compaction can derive from only a mild preference for living near those who are alike in certain respects. The aggregate outcome of this mild preference, however, can be segregation. The Nobel Prize winning economist Thomas Schelling has demonstrated why this is so, as an example of the social dilemmas from the unintended aggregate level consequences of individual preferences (Schelling 1977).

Using a checkerboard of black and white pieces, Schelling demonstrated that it requires no more than a mild preference within-group compaction to create segregation (ibid.). Starting with a community with many members of an in-group and some members of an out-group in equilibrium, Schelling shows that the arrival of more members of the out-group eventually leads to a tipping point: that mix of ingroup and out-group members such that any increase in the out-group will lead to significant flight by the in-group.

Thus individuals may not choose to live in highly segregated communities, but the combination of a mild individual level preference for some in-group homogeneity, along with the existence of a tipping point, rapidly leads to segregation in the aggregate. We can observe the results of this process in many gateway cities and 
metropolitan areas, such as Miami, Los Angeles, and San Francisco, where subgroups of the pre-existing population, typically white and black residents, have left in significant numbers, in response to immigration (Barone 2007).

The Schelling tipping point describes how the interaction between individual preference and aggregate outcome explains segregation. But why would individuals have a preference for in-groups, however mild? Why not seek diversity instead? One explanation can be found in the literature on "social capital".

The concept of social capital was proposed by sociologist James Coleman to explain the superior academic performance of parochial school students compared to public school pupils (Coleman and Graf 1987). Coleman argued that parochial school pupils did better because of the dense social ties that existed between parents, teachers and pupils. These social ties, built on reciprocity and trust, facilitated surveillance and monitoring of pupils, making it easier for the school community to enforce norms, such as studying hard (ibid.). In other words, students in Catholic schools did better than their public school counterparts because pupils, parents and staff knew each other well, watched over each other, and intervened when problems arose.

If norms are facilitated by greater reciprocity and trust that pervades communities dominated by in-group members, then, assuming individuals seek and value certain norms, they will prefer to live within communities where in-group members dominate. In other words, preference for dense social ties will promote social 
compaction, rather than social fragmentation. Putnam (2007) found that in diverse communities, inhabitants were less interested in other members, associated less with them, and generally lacked the dense social ties necessary for community social capital. If the desire for dense social ties motivates migration and residential choices, and if these social preferences are correlated with partisan preferences, then findings from social capital theory provide reasons why individual level decisions lead to sectionalism.

In conclusion, the distribution of voters across the political landscape affects Congressional electoral outcomes by shaping the partisan composition of the district. The consequence of such sectionalism is that the distribution of voters can contribute to polarization in national politics by awarding electoral victories to Congressional candidates who may reflect, in their ideology, the median voter in their district, but not necessarily the median voter in the national electorate. If the distribution of voters in these districts reflects significant social compaction, then representatives who appeal to the median voter in the district may be fairly polarizing to the electorate at large.

To finish specifying my theory, I need to relate what I have proposed with the scholarly literature on elections and voting behavior. Ideally, I can link my theory to realignment theory, which is the conventional framework political scientists employ when thinking about electoral behavior. Is realignment contributing to party-safe elections? If so, how? My prime hypothesis is that these sections are caused not by 
conversion or generational replacement, although they may play a part, but by patterns of migration and settlement.

\subsection{Sectionalism and Realignment Theory}

I noted previously that realignment theorists argue that the balance of support for the two parties shifts when levels of support for a party fall across the electorate because of general electoral circumstances, such as the collapse in support for the Republican Party in the aftermath of the Stock Market Crash and the Great Depression, or when levels of support for a party by specific social groups shifts as their party affiliation changes, as with Black Americans voting for Democratic Party in the 1950's and 1960s (Stonecash, Brewer and Mariani 2003). I also noted the debate over whether it occurs quickly, in one "critical election" (Key 1955), or more slowly, in a secular realignment (Key 1959), as new issues become salient (Carmines and Stimson 1989), and the electorate re-orientates their party affiliation to match their attitudes to new issues (Abramowitz 1994; Layman and Carsey 2006). But now, I need to consider what realignment theory says about the processes by which realignment occurs.

Scholars largely agree that realignment since the 1960s has aligned economic and social conservatives with the Republican Party, and economic and social liberals with the Democratic Party (Abramowitz 1994, Stonecash 2006, Black and Black 2007). Nevertheless, they disagree about how this happened: is it conversion of existing 
voters, mobilization of new voters, or generational replacement (Anderson 1979; Petrocik 1981)? It is likely all three processes played a part. But a fourth process of realignment has received far less attention from scholars: redistribution of the electorate through migration.

This is not to say migration has gone unnoticed. Polsby (2004) for instance, has pointed out that post-war migration to the Sunbelt changed the patterns of partisan support by adding liberals to Democratic electoral coalitions in the South, while subtracting native Southerners from those same coalitions. In other words, the Southern Realignment was driven not just by conversion of white voters (from the Democratic to the Republican Party), or mobilization of black voters into the electorate (Stonecash 2003), but also by migration of voters, from North to South. But on the whole, compared with the other processes, migration has received relatively little attention.

In this dissertation, by contrast, migration takes pride of place as a causal process. In my account, migration not only contributes to regional realignment, such as the Southern realignment, since migrants are not randomly selected, but self-selected (only some households can make the effort to move from one part of the country to another), but also contributes to partisan polarization, since migration contributes to partisan sections, and thus party-safe elections. I have suggested that this does not require purposive behavior, but that individual choices lead to aggregate outcomes that those individuals may not necessarily prefer. 
In this chapter, I have developed the theoretical linkages, drawn from the scholarly literature and logic, for my claim that migration contributes to party-safe districts. Linkages such as these constitute a set of reasons why my theory is plausible, why claims such as migration is politically consequential, or that migrants are stable partisans unaffected by their new context, can be plausibly made. Much scholarship consists of this sort of specification: authors articulate and defend a series of statements that rely on the force of logic, reference to literature, or to empirical experience to knit the argument together. Formal theory, rational choice theory and normative theory, in particular pursue this approach. ${ }^{8}$ My goal, however, is not just to describe an explanatory theory of party-safe elections, but to test it, by comparing predictions from the theory against empirical observations.

My goal is to propose an explanation of a social outcome without reference to whether that outcome is good or bad. Accordingly, there are no references here about what American elections should resemble, or what the outcome should be; my objective is to describe them in some form, and to analyze certain features of the elections, as they pertain to my research question. In other words, my dissertation is an exercise in positive social science, not an attempt at normative theory. My objective is a positive, empirical theory of elections, tested using data.

\footnotetext{
${ }^{8}$ Rational choice theorists, in particular, have been criticized for simply articulating theories without offering empirical support for them. See Green and Shapiro (1994) for an influential critique in this vein.
} 
The essential requirement of an empirical theory is that it offers statements that are capable of failing an empirical test, of being falsified. Falsification does not mean that all the constituent elements of a theory - the assumptions, propositions or axioms that prefigure the theory - need be falsifiable: theories often contain certain assumptions, or core proposition, that are not amenable to testing. ${ }^{9}$ This is partly a matter of practicality: I do not, for instance, seek to test or independently verify many of the theoretical linkages I discussed above; I referred to literature and logic to support those statements. Nevertheless, any empirical theory must offer a set of hypotheses, or predictions, that are amenable to empirical testing. These testable statements need to be non-tautological, meaning they are stated in terms that are defined independently of each other (as opposed to a definition, which is stated as an identity). In this study, I will test four such non-tautological statements, or hypotheses $^{10}$

The first hypothesis is that Florida can be divided into clearly distinguishable, and persistent, partisan sections. The second hypothesis is that Florida voters have become increasingly partisan in their voting behavior since 1980 . The third hypothesis is that the degree of individual and household migration into a county predicts how that county will vote. The last hypothesis is that the degree of religiosity

\footnotetext{
${ }^{9}$ Lakatos (1971) is the standard reference with respect to this idea of "core propositions" that are not amenable to testing.

${ }^{10}$ The premise that a social reality exists independently of the researcher and that it can be objectively recorded, is referred to as foundationalism by epistemologists. The premise that social reality can only be interpreted, and not objectively described or explained, is labeled interpretivism, or constructivism. Constructivists typically do not concern themselves with testing their theories. See Sanders (2010) for a recent discussion of these issues.
} 
of the county population predicts how that county will vote. I will return to these four hypotheses in chapters five and six.

\section{CONCLUSION: A GENERAL THEORY OF ELECTIONS}

My theory of party-safe elections is built on two central concepts: stable partisanship identification at the individual level, and partisan sections, at the aggregate level. Whereas sectionalism is not commonly invoked in American electoral studies, partisanship has a long tradition in political science. The concept of partisanship deployed here is very much in the "social-psychological" tradition of the Michigan School (Campbell et al. 1960), where "social" refers to the political socialization experienced in childhood and adolescence, and "psychological" refers to the character of the political orientations that emerge in adulthood, ostensibly as a result of the earlier socialization ( ibid.).

Two aspects of this theoretical approach deserve comment. First, this socialpsychological explanation identifies social processes or behavioral traits as the cause of voting behavior. In other words, it is a structural explanation, as opposed to explanations that identify the cause of voting behavior in the workings of the human mind, as in psychological or rational choice explanations. And second, these processes and traits are observable among individuals and groups across time and space, as opposed to contingent processes, driven by events or choices specific to a 
particular time or place. Explanations that find the cause in enduring constraints to behavior imposed by social structures or workings of the human mind are typically classed as general explanations (Parsons 2008).

The logic behind general explanations can be structural, psychological, or rational choice, depending on the type of causal factors employed. General explanations are similarly agnostic with respect to ideology: Marxist theories of class conflict are general explanations (employing a structural logic), as are behavioral economic theories of risk-avoidance behavior taught in business schools (employing methodological individualism). The Michigan school social-psychological theory of voting is a general explanation, employing both structural and psychological variables. And my structural theory of party-safe elections identifies the cause to be the social and demographic composition of the electoral district - exogenous constraints on choice and action that pre-date the actor in question or the event being studied rather than contingent factors such as what happened on election day or in the campaign before it - is a general explanation.

Redistricting, by contrast, is a particular explanation, where the outcome is explained not by a universal process or structural constraints, but by historical contingency, by choices made in a particular manner at a particular time by a specific group or individuals (Parsons 2008). If a state redesigns electoral districts after every decennial census, the process is specific to the state, and the outcome depends on the choices 
made by redistricting commission members, legislators, or judges - specific groups and individuals that emerge in a specific context.

The virtue of a general theory is that, unlike a particular theory, it is applicable in a variety of contexts - it is generalizable. As such, my theory of sectionalism and partysafe elections should be applicable across the American political landscape, and testable in any region or state with a reasonably number of counties and Congressional districts. In this dissertation, I test my theory on Florida. I do this for two reasons: to render the test manageable, and, at the same time, to take advantage of the range of observations offered by a state of such size and diversity. To test the theory, I need access to a sizeable set of empirical observations with which to test the four hypotheses stated in the previous section. The method I use to collect this data is the topic of the next chapter. 


\section{CHAPTER 4:}

METHODOLOGY AND RESEARCH DESIGN 
In this chapter, I will describe my research design, or the methodological choices I make in order to answer the research question: what causes party-safe elections? As I noted in the previous chapter, my goal is to present and test an empirical theory of elections; my research design must be consistent with that scholarly objective. Research design is less a matter of being right or wrong, and more a matter of making sensible and logical methodological choices, given what social scientists typically do.

In this chapter, I discuss three key choices I have had to make to undertake my analysis. One is whether to adopt a qualitative or quantitative approach. This is discussed in Section 1. Another choice is whether to seek to explain, as opposed to describe, the phenomena of interest, and if so, how to go about it. My choice of explanatory method, ordinary linear multiple regression, is discussed in Section II. A third important choice is what data to collect as evidence against which to test the hypotheses that constitute the explanation; I discuss this topic in Section III.

\section{QUALITATIVE AND QUANTITATIVE METHODS}

In general, political scientists employ one of three methods to conduct research: quantitative analysis, qualitative analysis, and formal models. Each method is associated with certain techniques of data collection and analysis, and each is associated with certain sub-fields within the discipline of Political Science. Bennet et al. (2003) survey approximately one thousand articles published in ten peer reviewed 
political science journals over a period of two decades, and find that qualitative and quantitative methods dominate in the American Politics sub-field.

Table 1 summarizes the breakdown of methods employed in American Politics. The percentage total is greater than one hundred because some articles employ a mixture of quantitative and formal methods. We can see that most scholarship in American Politics employs quantitative methods, in marked contrast to other sub-fields, such as International Politics, in which the qualitative method dominates. I will begin by clarifying the key features of these two methods: this will serve to contextualize and introduce my own research design, which hews to the quantitative approach.

\subsection{Qualitative Methods}

In the qualitative approach, researchers generally have two goals: explanation, or understanding. If the goal is explanation, researchers seek to trace the processes or mechanisms that lead from cause to effect (Bennet and Elman 2006). To accomplish this, researchers tend to focus on one or a few cases in order to emphasize the historical and contextual aspects of the outcome of interest. In short, the goal is to explain the outcome in individual cases, rather than generalize across many cases (Mahoney and Goertz 2006). ${ }^{11}$

\footnotetext{
${ }^{11}$ A contemporary example of this qualitative, historical approach in American Politics is the literature on American Political Development (APD). See, inter alia, Skowronek (1982), Skocpol (1995), Orren and Skowronek (2004).
} 
Table 1 Methods in Scholarly Articles on American Politics, 1980-2000
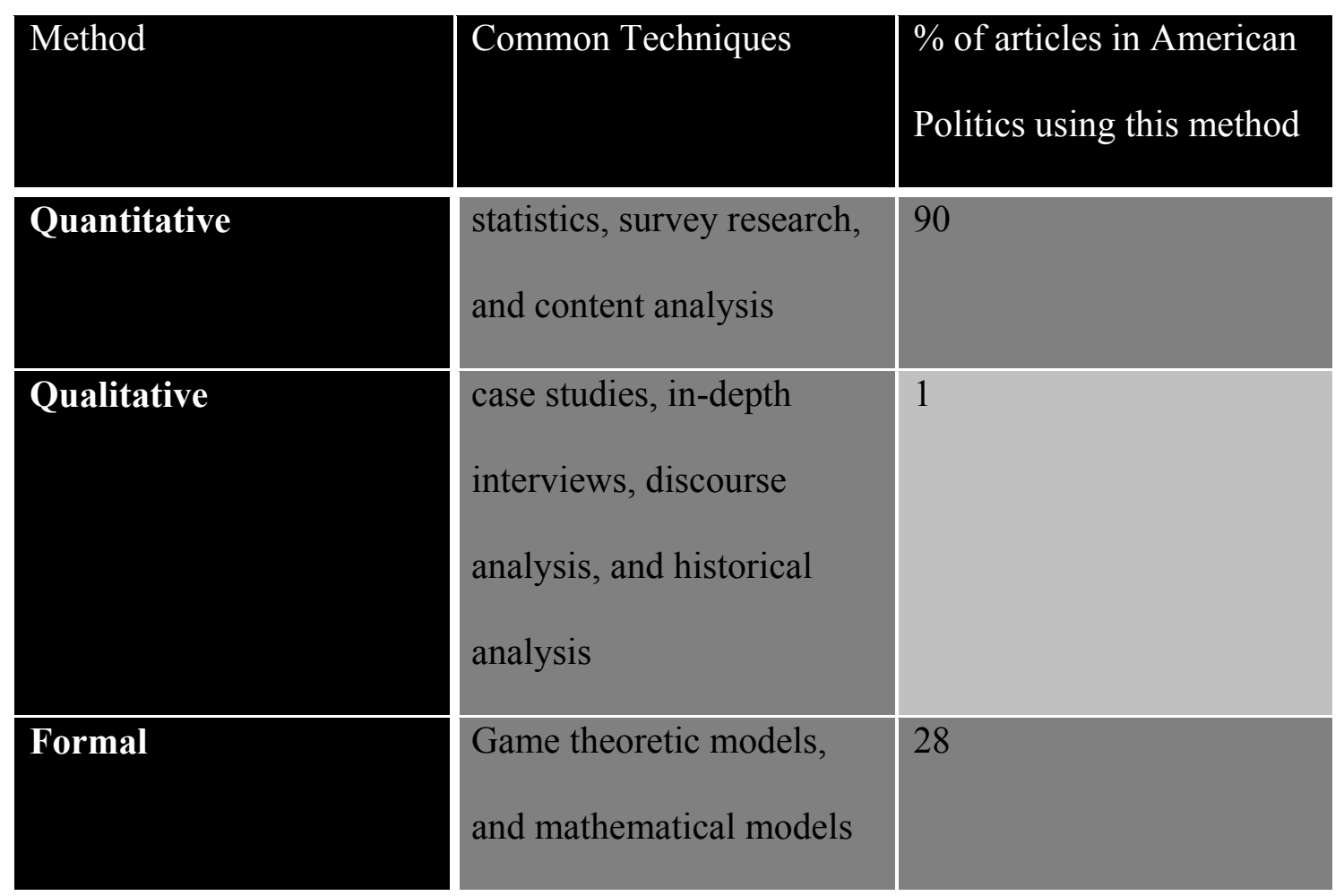

\section{Qualitative}

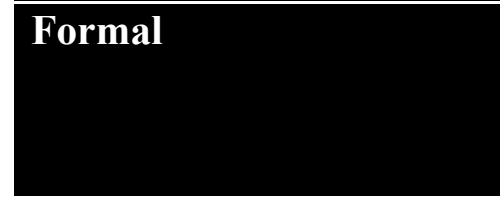

Source: Bennet et al. (2003)

Other qualitative researchers, however, seek not to explain an outcome, but to understand it. In this interpretivist approach, scholars treat empirical phenomena as social constructions that require interpretation, rather than as objective facts that support an argument created by the researcher, regarding about cause and effect. These interpretivist qualitative scholars take the position that social outcomes are such that a researcher can only hope to understand how a participating actor or agent 
subjectively interpreted the outcome of interest; social outcomes cannot be objectively "explained". 12

Whether explanatory or interpretive, the two characteristic features of the qualitative method are (i) researchers typically attempt to trace the processes within a single case of the outcome of interest, or to compare processes in a few cases, and (ii) researchers typically employ concepts that take the form of categories rather than interval, ordinal or ratio level variables. These two features of qualitative methods distinguish it from the quantitative method.

\subsection{Quantitative Methods}

In the quantitative approach, the goal is typically to describe and explain the outcome of interest, rather than to interpret it from the perspective of the participants, where explanation is conceived as estimating, as precisely as possible, the relative weight of different kinds of causes, or independent variables, on the outcome of interest. In the quantitative approach, empirical phenomena are treated as facts that exist objectively, and independently of the researcher.

Quantitative researchers work from the premise that by observing repeated instances of the same behavior, such as the vote outcome in elections, we can make inferences

\footnotetext{
${ }^{12}$ This is, in essence, the theoretical objective of the sprawling project labeled "constructivism", which became influential in the study of IR in the 1990s. See Parsons (2010) for a concise discussion of the explanation-understanding binary.
} 
and generalizations about the behavior or outcome of interest. This stems from a mathematical principle that the more observations we can make of a class of phenomena, the more accurate and precise tend to be the measures of the values and distributions of variables of interest, as well as of the estimates of the associations between them. According to statistical theory, large numbers of observations have the property that any relationships or associations that are discovered in them are less likely to be a result of randomness or chance than from a small number of observations (John 2010).

As Table 1 illustrates, the study of American politics is dominated by quantitative methods. ${ }^{13}$ Whereas training and socialization doubtless play a part, one reason for this outcome is surely the abundance of data, measured at the interval level, that are available on American politics. Much of these data are collected by governmental agencies, or funded by them, whether at the federal or state level. Whatever the source, the result is that American Politics scholars can take advantage of extensive sets of secondary data, at the individual level data, such as the National Election Studies (NES) and the General Social Survey (GSS), and at the aggregate level, such as election returns at the state and sub-state levels, votes in U.S. Congress, and census data collected by the U.S. Census Bureau.

My study employs two sets of aggregate level data collected at the county level election returns for U.S. Congress, U.S. President, and some state level elections, as

13 The total does not add to 100 , as some articles combine quantitative and formal methods. 
well as demographic data collected by the U.S. Census Bureau, to test the four hypotheses outlined in the previous chapter. In this quantitative analysis, I describe the outcome of interest visually, and employ statistical methods to measure the relative weight of different structural variables on the outcome of interest - party-safe elections. A combination of logic and statistical control by means of regression analysis define the method of explanation in this dissertation. I expand on this in the next section.

\section{ANALYTIC METHOD}

The data analysis needs to fit my goal, which is to test my hypotheses regarding elections. This testing requires that I identify observable implications of my theoretical explanation and make predictions: if the hypothesis is true, what should we expect to see? This approach assumes that theories must be capable of generating predictions, which can be empirically tested using evidence gathered in a systematic, replicable manner, an approach that owes much to the advocacy of methodologists such as Gary King (1994). The key is state the predictions suggested by the hypothesis: the hypothesis is falsified if the empirical evidence does not support the prediction. I stated four such hypotheses in the previous chapter: the next two chapters will be devoted to comparing the predictions that follow from these hypotheses with empirical data. 
To test my proposed theory, I will use the secondary data in two ways. In chapter 5, I will test two hypotheses regarding the value or distribution of values of a key variable, using visual representation of data. Visual representation allows me to summarize and present a large amount of data in a succinct manner. I use bar charts, dot plots, line graphs and maps to describe my outcome of interest: the distribution of voters in Florida, and whether distinct political sections are visible in the Florida political landscape. ${ }^{14}$ In chapter 6, I will test two hypotheses regarding the effect of certain structural variables, to explain the outcome of interest, and in particular, the effect of residential mobility, if any, in creating any distinct or persistent partisan sections. To test these hypotheses, I will use a series of multiple regression models that estimate the causal effect of these structural variables on county level election returns in Florida.

This chapter serves as prologue to these activities. In this chapter, I discuss the methodological choices that are necessary to perform tests of these hypotheses, as well as to build the multiple regression models.

\subsection{Experimental vs. Statistical Approaches to Explanation}

Researchers who seek to explain social outcomes confront two key tasks. One is how to account for alternative explanations. To offer convincing explanations of social or

\footnotetext{
${ }^{14}$ Visual representation is often underutilized in social sciences (Hancke 2010). For methods of graphing data, see Tukey (1977), Cleveland (1994), Jacoby (1997), among others.
} 
political outcomes, social scientists must rule out, or "control for", alternative explanations, as much as possible. There are basically two ways to do this: experimental control, or statistical control (Allison 1999). In this dissertation, I will use statistical control, which inheres in multiple regression, a statistical test that examines the simultaneous effect of multiple factors on the outcome variable.

The other issue that researchers confront when seeking to explain is to sort out cause and effect: if two variables are related, and the relationship is one of cause and effect, what is the direction of causation? When the postulated direction is incoherent or incorrect, the possibility of reverse causation arises. If the experimental method is being employed, researchers try to establish the direction of causality by reference to logic, including observed time order; if the method is non-experimental, the researcher must rely on theory to make the case for cause and effect.

The experimental method offers the most effective way of controlling for rival explanations, and for confirming causal direction. Experimental researchers use randomization to control for the influence of other independent variables - whether they have been identified or not - and they establish causation by controlling the assignation of values of the independent variable (when a treatment group is observed to behave differently from the control group after the researcher administers the treatment, doubts regarding what causes what are reduced, if not eliminated). But where an experiment is not possible, researchers need some other way to control for alternative explanations; here, multiple regression can help us sort out which variable 
is having what effect. Statistics by itself, however, no matter how sophisticated, cannot substitute for logic and theory, and at the end of the day, researchers must rely on logic and theory to establish causation. ${ }^{15}$

In practice, this can be as simple as asking whether it is plausible that what I have defined as the effect could in fact be the cause. Is it likely that American households look to see who won a Congressional election, and, depending on the result, decide whether to move? What happens if the district is re-designed, or eliminated - do they then repeat this exercise after each decennial census? Or is it more likely that a household will make a residential decision that takes into account household finances, location of employer, the school district, or the proximity of family members, churches and other institutions important to their lifestyle - without much thought to what electoral districts are involved?

Since the second possibility appears much more plausible than the first, the direction of causation between residential choice and election results, assuming there is such a relationship, is likely to be from the residential choice to election results, rather than the other way around. The possibility of reverse causation appears even less likely with respect to the other independent variables. Is it likely that election results cause changes in the proportion of a county's population that is non-white, collegeeducated, or in the armed forces - or is any relationship likely to be in the other direction? Again, logic provides sufficient guidance on this question.

\footnotetext{
${ }^{15}$ Reynolds (1971) argues that the stronger and more compelling the research design, the less the need for elaborate statistics.
} 
However, while logic can help clarify the direction of causation, it cannot account for alternative explanations; in order to do that I need to conduct an experiment or control for these other explanations or variables statistically. In this dissertation, I employ the most common statistical method used by both social and natural scientists to explain an outcome while controlling for other variables: multiple regression analysis.

Multiple regression is used to examine which of several independent variables affect the dependent variable, and to estimate the size and direction of the effect. When used to explain an outcome, multiple regression provides an estimate of the independent effect of one of the variables on the outcome of interest, controlling for the effect of the other variables. When used to predict an outcome, multiple regression can measure how much the postulated independent variables together predict the variation in the outcome (Allison 1999).

Whereas multiple regression analysis can accommodate interval, ordinal and categorical levels of measurement as inputs, with the latter represented as dummy variables, most researchers seek interval level measures, whenever possible, as they are believed to produce the most efficient estimates from Ordinary Least Squares (OLS) multiple regression (Fox 1997). Since the data sets of election results and demographic data are interval level measures, my data are a good fit for this type of analysis. 
To build the models, I have to make several decisions, such as what variables to select, and what assumptions to make about them. To help make these decisions, my guide is the principle of parsimony, variously referred to as lex parsimoniae, or Occam's Razor. ${ }^{16}$ The principle can be interpreted in two ways: make things only as complicated as they need to be, or, alternatively, the simplest explanation is probably the best. I will use the simplicity and parsimony heuristic to make a series of theoretical and methodological decisions. I begin with the decisions regarding inputs for the multiple regression models.

\subsection{Specifying the Ordinary Least Squares (OLS) Regression Model}

In this section, I discuss three fundamental features of specifying a regression model: what independent variables to put into the model, what type of relationship is assumed between these variables and the outcome, or dependent variable (linear or nonlinear?) and how to deal with the potential problem of correlation between independent variables in a multiple regression model - something that often occurs with aggregate level data, and which compromises the results of multiple regression analysis. I will address each in turn. ${ }^{17}$

\footnotetext{
${ }^{16}$ This term refers to the fourteenth century English logician and Franciscan Father William of Occam, although the principle pre-dates Occam.

${ }^{17}$ For an introduction to regression analysis see, inter alia, Nachmias and Nachmias (2004), Allison (1999), and Miller (2005). For more advanced features of regression see, inter alia, Fox (1997), Kennedy (2003), and Gujarati (2002).
} 
First, how to select the variables to be included in the model? Since social reality is complex, there will be an enormous number of potential variables that may affect the outcome of interest. It would be possible to control for all these possible variables in a controlled experiment. But in a non-experimental research, I must choose certain variables to select as control variables, a selection process that is guided by logic, the theory I am testing, or the relevant scholarly literature. Regardless of the selection process, control variables should satisfy two criteria: they should influence values of the dependent variable, and they should be correlated with the key causal variable(s) of interest (King et al. 1994).

One obvious problem is certain variables may be omitted from the causal model, variables that have an effect on the outcome of interest. The consequence of omitted variables is typically to bias the statistical estimates: repeated iterations will produce estimates that are consistently too high or too low (King et at 1994). A statistical model cannot alleviate the problem of biased results due to omitted variables. In many practical instances, however, it is possible to consider how any omitted variable might be related to the dependent variable, and then to estimate the direction of bias (Allison 1999). To a certain extent, researchers must accept that social science produces partial explanations - scholars rarely capture all aspects of complex social reality within one model or explanation. I will return to this matter in the conclusion.

Second, is the form of the relationship between the independent and dependent variables - linear or non-linear? If we assume a linear function, then we expect that a 
straight line is a good approximation of the relationship between the independent and dependent variables. With a linearity assumption, the ordinary least squares (OLS) method is an appropriate regression model to use. If we assume that the relationship is not linear, but rather polynomial, parametric, logarithmic, or some other non-linear function, then the OLS model is not appropriate.

This choice, regarding the relationship function, can be made a priori, or after initial investigations indicate that the relationship between the causal variable and the dependent variable may be nonlinear. Since I do not have any compelling reason to suspect that the relationship between the distribution of voters or migration patterns and Congressional election results in Florida is nonlinear, the principle of parsimony suggests that I consider a linear relationship before investigating more complicated functions. After building the model, the graph of the regression line produced by the least squares method, if it is a straight line, is an indicator that the relationship between my independent and dependent variables can be reasonably construed to be linear.

Third, I must address the issue of multicollinearity. This is a particular problem with aggregate level data, which is the type of data I am using in this study. Multicollinearity refers to the condition where the selected independent variables are highly correlated with each other. Whereas strict independence among the independent variables is not a requirement for regression analysis in general (Allison 1999), avoiding correlated independent variables is important if we are to generate 
precise estimates from multiple regression, as correlation among the independent variables increases the standard error of the regression coefficients. ${ }^{18}$

There are essentially three solutions to multicollinearity: change the type of data from aggregate level to individual level data; increase the number of observations used in the analysis; or delete some of the independent variables used as inputs in the model (Allison 1999, Kennedy 2004). The first two options are undesirable or impractical, whereas the last option is consistent with the principle of parsimony. Consequently, to minimize multicollinearity, I need a way to eliminate certain independent variables from the set of regression inputs, on theoretical, logical or empirical grounds. The result will be a more parsimonious set of variables to enter into the regression models.

To filter the number of variables and obtain a spare regression model, I use a twostage filtering process. First, I run correlations between all my independent variables and the dependent variable - the winning two-party vote margin. From the results, I select those variables that are most correlated with the winning vote margin, as measured by the correlation coefficients, and reject others. Correlation coefficients estimate how much two variables, $\mathrm{x}$ and $\mathrm{y}$, are associated, by measuring the size and direction of the association. The correlation coefficient between $\mathrm{x}$ and $\mathrm{y}$ ignores the effect of any other variables on the relationship between $\mathrm{x}$ and $\mathrm{y}$.

\footnotetext{
${ }^{18}$ Multicollinearity is often at work when the sign (direction) of a regression coefficient is at odds with other results from the same or related models (Allison 1999; Kennedy 2003).
} 
The second step in my filtering process is to regress these selected variables against the dependent variable - the margin of victory of the total two-party vote in each county. Those variables with the most significant regression coefficients are then selected for inclusion in the final regression models, where they are combined with the key causal variable in my theory - residential migration. Regression coefficients estimate the size and direction of the association between two variables, while taking into account the effect of other variables on that association. This "controlling for" other variables distinguishes regression coefficients from correlation coefficients, and forms the basis for making causal statements using regression analysis.

Regression coefficients can be reported as unstandardized or standardized coefficients. An unstandardized coefficient is an estimate of the marginal effect of a one-unit increase in the independent variable on the dependent variable, expressed in the same units as the dependent variable, which, in this study, is the percentage winning margin of the two-party vote share. A standardized coefficient is an estimate of the marginal effect of a one-standard deviation increase in the independent variable on the dependent variable, expressed in standard deviation units of the dependent variable. Standardization helps us to make sense of comparisons when the original units of the variables are hard to compare meaningfully, or have no inherent meaning, as in attitudinal scales in a survey instrument.

Regression analysis typically produces many other statistics apart from the regression coefficients. For my purposes, two other statistics matter: the regression test 
statistics, and the overall model fit. I will discuss these two statistics, along with the regression results, in chapter 6 . In the remainder of this chapter, I will discuss the sources and types of data I will use to test the hypotheses.

\section{SOURCES AND TYPE OF DATA}

I use three sources of data in this study: (i) election returns for each county in Florida, for national and state-wide elections, from 1980 onwards, collected by the Florida Division of Elections, and archived and publicly available online; (ii) decennial census data for Florida for 1990 and 2000, collected by the U.S. Bureau of the Census, and archived and publicly available online; and (iii) mid-decade sample data from the American Community Survey of 2006, collected by the U.S. Bureau of the Census, and archived and publicly available online.

With election returns, I followed the following process. The Florida Division of Elections raw data was downloaded into Excel spreadsheets. All votes that were not for the Democratic and Republican Parties were removed, and the remaining raw data were used to calculate the two-party winning vote margin for the Democratic and Republican Parties. The formula used was (Republican candidate vote - Democratic candidate vote total)/two-party total x 100. This procedure was used for state-level elections, for U.S. Senate, and for U.S. President. 
For U.S. House elections, some additional steps were required to turn data at the precinct and Congressional district level, into data at the county level. In other words, I had to use the raw data to reconstruct House elections as if they were held within counties. In many instances, portions of election returns for Congressional districts had to be summed individually to create county-level results since some counties are arrayed across two or more Congressional districts. In this way, I created "virtual" Congressional districts out of the counties.

The 1990 and 2000 U.S. Census data were taken from the Census Bureau files online, and input manually into Excel spreadsheets. The 2006 ACS sample survey data were taken from the City-Data files, also archived online, and entered manually into Excel spreadsheets. After checking for errors and omissions, the data was uploaded into SPSS, transformed, and entered into the OLS regression model. ${ }^{19}$ Any missing data are omitted completely from the analysis, using the default method ("listwise deletion"). ${ }^{20}$ The available data were sufficient in size and scope to satisfy regression requirements (described below). Further details on where the data set is housed, and how they were loaded into spreadsheets is presented in Appendix A and B.

In chapter 5 I use the election data set to describe election returns in Florida over a twenty-six year period; I compare the data with predictions from two descriptive hypotheses. In chapter 6 , I use the election data and the census data to explain

\footnotetext{
${ }^{19}$ Data can be loaded directly into SPSS from Excel; other statistical applications may require first converting data into a text file.

${ }^{20}$ The alternative is to give missing values an imputed value, typically done using the mean value or estimated using the maximum likelihood method.
} 
election returns, by estimating the effect of different variables on election returns, using OLS regression.

In the rest of this chapter, I will address four issues related to creating a data set: the possibility of bias in the data that is collected, measurement errors, the level of measurement, and the number of observations, or size of data set.

\subsection{Sample Bias}

Many social science researchers use data drawn from a sample of the universe of cases that belongs to the phenomena being studied. In American Politics scholarship, data often take the form of survey responses taken from a sample of the electorate, since surveying the entire electorate is not practical. When sampling, the researcher must consider whether the sample statistics are likely to approximate the population parameters, or whether the statistics may be biased.

Bias emerges when statistical estimates obtained from a data set, whether simple such as a mean, or a more complex statistic, such as a regression coefficient, tend to be consistently higher or consistently lower than the "true value." The bias can be avoided, however, if the data set consists of the entire population, rather than a sample. In this study, the observations used for independent and dependent variables come from the entire population of sixty-seven Florida counties. with one exception: 
independent demographic variables used for the final regression model in chapter 6 uses data from the 2006 American Community Survey, a mid-decade survey conducted by the U.S. Census Bureau using sample of the population in each state.

\subsection{Measurement Error and Type of Data}

Collecting data is not useful if the data do not measure the variables of interest with sufficient accuracy. Whereas some variables, such as class, may have indicators that are easy to measure and do not generate much controversy, such as the median household income, or the percentage of the county population possessing a four-year college degree, other variables often employed by social scientists, such as "legitimacy", or "culture", often do not have straightforward indicators by which to measure them. In such instances, scholars need to defend and argue for a particular indicator, and consider measurement error associated with it, before data collection or analysis.

In this study, however, I employ aggregate level concepts that have concrete, intuitive, indicators of measures, expressed as percentage differences and percentages of the whole. For my dependant variable, electoral competitiveness in different Florida counties, I use the winning margin of the two-party vote at the county level, repeated for elections for various offices. The dependent variable measures are calculated from the raw data, consisting of the total votes cast in each county for the 
two main parties. For my independent variables, I use the proportion of county population composed of specific sub-groups, which is simply the raw data in the Census Bureau files. These straightforward, widely used measures, collected by state and Federal governments, minimize issues of validity of indicators and errors in measurement.

The data I employ in this study are interval level measures, of two types: winning election margins (for the dependent variable), and the proportion of county population that each subgroup constitutes (for independent variables). With interval level data, the difference between one interval and the next is measurable and consistent, as in the difference between $10 \%$ and $11 \%$, which is measurable as half the size of the difference between $10 \%$ and $12 \%$. Because of this information content, interval level measures produce the most robust results from regression analysis (Allison 1999). Ordinal level data, by contrast, tells us that one measure is greater than another, such as in a "feeling thermometer" used by political scientists to survey opinion, but does not tell us anything more about those differences. Ordinal level data, as well as categorical data, can be used in regression analysis, but they require different regression methods than ordinary least squares. The observations used as data in this study are all measured at the interval level; in that sense, they are a good fit for OLS regression analysis. 


\subsection{Number of Observations}

One other issue I must consider is how much data are needed for my analysis; the number of observations is a central to the efficacy of large- $\mathrm{N}$ quantitative analysis, and regression analysis in particular. Quantitative researchers generally seek more observations rather than fewer: more observations not only maximizes the amount of information and minimizes the influence of randomness, outliers, errors, and multicollinearity, but they render statistical estimates more robust, as noted earlier. As a rule of thumb, regression analysis is best undertaken when the number of observations outnumbers the number of independent variables by a ratio of at least ten to one. In this study, I gather observations for sixty-seven countries for election cycles covering a quarter of a century for the dependent variable, and approximately fifteen independent variables. As noted, I further reduce the number of independent variables by using a two-step process, thus creating the most parsimonious model one that seeks to use the fewest variables to explain or predict the outcome. The final regression models analyzed in chapter six are left with approximately six independent variables, and approximately sixty observations (reflecting the Florida counties) for each dependent variable.

With fewer observations, and with smaller data sets, regression coefficients are not necessarily less accurate, but they may be less reliable: repeatedly running the regression may produce different regression coefficient values. In particular, regression analysis performed with fewer rather than more observations increases the 
probability that the model mistakenly suggests a variable has no influence - that is, the regression coefficient, were it accurate, would be non-zero (Allison 1999).

With large samples, encompassing more than one thousand observations, for instance, regression analysis may pose the opposite problem: the model may suggest that variables have causal effects when they do not - that is, the coefficient, were it accurate, would be zero. The likelihood of finding spurious relationships between independent variables and the dependent variable looms larger the bigger the data set - a condition commonly referred to as data mining. Given the size of my data sets, mistaking random patterns in the data for actual relationships is less of a problem in this study.

\section{CONCLUSION}

In this chapter, I have discussed a series of methodological choices I have made to collect and analyze data, for the purpose of testing the hypotheses that constitute my explanatory theory of party-safe elections. I have discussed the source of data, the type of data, and the method I have chosen to analyze this data: ordinary least squares multiple linear regression. The regression analysis is the central element of my quantitative, non-experimental method of explanation, one that uses statistics to control for alternative explanations (variables), and where explanation is defined as estimating the causal weight of different independent variables on the outcome of 
interest - in this case, the two-party election vote margins in Florida, measured at the county level.

These decisions together constitute my research design, one that is guided by the principle of parsimony: choose the simple option, unless given compelling reason to do otherwise. Since these methodological choices have consequences, I have discussed the most important ones that attend quantitative methods, such as model specification, the selection of variables, endogeneity, and measurement error. In the next chapter, I discuss how I use the data on election returns to investigate the existence of partisan sections in Florida. 


\section{CHAPTER 5:}

PARTISAN SECTIONS IN FLORIDA 


\section{INTRODUCTION}

Before I can explain something, such as party-safe elections, I must describe it. One useful guide to help me do this is to consider the observable implications of my theory. These implications are expressed as theoretical statements stated in the form of hypotheses. ${ }^{21}$ Since my theory proposes that partisanship and sectionalism characterizes voting behavior in Florida, it follows that a useful description will one guided by my hypotheses regarding sectionalism and partisanship.

The first hypothesis is that election results in Florida, examined at the level of constant geographic units such as counties, will describe distinctive geographic patterns and trends. At the aggregate level, this electoral sectionalism should be observable in distinctive patterns of winning vote margins within Florida counties in elections for U.S. President and the U.S. House of Representatives.

The second hypothesis is that patterns of voting for different offices, again examined at the county level, should converge over time. In other words, if voters are partisan, then will vote along party lines rather than in response to individual candidates, prevailing economic conditions, or campaign effects, and election results will show evidence of party-line voting up and down the ballot. At the aggregate level, this

\footnotetext{
${ }^{21}$ In general, hypotheses are of two types: those that postulate a difference in the values of variables, and those that predict the direction and strength of a relationship between variables (Shoemaker et al. 2003). The discussion in this chapter is motivated by the former type of hypothesis; the next chapter by the latter.
} 
"straight-ticket" voting should be observable as convergent patterns of results for a variety of elections, for statewide office as well as for U.S. President or Congress.

In this chapter, I will test these two descriptive hypotheses, using aggregate level data collected from secondary sources. In this section, I will explain how I plan to do this, and why. Specifically, I will collate results for a variety of elections, and marshal these observations into an organized, precise, and systematic description of electoral results in Florida, which can then be compared with the hypotheses, or predictions.

By description that is organized, I mean one that simplifies some element of social reality, one that is usually complex. Simplification of this type is essential for making sense of something as complex as election outcomes, an outcome that is affected by a range of factors, short and long term. Simplification also helps us to focus on that which we want to explain. Typically, scholars simplify by making assumptions, that is, by taking certain statements as given, rather than hypotheses to be tested. Like most theoretical statements, these assumptions usually say something about the nature or value of some concept or about the relationship between one or more concepts. Ideally, assumptions should be plausible, clearly stated, and limited in number - they should not outnumber the statements to be tested, lest they undermine that description. ${ }^{22}$

\footnotetext{
${ }^{22}$ Methodologists apply the same rule of thumb regarding the number of assumptions and the number of explanatory hypotheses in an explanation: the former should not outnumber the latter.
} 
In the present chapter, my central assumption is that elections in Florida for U.S. President, U.S. Congress, and statewide offices are usefully conceived as a competition between a Republican candidate and a Democratic candidate; any and all other candidates are essentially inconsequential to the outcome. In the analysis that follows, elections that do not involve a candidate from both the Republican facing off against a candidate from the Democratic Party are excluded from the set of observations, unless otherwise noted. ${ }^{23}$ The exclusion rule, if applied, only applies to elections for U.S. House; almost all other elections in Florida, as in the U.S. in general, are affairs dominated by the two major parties. Nevertheless, the exclusion rule generates what methodologists refer to as a "restrictive model" (King et al. (1994). The restrictive model I employ here treats state and Federal elections in Florida as phenomena usefully defined by two-party competition.

By description that is precise, I mean one in which concepts are clearly defined, both theoretically (what does the concept mean?) and operationally (how is it measured?). One way to achieve this precision is to use, whenever possible, quantitative measures of those things I wish to describe. Using such measures does not mean that only quantitative measures are valid; some phenomena are simply not amenable to quantification, whereas others can only be quantified poorly. So researchers must exercise judgment, and readers will evaluate those judgments, given the research

\footnotetext{
${ }^{23}$ Very few elections in Florida for national or statewide office award third party candidates with more than $1 \%$ of the total votes cast.
} 
question. ${ }^{24}$ In this chapter, the hypotheses are operationalized using a numerical measure - the winning margin of the two-party vote in various elections held in Florida.

Finally, by description that is systematic, I refer to the outcome of data collection, rather than the process. Assuming that social reality is composed of two types of events and phenomena: those that are repeated and predictable in nature, and those that are singular and unpredictable. Is one of these two aspects of reality more important than the other? Of course not: singular, "black swan" events are as important and consequential as scheduled events, and an individual scholar may choose to study the contingent or particular, such as campaign events or the personality of a leader. ${ }^{25}$ In this study, however, I am interested in phenomena that are intrinsically systematic and predictable, rather than singular: persistent patterns of political sectionalism. In short, I am interested in patterns observable from repeated incidences of an event (in this case elections), rather than incidents, or the actions of individuals.

The observations I employ in this chapter are election results from Florida for national and statewide office, collected at the county level. ${ }^{26}$ The resulting data form

\footnotetext{
24 Reynolds (2006) discusses the importance of "inter-subjective agreement" for building social scientific theories.

${ }^{25}$ King et al. (1994) argue that this difference does not affect the design of social inquiry, since the study of the contingent can produce general knowledge if the scholar adheres to certain principles of research design, and the logic of inference.

${ }^{26}$ Other possible observations that can describe political sectionalism and partisanship are voter registration information, exit polls, and opinion polls.
} 
a set of univariate statistics, defined as values on a continuous variable for various units of a categorical variable. To analyze such univariate data, scholars can turn to inferential statistics: given a categorical variable, such as counties, and a quantitative variable, such as the two-party vote margin, we can propose hypotheses and test them, using statistical tests such as the t-test, or the F-test. I will test two explanatory hypotheses using this approach in chapter six.

In this chapter, I use an alternative approach: the visual representation of data (Cleveland 1994). This is because to interpret univariate observations, we need to answer two important questions: what is the trend among counties and regions, and what are differences between them? To illustrate patterns and trends across space and time, visual representation is simply the most effective method. To present and display quantitative variables for different units of a categorical variable, researchers have recourse to a variety graphical choices, including bar charts, dot plots, and Qplots (Tukey 1977; Jacoby 1997).

In section I, address the sectionalism hypothesis. I review the distribution of election results at the county level, using the county as the unit of analysis, and the winning margin of the two-party vote as the measure of electoral results. In section II, I look at the results from a regional perspective: if my prediction regarding sections is valid, then those sections should be visible at the level of region. In section III, I turn to the partisanship hypothesis. I review the covariance of the vote for elections for different offices, including U.S. President, U.S. Congress, Governor and State Agriculture 
Commissioner; if my prediction that election results are increasingly influenced by partisanship is valid, then those election results should display convergence in the results of elections for different offices.

\section{ELECTIONS IN FLORIDA: A COUNTY-LEVEL PERSPECTIVE}

To test the hypotheses, I need to compare the predictions against empirical evidence. In section $1.1 \mathrm{I}$ take a first cut at some relevant data, using county level returns from the presidential election of 2004, and U.S. House elections of 2006. The elections of 2006 will serve as useful comparison with the 2004 election returns, since mid-term House elections are not biased in favor of the presidential party because of "presidential coat-tails", as can be observed with House election returns during a presidential election year.

\subsection{The 2004 Presidential Election at the County Level}

First, I consider the distribution of election returns from 2004. This gives me a sense of the range of outcomes that I am dealing with, and helps me to make appropriate decisions regarding reference values or cutoffs - standards we can adopt to help make comparisons between counties, to identify patterns, and trends. Figure 1 shows the distribution of values for the Presidential election of 2004. 
The graph plots the winning margin of victory for the Democratic or Republican candidate in each county, expressed as the relative difference, in percentage terms, of the share of the two-party vote won by the winning candidate. The graph takes the form of a dot plot, which displays the units (counties) along the y-axis; the dot plot also allows me to label individual values and describe the overall shape of the distribution of observations. ${ }^{27}$ The vertical line down the middle of the graph indicates a zero winning margin - a dead heat between the two candidates. A dot to the right of the vertical line indicates a Republican victory; to the left, a Democratic victory. The length of the horizontal line to the dot indicates the margin of victory.

The graph indicates that the 2004 Republican presidential candidate, George W. Bush, won fifty-six of the sixty-seven Florida counties, and his Democratic challenger, John Kerry, won eleven. Among the counties with a Republican winning margin, the distribution is fairly smooth: there is a steady increase in Republican winning margins, especially from Sarasota County to Okaloosa County at the upper end of the range of Republican counties.

Two observations are immediate and obvious from the graph. First, the vast majority of Florida counties were not competitive in the presidential election of 2004, and, second, most of the state, territorially, favored the Republican candidate for President. There is also one clearly observable modal value, between Martin and Hendry

\footnotetext{
${ }^{27}$ Dot plots are easier to process than pie charts, as they involve comparison along a common scale, as opposed to angles in a pie chart. Dot plots are also superior to histograms for displaying differences among values visually. Jacoby (1997) illustrates and amplifies these points.
} 
Counties, where successive counties pile up almost vertically, as they cluster around the $17 \%$ winning vote margin value. 
Fig. 1 Winning Margins of the Two-Party Vote in 2004 U.S. Presidential Election, by Florida County

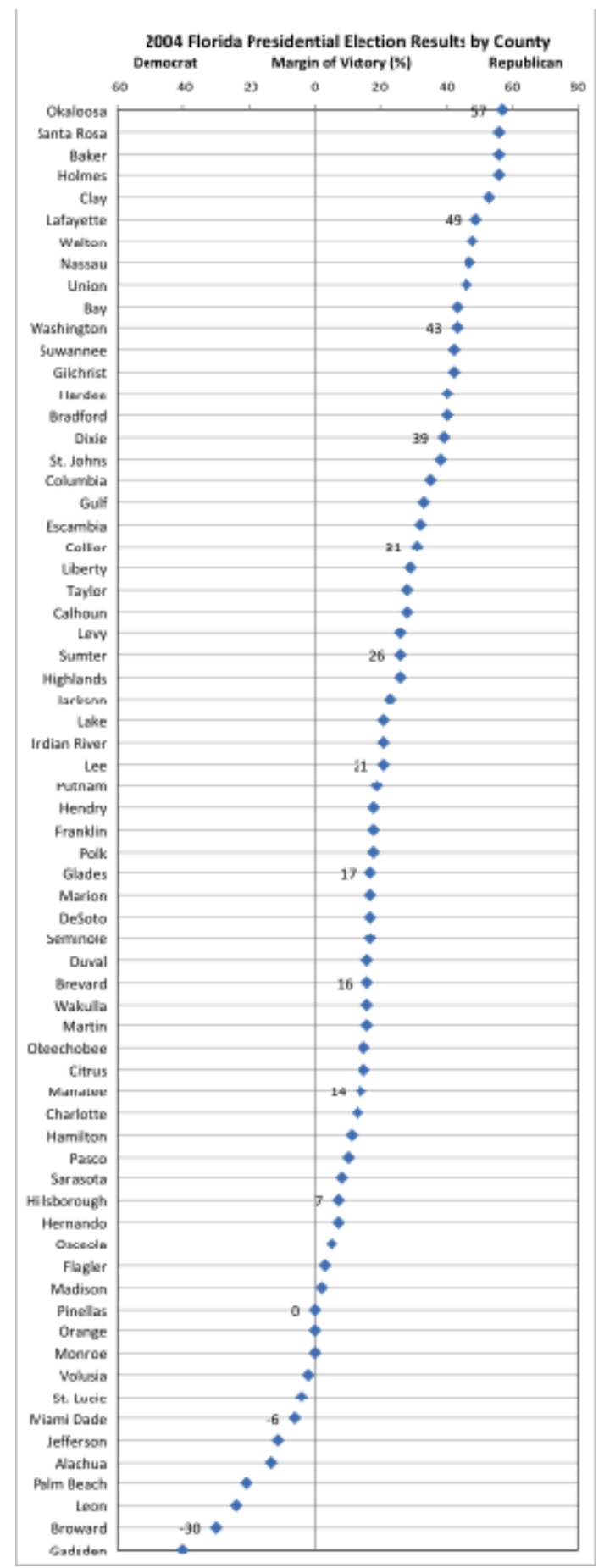

Source: Author Calculations, from Florida Division of Elections Data 
On closer inspection, it is evident that Democratic presidential voting at the county level also produces party-safe Democratic counties. These six party-safe Democratic counties start with Jefferson County and Alachua County in Central Florida, followed by a gap in the winning margin to Palm Beach and Broward counties in Southeast Florida, and Leon County and Gadsden counties in the Democratic stronghold in North Central Florida, the last county representing the outlier at the bottom of the graph. There were also close Democratic victories in four counties, with Miami-Dade County straddling the divide between the party-safe Democratic counties and the narrow Democratic counties, with a $6.3 \%$ margin of victory for Democratic candidate John Kerry. The distribution of Democratic counties is not as smooth as the Republican distribution, with larger intervals in the vote margins between counties partly because there are far fewer Democratic counties. Nevertheless, these few Democratic counties are so heavily populated that Democrats are competitive in statewide races.

In short, the visual representation of the geographic distribution of Presidential voting in Florida describes a strikingly uneven distribution, and offers credible indication that the distribution is not random. Territorially, the bulk of the state's Democratic voters appear to live in the urban conurbations of Southeast Florida, Central Florida, and North Central Florida; the rest of the state clearly favored the Republican Party candidate, often by overwhelming margins. 
To better compare the differences between the counties, Republican or Democratic, and to do so more precisely, we can identify a reference value. Typically this reference value tends be an average value, such as the mean. Reviewing the results of the 2004 presidential election, we see that the mean victory margin for the Republican counties was $26.7 \%$, whereas in the Democratic counties the mean victory margin was $11.3 \%$; for all Florida counties the mean was $24.3 \%$. These mean values indicate that most Florida counties were simply not competitive in the presidential election of 2004, and that in most Florida counties the Republican candidate won by a large margin.

Since the mean can be affected by outlying values, and we have already come across outliers, such as Gadsden County, the median may be a better choice of the average winning margin of victory than the mean. ${ }^{28}$ The median values of the victory margins for Republican and Democratic counties turn out to be $23 \%$ and $11 \%$ respectively, with a median for all Florida counties of $21.2 \%$ - slightly lower than the values using the mean but still resoundingly uncompetitive. The results are summarized in Table 1.

Since the Republican median winning margin of victory is so high, any reference derived from it would mean all but two Democratic counties (Broward and Gadsden) would be classified as below average for competitiveness. Thus a useful reference value for analyzing the election results should take into account the Democratic winning margins of victory. Accordingly, I will define any election with a margin of

\footnotetext{
${ }^{28}$ Henceforth any references to "the average value" will refer to the median, unless otherwise indicated.
} 
victory less than $10 \%$ as "competitive", and any margin of victory above $10 \%$ will be defined as "uncompetitive".

Table 2 Republican Margin of Victory, 2004 U.S. Presidential Election, by Florida County

\begin{tabular}{llll} 
& All Counties & Rep & Dem \\
\cline { 1 - 3 } Number of Counties & 67 & 56 & 11 \\
Average Margin of victory & 24.3 & 26.7 & 13.9 \\
Median Margin of victory & 21.2 & 23.2 & 11.3 \\
High Value & 56.5 & 56.5 & 40.1 \\
Low Value & 0.1 & 0.1 & 0.2
\end{tabular}

Source: Author Calculations, from Florida Division of Elections Data

Using the $10 \%$ cutoff, it is clear that most Florida counties were simply not electorally competitive in the 2004 presidential election, but were, instead, uncompetitive and party-safe. If presidential election returns at the county level appear party-safe, it follows that elections for other offices, such as Congress or statewide offices, if analyzed at the county level, may also be party safe. If so, such uncompetitive elections would raise doubts about whether partisan redistricting, or "gerrymandering", were necessary to create uncompetitive elections. Such 
institutional design could contribute to uncompetitive elections, but it would not appear to be necessary in most places in Florida.

To get a sense of what this means for the Florida political landscape, it is instructive to create a map of the state using the presidential election results by county. To get a more robust sense of the county partisan profile, I use the average of the 2000 and 2004 presidential elections; this smoothes out any period effects that might bias results from any individual election year. Looking at Figure 2, it is evident that the patterns from the 2004 election emerge using the 2000/2004 combined data: vast swathes of Republican presidential voting territory, with Democratic bastions in North Central Florida and Southeast Florida, around Fort Lauderdale and West Palm Beach, and competitive presidential election counties in Central Florida, around Tampa and Orlando.

Using this same analytic approach, I will next consider Congressional elections in Florida. Once again, the county will be the unit of analysis. If Congressional elections appear as uncompetitive at the county level as presidential elections do, then there is more reason to doubt that redistricting is the cause of party-safe Congressional elections. 
Figure 2 Florida County Partisanship, using Average Winning Margins of the Two-Party Vote in U.S. Presidential Elections of 2000 and 2004

\section{Florida Counties \\ Elections for U.S. President Margin of Victory, 2000-2004}

Safe Democrat (Margin $>=10 \%$ )
Competitive (Margin 0-9\%)
Safe Republican (Margin $>=10 \%$ )

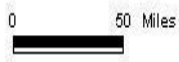

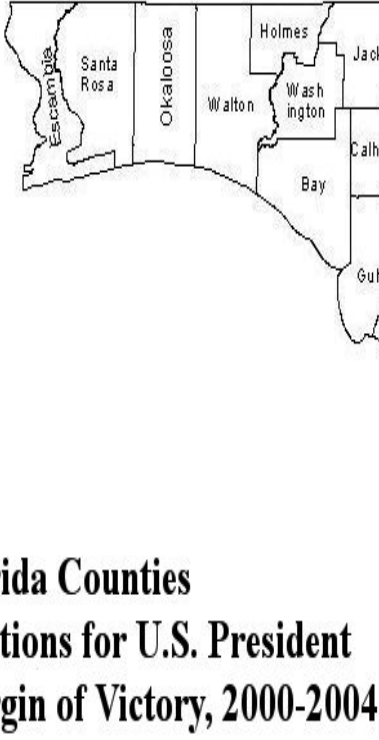

Sale Republican (Margin $>=10 \%)$
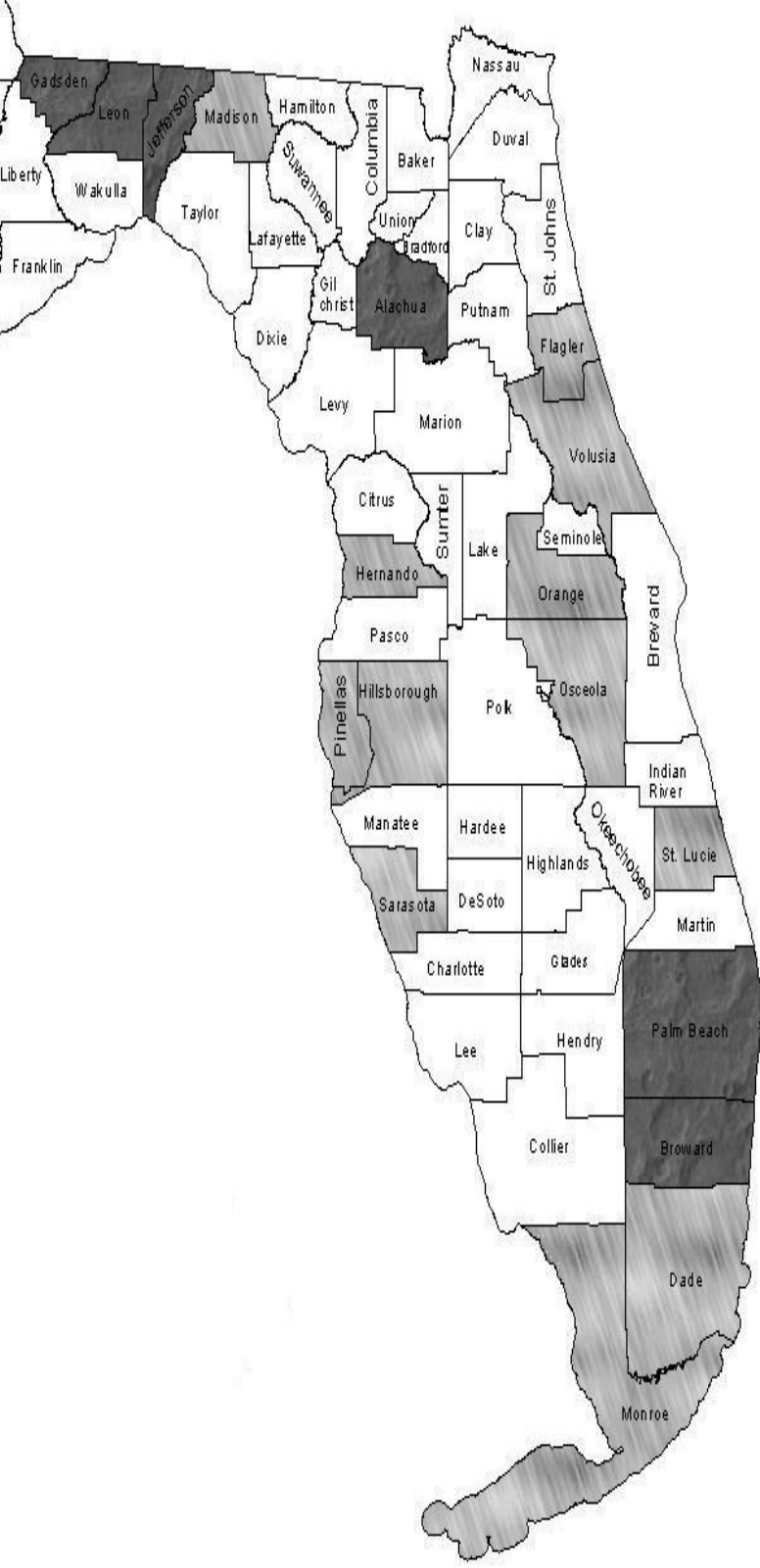

Source: Author Calculations, from Florida Division of Elections Data 


\subsection{The 2006 U.S House Elections at the Florida County Level}

To analyze U.S. House election results, I could replicate the analysis I have just done for Congressional results in 2004. The results from the previous section, however, indicate there is a significant Republican Party advantage in the distribution of voters in Florida. Given that the distribution of voters matters for Congressional elections in a way that it does not matter for elections for U.S. President or Florida Governor, which are simply decided by the state-wide aggregate vote breakdown, I can develop a stronger test of the sectionalism hypothesis by using results from mid-term Congressional elections of 2006, which are not likely to benefit Republican Party candidates since there will be no presidential coat-tails. ${ }^{29}$ On the contrary, the 2006 mid-term election is considered a "wave election", favorable to Democrats. ${ }^{30}$ So if I find that patterns of voting in Congressional elections in 2006 are similar to voting in presidential election in 2004 , I can be fairly confident that my findings are not a function of bias, stemming from the choice of election year.

Figure 3 graphs the distribution of 2006 Congressional election results across Florida counties. In this instance, I graph victory margins for fifty-seven counties, rather than sixty-seven, as there are some missing data. ${ }^{31}$ I make an exception to my exclusion

\footnotetext{
${ }^{29}$ Presidential "coattails" refer to the boost candidates of the winning presidential candidate's party receive in presidential election years.

${ }^{30}$ A wave election is one in which the prevailing political sentiment is such that one party gains a significant advantage. The significant mid-term wave elections of the last 25 years have been1994 and 2010. The Democrats won 31 seats in the 2006 mid-term election - enough to be considered a wave election by political analysts.

${ }^{31}$ The missing counties are indicated in the dot plot in Figure 3.
} 
rule, however, and include Broward County in the analysis, even though it includes data for an election that featured a Democrat against a Write-In candidate, with no Republican contesting that seat, because the county is simply too large to ignore without distorting results.

The overall distribution and pattern of results is very similar to that from the 2004 presidential election. The plot shows that most counties with two party choices were not competitive, and that Republican voters dominated in voting for the U.S. House in most counties across the state, winning forty-four out of the fifty-seven counties with available data.

The distribution of Republican Congressional counties is smooth, as with the 2004 presidential distribution, with a steady increase in Republican winning margins, especially from Osceola County up to Walton County at the upper end of the distribution. There are two modal values in the distribution - indicated by the areas where the counties follow each other almost vertically - between Pinellas County and Lake County, with victory margins clustered at approximately $22 \%$, and between Seminole and Bradford counties, with victory margins clustered around $29 \%$.

Democratic voters were again concentrated in a few counties, just as in voting for the presidential election in 2004. Thirty-six of the forty-four counties won by the Republican Party were not competitive, using my 10\% margin of victory cut-off. 
Overall, the Democratic Party won three counties - Jefferson, Leon and Gadsden, all in the North Central Florida - with a large, party-safe, margin.

The distribution of Democratic victory margins is unimodal, with the mode indicated by the near vertical spread of values between Alachua and Palm Beach Counties, at approximately the $6 \%$ margin of victory. After a smooth increase through Okeechobee, St. Lucie and Glades Counties, with margins of approximately $9 \%$, the distribution skips to the outliers in North Central Florida, Leon and Jefferson Counties, with a 23\% aggregate margin of victory for the Democratic Party. As with presidential voting in 2004, Democratic Congressional voters in 2006 were concentrated in a few counties.

In sum, the distribution of Congressional voting outcomes in the 2006 mid-terms among Florida counties is similar to the distribution of voting in the 2004 presidential election. In both instances, the election results portray a state in which voters for each party appear to be concentrated in certain areas of the state. The distribution of voting is uneven, or lumpy, and does not appear to be random. But what of the margin of victory for these Congressional elections? How does voting for the House stack up against voting for the President in terms of electoral competitiveness? Are Congressional elections less competitive, as the redistricting explanation of elections would suggest? 
Fig. 3 Winning Margins of the Two-Party Vote in 2006 U.S. House Elections, by Florida County

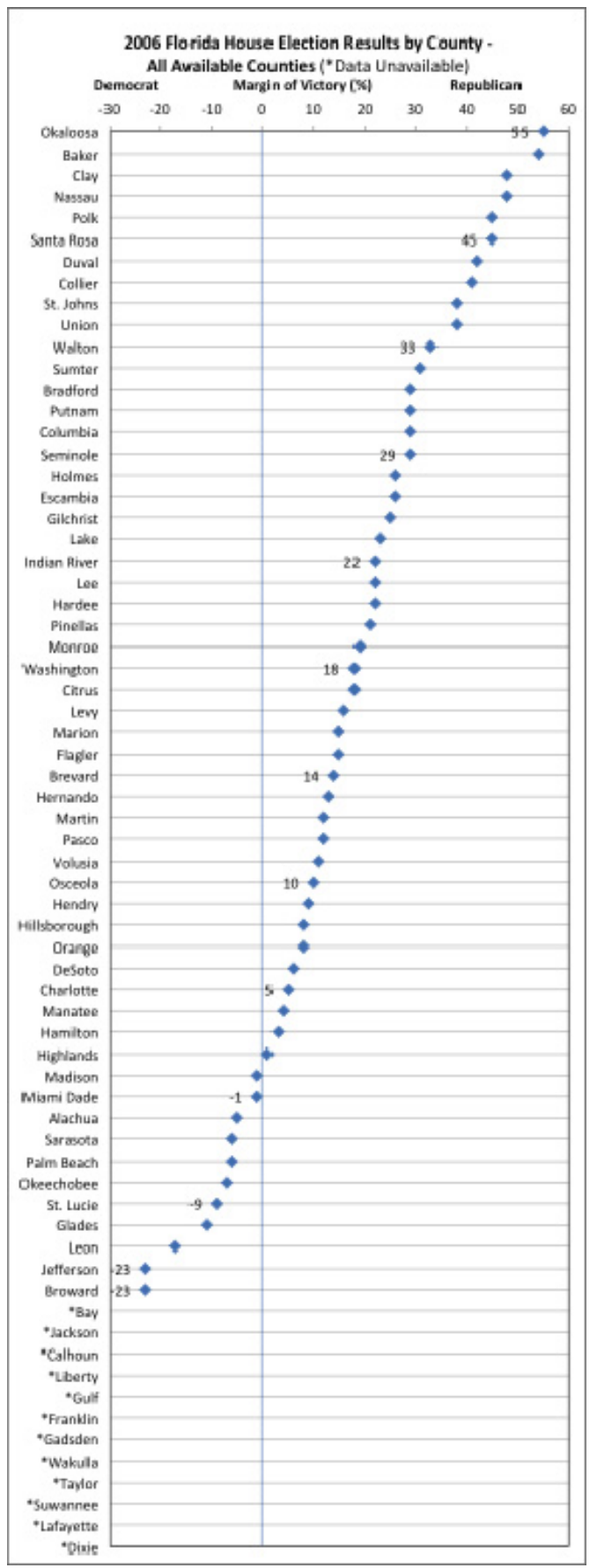

Source: Author Calculations, from Florida Division of Elections Data 


\subsection{Uncompetitive Florida Counties}

The results indicate that the vast majority of Florida counties were not competitive in the Congressional elections of 2006. As in the presidential election in 2004, most counties delivered a victory for the Republican candidate by a wide margin, although the counties that delivered their vote to the Democratic Party in the 2006 mid-term elections were, on the whole, more competitive than Democratic presidential counties in 2004. House Democratic counties in 2006 enjoyed a median victory margin of $6.2 \%$, compared with $11.3 \%$ in the 2004 presidential election.

The mean margin of victory in 2006 House elections for the Republican counties was $23.6 \%$, and the median was $21.9 \%$ - similar to the margins in 2004 for President. For the Democrat counties, on the other hand, the mean was $8.4 \%$, and the median was $6.2 \%$ - slightly more competitive than in the 2004 presidential election. For counties in the state as a whole, the mean was $20.8 \%$, and the median was $17.9 \%$. So elections, measured at the county level, for U.S. House in 2006, in those elections where voters had a choice between a Democratic and Republican candidate, were more competitive, by an aggregate margin of $4 \%$, than the presidential election in the same counties in 2004.

In sum, Florida counties were uncompetitive in the mid-term House elections of 2006, but less so than in the presidential elections in 2004. If Congressional districts, by their design, render elections less competitive, then that outcome is not apparent 
from county-level analysis. If anything, Congressional elections, at the county level, appear more competitive than presidential elections. Such an outcome is not what the "gerrymandering" explanation would predict. Table 3 summarizes these results.

Table 3 Republican Margin of Victory, 2006 U.S. House Elections in which Both Parties Fielded a Candidate, by Florida County

\begin{tabular}{llll} 
& All & Rep & Dem \\
\cline { 1 - 2 } No. of Counties & 54 & 44 & 10 \\
Average margin of victory & 20.8 & 23.6 & 8.4 \\
Median margin of victory & 17.9 & 21.9 & 6.2 \\
High value & 54.6 & 54.6 & 23.0 \\
Low value & 0.6 & 1.2 & 0.6
\end{tabular}

Source: Author Calculations, from Florida Division of Elections Data

\subsection{The Distribution of Voters and "Purple" Florida}

Figure 3 indicates that partisan identification as a sectional phenomenon is not static, but evolving, an observation that is consistent with my hypothesis (that I will test in the next chapter) that residential mobility and migration patterns are a cause of these 
sections. At this point, we can review the consequences of the sectional distribution of voters for presidential voting, as opposed to Congressional elections. In presidential elections (and for statewide offices such as Governor), the politically polarized sections are a wash. The uneven distribution of voters into partisan sections affects where candidates invest time and resources during the election campaign in order to maximize the turnout in their favor. But it does not determine whether the election is competitive or party-safe, since the Republican territorial advantage is cancelled out by the concentration of the state's population in the Democratic stronghold in Southeast Florida, which harbors approximately half of the electorate. ${ }^{32}$ Such an asymmetric population distribution makes Florida a competitive "purple" state, with low single digit, often nail-bitingly close, margins of victory in elections for president and for Governor. ${ }^{33}$

In Congressional elections, however, the distribution of voters into partisan sections should determine whether those elections are competitive, or party-safe. Before reviewing that difference, we need to investigate whether House election returns carve out partisan sections. As with presidential elections, these sections should be evident at the regional level. In the next section, I look at region-level results for House elections, and compare the findings with those for presidential elections.

\footnotetext{
${ }^{32}$ Miami-Dade, Broward, and Palm Beach Counties compose half the electorate. Take away these three counties, and the remaining sixty-three Florida counties form a state that would resemble Texas in statewide and national offices.

${ }^{33}$ Barack Obama won Florida's Electoral College votes by $2.8 \%$ in 2008; Rick Scott won the Governors race by $2 \%$ in 2010 .
} 


\subsection{Conclusion}

The geographic distribution of presidential voting in Florida created party-safe counties in 2004, while the geographic distribution of Congressional voting also created party-safe counties in 2006 - suggesting that elections in Florida can be partysafe without partisan gerrymandering of electoral districts. In fact, counties in the Congressional elections in 2006 were, on average, slightly more competitive than the same counties were in 2004 presidential elections.

If this is in any some way a result of the design of districts, and the rational decisions of political elites to run in those districts, then a more logical conclusion may be that redistricting actually contributed to making elections more competitive, at least at the county level. At minimum, county-level analysis of election returns in Florida casts doubt on the argument that redistricting is the cause of party-safe elections.

In the next chapter, I will develop a structural explanation for the preponderance of party-safe county elections in Florida by testing the hypothesis that migration patterns are the cause of these sections. But before I do that, I need to test the hypothesis on more data, rather than drawing conclusions by looking at two elections, in two different years. In order to make more general statements, I need to take a broader view, over a longer period of time. One possible approach is to describe and analyze electoral results using units that are larger than the county; a reasonable tactic given that some Florida counties only have a few thousand voters. If sections exist, we 
should be able to identify them if we combine counties in some manner. One logical aggregation is to combine county level results into region-level results.

\section{DO FLORIDA REGIONS FORM POLITICAL SECTIONS?}

We can combine the county level results into eight regional data series, reflecting the eight Florida regions that are used to describe Florida: the Northwest, North Central, Northeast, Central West, Central, Central East, Southwest and Southeast. Each region is composed of between five and sixteen counties, with each county belonging to only one region. (See Appendix D). In this section, I analyze the winning two-party vote margin in presidential and Congressional elections from this regional perspective.

\subsection{Presidential Voting: A Regional Perspective}

To best take advantage of the regional perspective, I need to consider a longer period of elections than I have done thus far. To accomplish this I take the average value for winning margin of victory over several election cycles, rather than simply the value for one election, as I did in Section 1. An average presents a more reliable measure of the dependent variable than a single observation, since an average smoothes out nonsystematic consequences such as period effects, as well as measurement errors induced by any missing data. 
To calculate an average winning margin for each region, I add votes cast for candidates of the two major parties for U.S. President in each county in a given region for two consecutive elections, and divide the sum by two. I do this for each of the last three decades. ${ }^{34}$ I then calculate the winning vote margin for the region over these two election cycles, using the same arithmetic as in the previous section. The results are summarized in the Table 4. As before, we should look for differences between regions, but also in trends over time.

Table 4 Comparison of Republican Average Winning Margins, in U.S. Presidential Elections in the 1980s, 1990's, and 2000s, by Florida Region

\begin{tabular}{l|llllllll} 
& NW & NC & NE & CW & C & CE & SW & SE \\
\hline $1980-84$ & 19.8 & 2.3 & 19.3 & 26.4 & 35.6 & 29.1 & 43.6 & 18.6 \\
$1988-92$ & 27.7 & -15.4 & 14.1 & -1.5 & 8.2 & 1.8 & 14.8 & -19.9 \\
$2000-04$ & 39.8 & -5.9 & 24.1 & 4.2 & 9.7 & 4.6 & 21.6 & -18.9
\end{tabular}

Source: Author Calculations, from Florida Division of Elections Data

In this three-decade time frame, we can see that the 1980s can be thought of as a baseline, where every region was Republican in presidential voting, with only North Central Florida being competitive. A decade later, North Central became Democratic

\footnotetext{
${ }^{34}$ This is similar to the procedure used in the Cooke Index, developed by the political analyst Charles Cooke, which uses the average of the results from the last two Presidential elections to create a measure of district ideology.
} 
party-safe, and has remained so; during that time the Southeast has flipped from party-safe Republican to party-safe Democratic in presidential voting since the 1980s.

The middle of the state - Central Florida, Central West Florida and Central East Florida - has become more competitive since the 1980s, whereas the North West, South West, and North East Florida have become less competitive, Republican strongholds. Overall, the regions describe some clear sections, with two Democratic strongholds: Southeast Florida and North Central Florida, three Republican strongholds: the Northeast, Northwest and Southwest Florida, and a more purple, competitive middle of the state.

We can clarify these regional sections in a clustered bar chart, which illustrates the patterns and differences among the regions. In figure 4 below, the eight regions are arrayed along the $\mathrm{x}$-axis, and the winning presidential vote margin along the $\mathrm{y}$-axis. The bar chart clarifies some differences between regions and trends among them. First, the Republican presidential candidates dominate the Florida landscape: most of the state's territory has tended to vote Republican in presidential elections. Second, Republican partisan identification has flipped in North Central and Southeast regions; realigning from Republican to Democratic voting in presidential elections by the early 1990s.

Third, every region became less Republican in the 1990s - except Northwest Florida, which has evolved over three decades into the most party safe Republican region in 
the state. A fourth trend is that every region became more Republican in the last decade - except Southeast Florida, which has evolved over three decades into the most party safe Democratic region in the state. The diametrically opposite partisan divergence between the two most distant regions of Florida - the Panhandle and the Miami-Fort Lauderdale-Palm Beach metropolitan area - is now the most striking partisan divide in the state. The analysis for 2000-2004 produces the map in Figure 4.

Figure 4 Comparison of Average Winning Margins of the Two-Party Vote in U.S. Presidential Elections in the 1980s, 1990s, and 2000s, by Florida Region

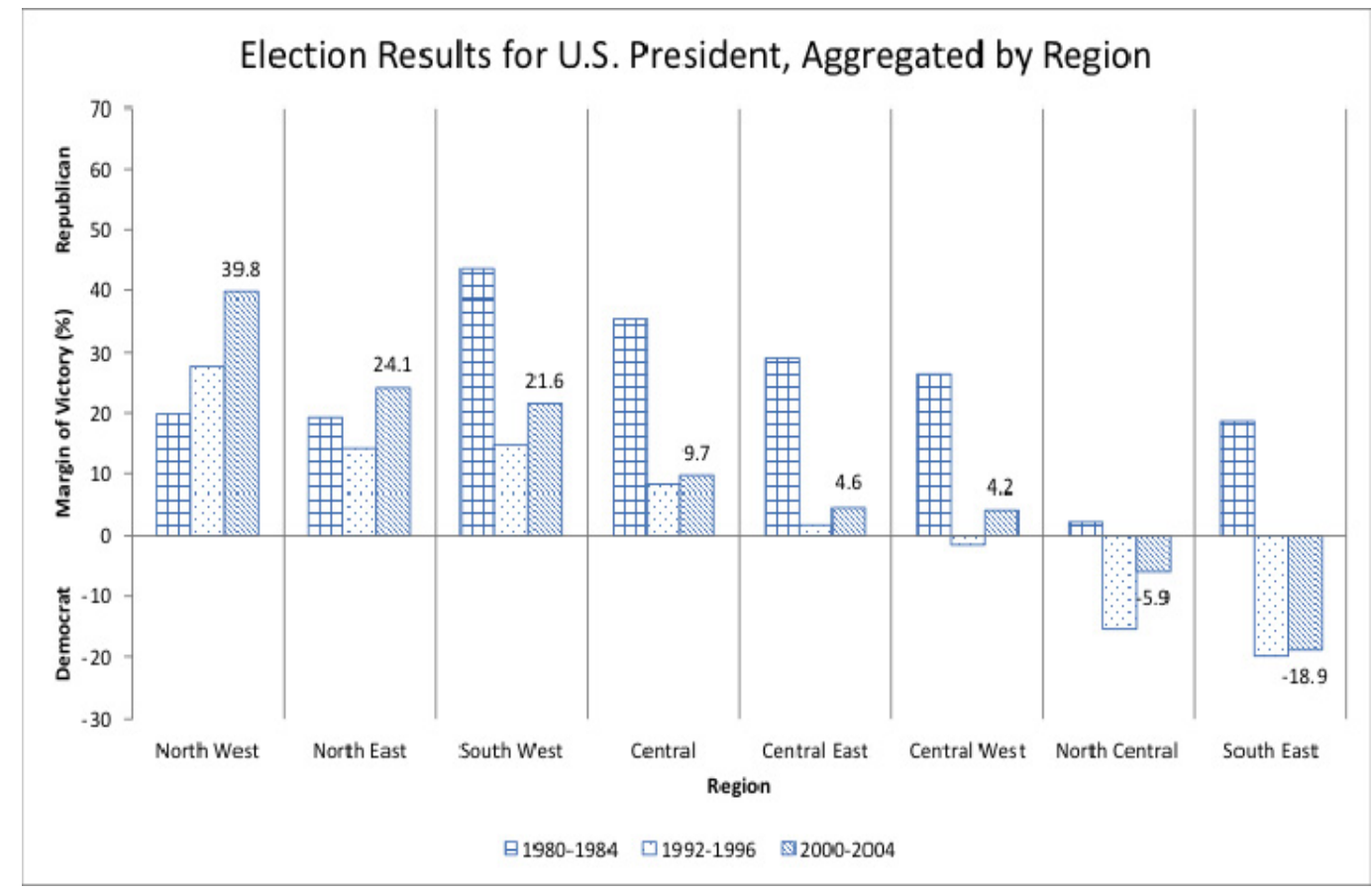

Source: Author Calculations, from Florida Division of Elections Data 
As before, let us look to see if Congressional elections create the same sectional divides. As in the discussion of Congressional elections in section 1, I assume that only two-party competition matters, and thus all votes for third parties are ignored.

First, we can analyze Congressional elections by considering a data set of elections that includes those that were contested by at least one candidate from either the Republican or Democratic Parties. This data set thus includes some lopsided elections in which one candidate won almost unopposed. Unfortunately, the available data set is not complete for the 1980s, but the remaining data is sufficient to identify sectional patterns and trends over the last twenty years. The results are summarized in table 5 .

Table 5 Comparison of Republican Average Winning Margins, in Successive U.S. House Elections, in the 1990s and 2000s, by Florida Region

\begin{tabular}{l|llllllll} 
& NW & NC & NE & CW & C & CE & SW & SE \\
\hline $1992-96$ & 11.9 & -28.5 & 15.2 & 16.2 & 32.4 & 8.7 & 65.5 & -3.8 \\
$2002-06$ & 34.9 & -11.2 & 44.7 & 18.5 & 21.5 & 22.4 & 32.1 & -2.5
\end{tabular}

Source: Author Calculations, from Florida Division of Elections Data 


\subsection{Voting in House Elections: A Regional View}

The pattern is very similar to regional variation of presidential voting in Table 2: two Democratic regions, in North Central and Southeast Florida, and six Republican regions. As before, the Northwest and Northeast are Republican strongholds, while Central West and Central East regions are Republican leaning rather than party safe. The clustered bar chart in figure 4 illustrates the pattern, as well as highlighting trends.

To make comparison easier, the regions are arrayed according to the partisan continuum exhibited in the presidential chart, with the most Republican presidential region, the North West, on the far left, and the most Democratic presidential region, the Southeast, on the far right. The first thing we notice is that the Congressional chart produces the same sections as the presidential graph: the North West and North East - party safe Republican sections, the Southeast and North Central Florida - party safe Democratic sections, and the three competitive central regions. 
Figure 5 Average Winning Margins of the Two-Party Vote in U.S. Presidential Elections of 2000-2004, by Florida Region

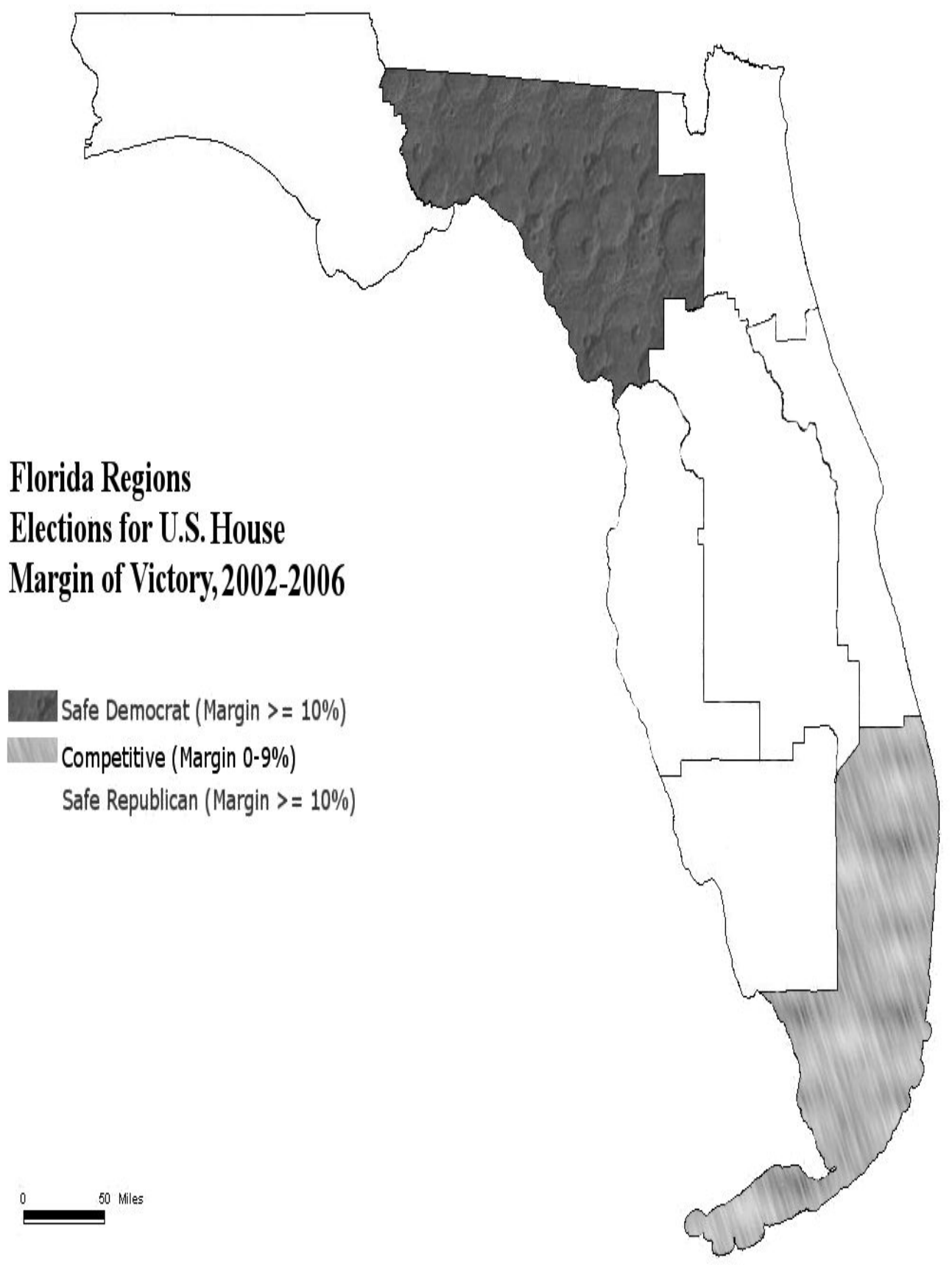

Source: Author Calculations, from Florida Division of Elections Data 
Whereas the sections are similar, the size of the margin of victory differs. In general, the winning victory margins are higher in the Congressional chart than in the presidential chart: the bars for the last decade, on the right of each cluster, tend to be higher in Figure 4. Thus, it appears that House elections are more party-safe than presidential elections. In particular, House elections are more party safe in the Northeast and the Central regions; they are more competitive in the Southeast. 
Figure 6 Comparison of Average Winning Margins of the Two-Party Vote in U.S. House Elections of the 1990s and 2000s, by Florida Region

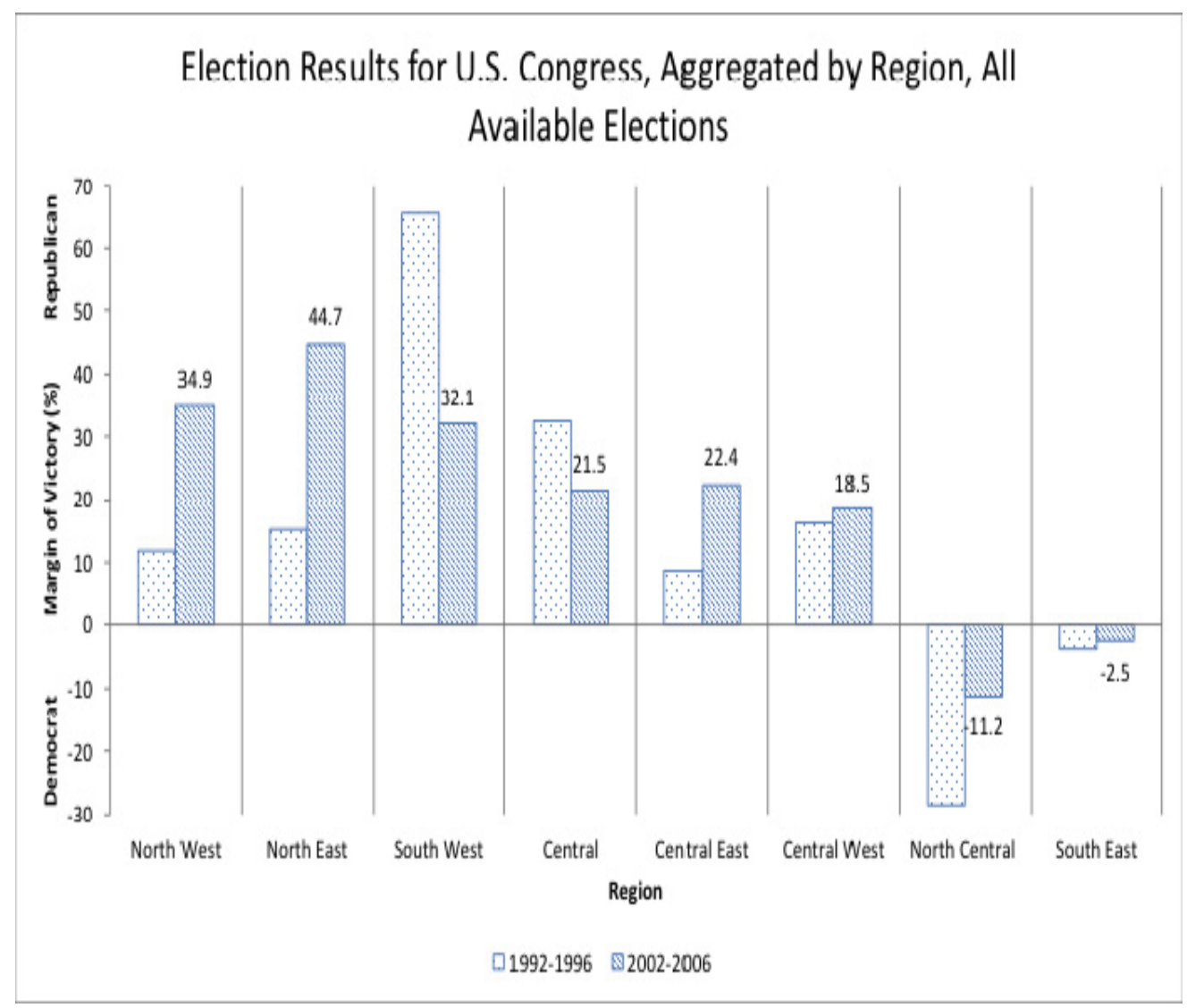

Source: Author Calculations, from Florida Division of Elections Data

To test these findings, we can repeat the exercise with a second data set of average winning margins, one that screens out all the uncontested elections, ones that did not 
feature candidates from both the Republican and Democratic parties. Since these uncontested elections, by definition, will not be competitive, the result of omitting them from the data set should be to create a sub-set of data used in the Table 3 , but one that is more competitive, with lower average winning margins. Using this sub-set, we obtain the results in Table 6 and Figure 7 below.

Table 6 Comparison of Republican Average Winning Margins, in U.S. House Elections, in the 1990s and 2000s, Only Elections in which Both Parties Fielded a Candidate, by Florida Region

\begin{tabular}{l|llllllll} 
& NW & NC & NE & CW & C & CE & SW & SE \\
\hline $1992-96$ & 11.3 & -29.6 & 10.6 & 13.2 & 30.8 & 8.7 & 43.0 & -7.5 \\
$2002-06$ & 34.9 & -19.4 & 43.1 & 17.7 & 21.1 & 19.9 & 29.7 & -6.1
\end{tabular}

Source: Author Calculations, from Florida Division of Elections Data

The results are basically the same with respect to the sections that emerge, and the trends they describe. This gives us confidence that distributions and the patterns we have obtained are likely to be reasonably accurate. The difference, however, is in the average regional winning margins. They are not uniformly lower, as hypothesized; some are the same, some are lower, and some are higher. In short, there is no obvious correlation between the presence or absence of uncontested elections, and overall prevalence of party-safe elections in the region as a whole over a period of time. 
Figure 7 Comparison of Average Winning Margins in U.S. House Elections in the 1990s and 2000s - Only Elections Contested by Both Parties, by Florida Region

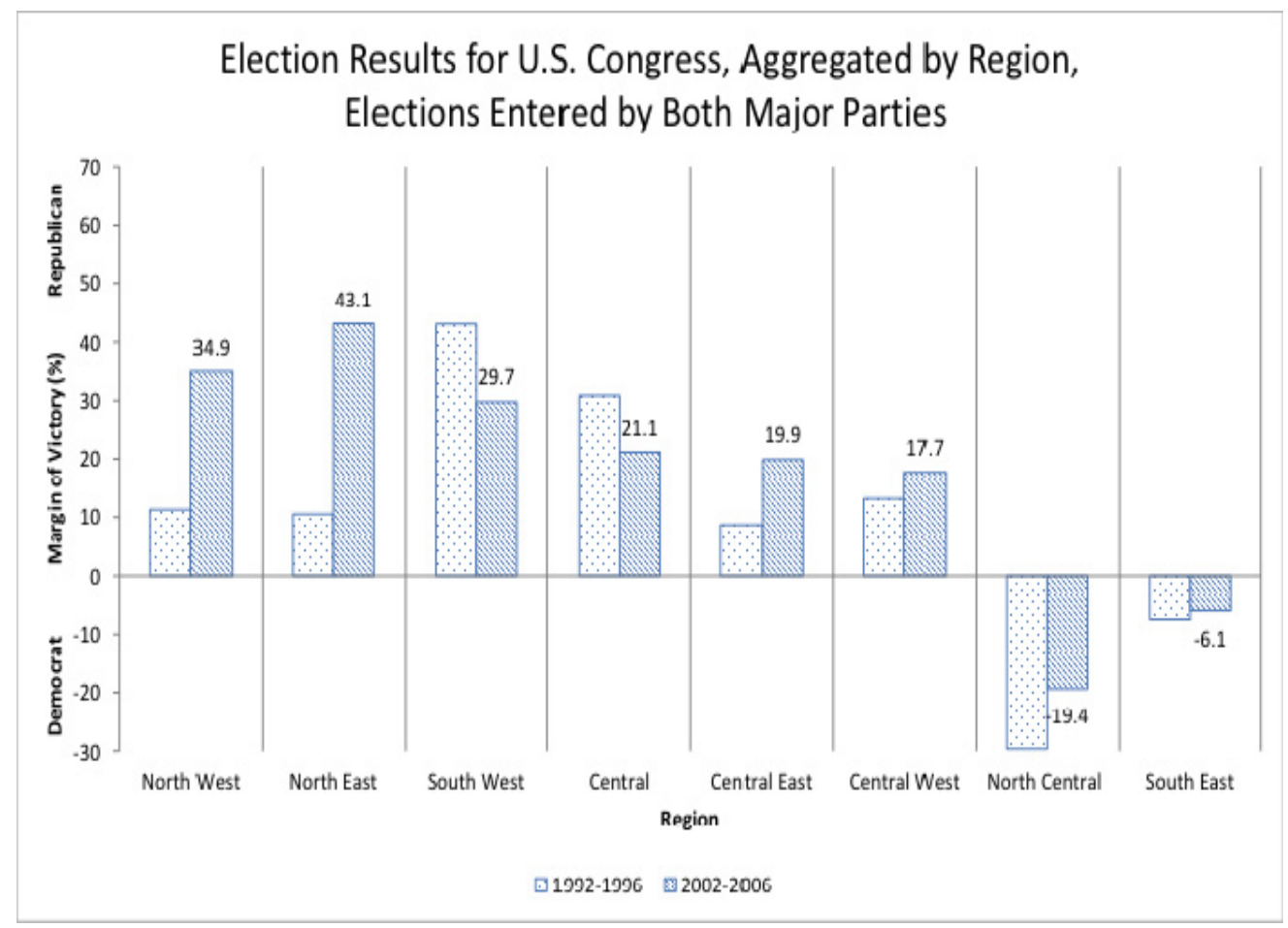

Source: Author Calculations, from Florida Division of Elections

One possible reason is that in certain regions, uncontested elections are a wash some are landslide Republican victories, others are landslide Democratic victories, and the net result is largely insignificant - as appears to be the case in the Northwest and the Central regions. In other regions, however, the net effect of uncontested elections is to move the needle on the regional averages as a whole in one direction. This appears to be true with Congressional elections in the Southwest in the 1990s, 
and Congressional elections in the North Central region in the last decade. In the former, uncontested elections made the district less competitive than it already was; in the latter, uncontested elections made the region more competitive than it was without them.

If we assume that these uncontested elections derive from gerrymandered districts that discourage candidates from one or other party from competing, we can view the difference between the two sets of Congressional winning vote margins presented in Tables 3 and 4 as an approximation for the influence of redistricting on House election results. The difference between the margins in Table 5 and Table 6, going from the former to the latter, gives us the results in Table 7 below.

Table 7 Effect of Uncontested U.S. House Elections on Republican Average Winning Margins, by Florida Region

\begin{tabular}{l|llllllll} 
& $\mathrm{NW}$ & $\mathrm{NC}$ & $\mathrm{NE}$ & $\mathrm{CW}$ & $\mathrm{C}$ & $\mathrm{CE}$ & $\mathrm{SW}$ & $\mathrm{SE}$ \\
\hline $1992-96$ & -.06 & -1.1 & -4.6 & -3.0 & -1.6 & 0.0 & -22.5 & -3.7 \\
$2002-06$ & 0.0 & -8.2 & -1.6 & -0.8 & -0.4 & -2.5 & -2.4 & -3.6
\end{tabular}

Source: Author Calculations, from Florida Division of Elections Data

Table 7 thus shows the difference between the average vote margins when all available elections, using the two party vote shares, are taken into account (Table 3) 
and the average vote margins when uncontested elections are screened out. A positive number indicates that the average winning margin in the region for that period was made more Republican by the presence of uncontested elections, whereas a negative number indicates that the average winning margin in Congressional elections in that region were made more Democratic by uncontested elections.

From Table 7, we see that in most regions, uncontested elections have not been a significant factor with respect to making the region more or less competitive in Congressional elections. We see that uncontested elections had the most significant influence in Congressional elections in the Southwest in the 1990s, and in the North Central region in the last decade. If we take away the uncontested elections in the Southwest, electoral winning margins in the 1990s become less Republican (or more Democratic), by $22.5 \%$. Thus uncontested elections made the region as a whole less competitive. But in North Central Florida, if we strip out the uncontested elections in the last decade, margins became less Republican, or more Democratic, by $8.2 \%$. But since this was a Democratic voting region to begin with, uncontested elections made the region as a whole more competitive. In other words, uncontested elections had opposite effects, on average, on electoral competition in these two different regions

If we assume that uncontested elections derive from gerrymandering, then it appears that the effect of gerrymandered districts, on the whole, differs significantly from one region to another, and from one census decade to another. Redistricting may or may not affect electoral competitiveness in a meaningful manner. If there is an effect, it 
may be to make elections more competitive, or less so. In short, the effect of redistricting on Congressional elections, to the extent that it exists, is much harder to pin down than the effect of sectionalism.

\subsection{Conclusion}

The evidence from county level and regional level data supports the hypothesis that Florida is composed of sections - geographic areas that are dominated by one or other party in elections - and that similar sections emerge from both presidential and House elections. These sectional patterns are not necessarily permanent: some sections become more pronounced in partisan profile; others become less so. Still others "flip" and change their partisan composition over time, from Republican to Democrat, or vice versa. But what is evident is that at any given time significant differences in voting behavior exist among different counties and regions in Florida.

The implication of such sectionalism is that U.S. House elections, which are structured around the geographic divisions of Florida into twenty-five electoral districts, will produce many elections that are uncompetitive - regardless of how the electoral district is drawn. But if sections matter more than gerrymandering, as I argue in this study, voters must be voting reliably for the same party, regardless of the candidate. In other words, my argument implies that voting in Florida elections is 
increasingly influenced, if not dominated, by partisanship. I will test this hypothesis in the remainder of this chapter.

\section{PARTISANSHIP AND FLORIDA ELECTIONS}

My second hypothesis is that election returns in Florida are increasingly partyoriented. In other words, voters rely on the party affiliation of the candidate to make the vote choice, rather than the candidate's platform or campaign efforts. Such partisanship does not mean policy positions or campaigns do not matter; in any individual election, they will surely play a part, and sometimes, they will be decisive, as any casual observer of presidential elections, can attest. My hypothesis is, rather, that party is an increasingly important driver of voting behavior and election results. In this section, I offer evidence against which to test the hypothesis that voters are increasingly voting along party lines. Given the hypothesis that partisanship is more important than before, and more important than other factors, then, one reasonable prediction is that, across many election cycles, in elections for different offices, we should see election results converging over time.

We can test this prediction against evidence visually by plotting election results across time for different elections, creating different "series". Within the axes, we can trace the results for different elections using different lines, creating multiple line 
graphs. As before, a positive number indicates a Republican winning vote margin, whereas a negative number indicates a Democratic winning vote margin.

The following multiple line graphs in Figure 8 below illustrate the voting trends for five large counties: Broward, Hillsborough, Orange, Duval, and Brevard Counties, representing the Southeast, Central West, Central, Northeast, and Central East regions of Florida respectively. Each graph plots the data series for each of six offices: U.S. President, U.S. Congress, U.S. Senator, Governor, State Attorney General, and Commissioner of Agriculture. Time in years is plotted on the x-axis, and the winning margin along the y-axis. The broken line for is for missing data. 
Figure 8 Graph of Winning Margins in Elections for State and U.S. Federal Government Offices, Between 1980 and 2006, for Five Large Florida Counties

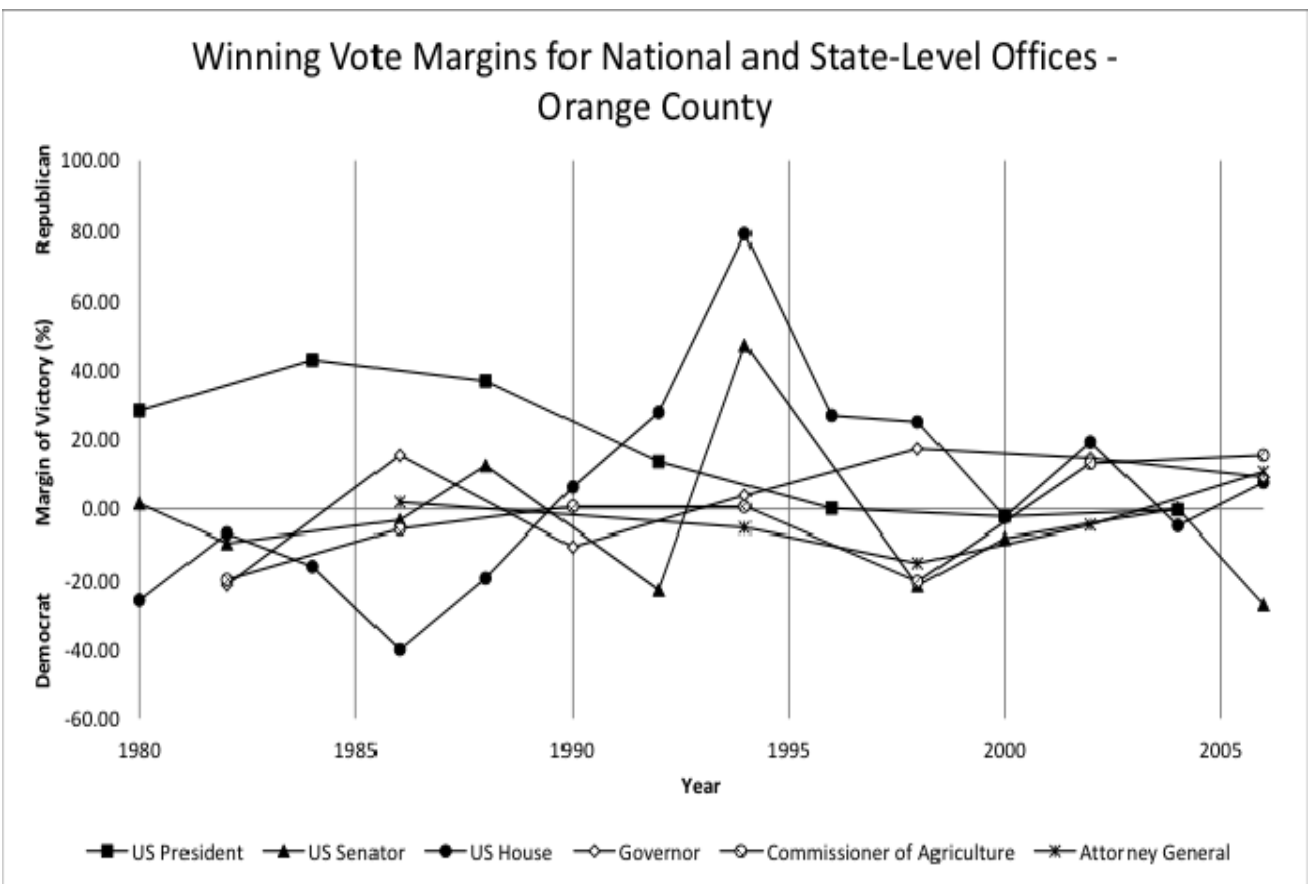



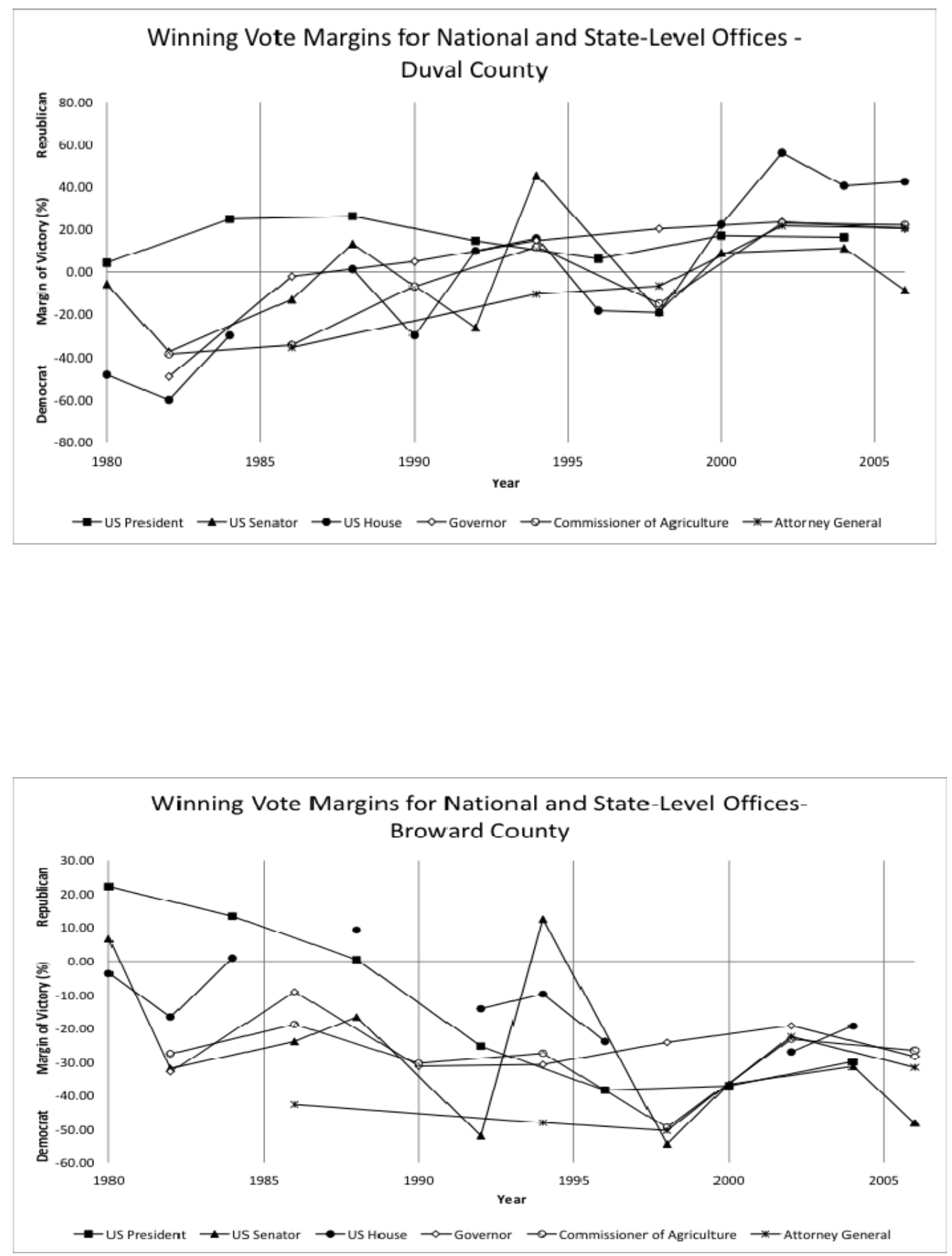

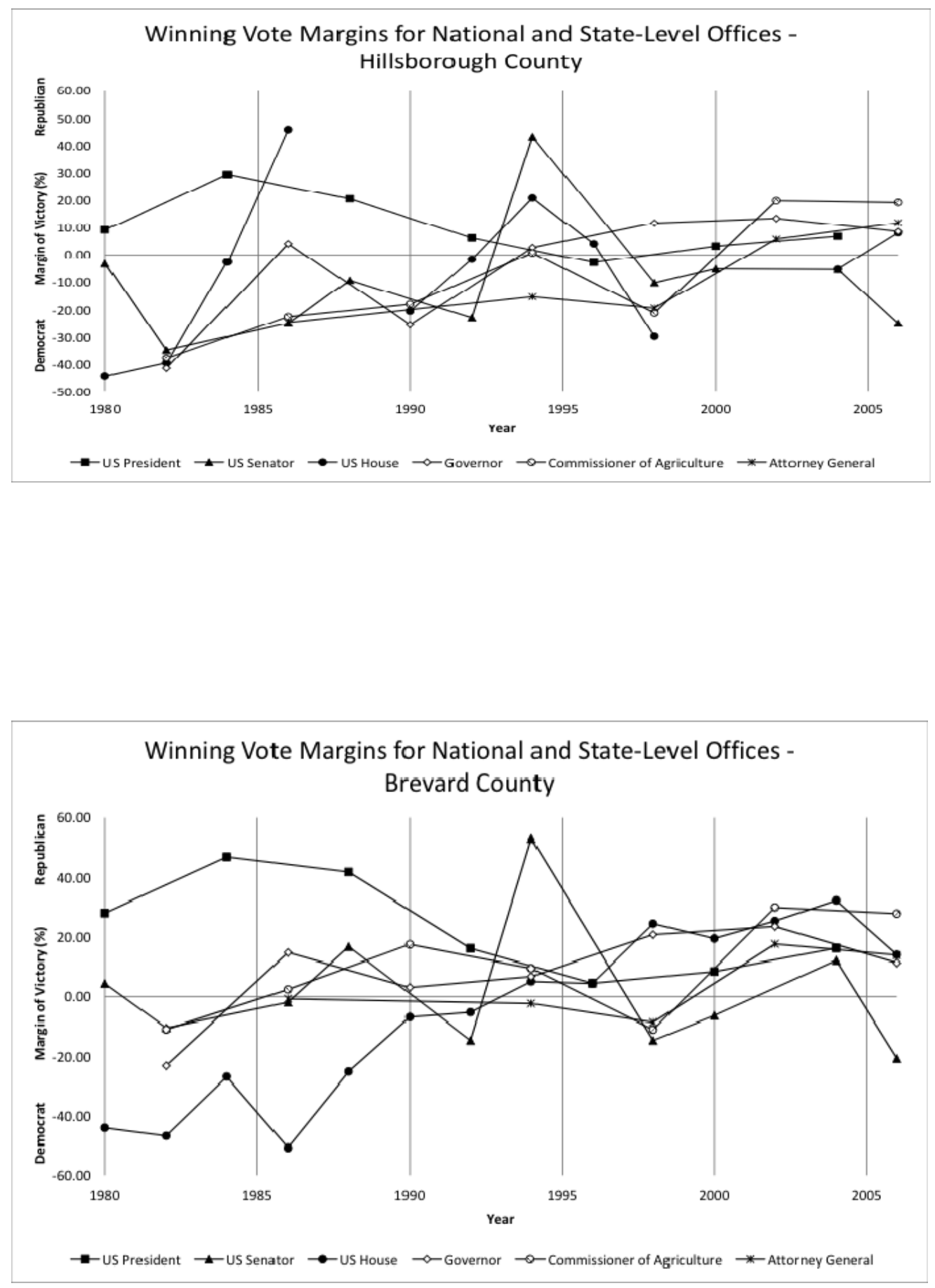

Source: Author Calculations, from Florida Division of Elections Data 
The charts in Figure 8 display three clear patterns. First, the lines in tandem reflect the characteristic partisan evolution of the counties: a slow upward drift of the election series for Duval and Brevard Counties, and to some extent Hillsborough County, indicating increasing Republican partisanship, a relatively flat graph for Orange County, indicating its competitive profile, and a marked decline in the election series for Broward County, consistent with increasing Democratic partisanship in that county.

Second, the volatility introduced by wave elections is also clearly visible, indicated by the sharp spikes up for the 1994 Republican wave, and the spike down for the 2006 Democratic wave. Third, the individualistic nature of the U.S. Senate is also visible, with even Republican counties such as Duval and Brevard providing comfortable victories for Democrat Bob Graham, visible in the downward spikes in the Senate series for 1992 and 1998.

For my purposes, however, the most important trend is the narrowing of the variation in the election result, with the lines converging as we move from left to right. In Brevard County, for example, there was approximately a $70 \%$ gap between presidential and House voting in 1980; by 2004, this had narrowed to less than $20 \%$. In Broward County, a President-Congress voting gap of almost $30 \%$ had narrowed to less than $10 \%$. The other election series show similar, if less dramatic, convergence. 
In the last section, we found that the sections suggested by county-level voting for U.S. President and U.S. House of Representatives came into focus when aggregated into regional units. It follows that the different election series graphed in figure 7 should also illustrate the sectional nature of Florida when combined into regions. To simplify the analysis, and to highlight the outcome of interest, I will plot three election series, rather than six. But which elections should I compare?

If party is the cue for the vote choice, rather than candidates, then the best comparison will be between a high-intensity election, one that is likely to capture the attention and interest of the electorate, with a low-intensity election, one that is least likely to generate voter interest. Of the six election series in the multiple line graphs, it is likely that the election least likely to be followed attentively by voters is for State Agriculture Commissioner. ${ }^{35}$ As with the county level graphs, the prediction is that both the high and low intensity elections will converge.

Figure 9 displays time series charts for the winning margins for U.S. President, U.S. Congress and State Agriculture Commission by region. As in the previous section, election years are along the $\mathrm{x}$-axis, and winning vote margins along the $\mathrm{y}$-axis, and gaps in the House data series indicate missing data.

\footnotetext{
${ }^{35}$ The office of Secretary of State of Florida became an appointed position in 2002 following the 1998 reforms of the Florida Cabinet, so that data series is omitted from this study. The Chief Financial Officer of Florida is an elected position created by the same reforms, but since that data series only starts in 2002, it is also omitted from this analysis.
} 
Figure 9 Graphs of Winning Margins in Elections for U.S. President, U.S. House, and Florida Agriculture Commissioner, Between 1980 and 2006, by Florida Region

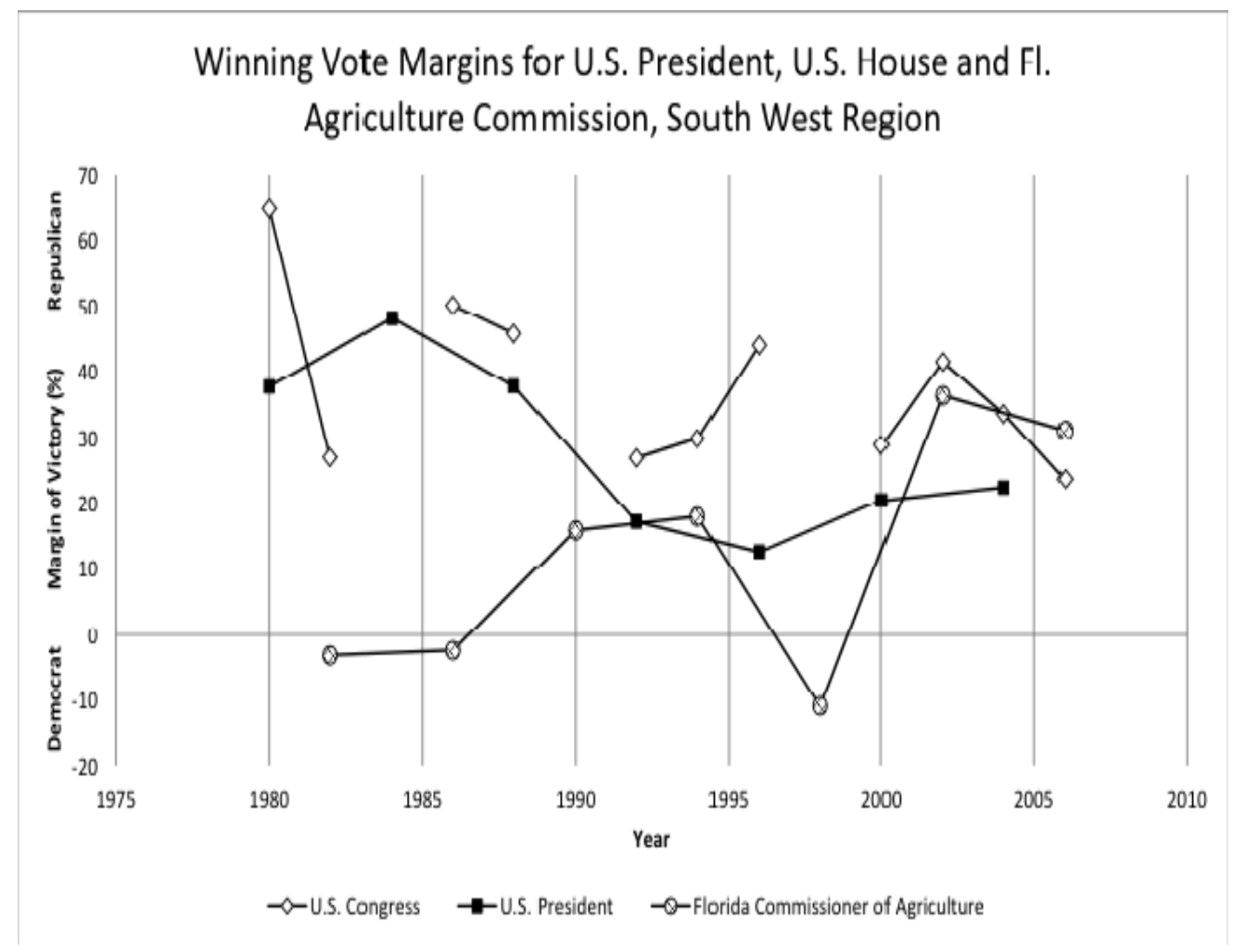




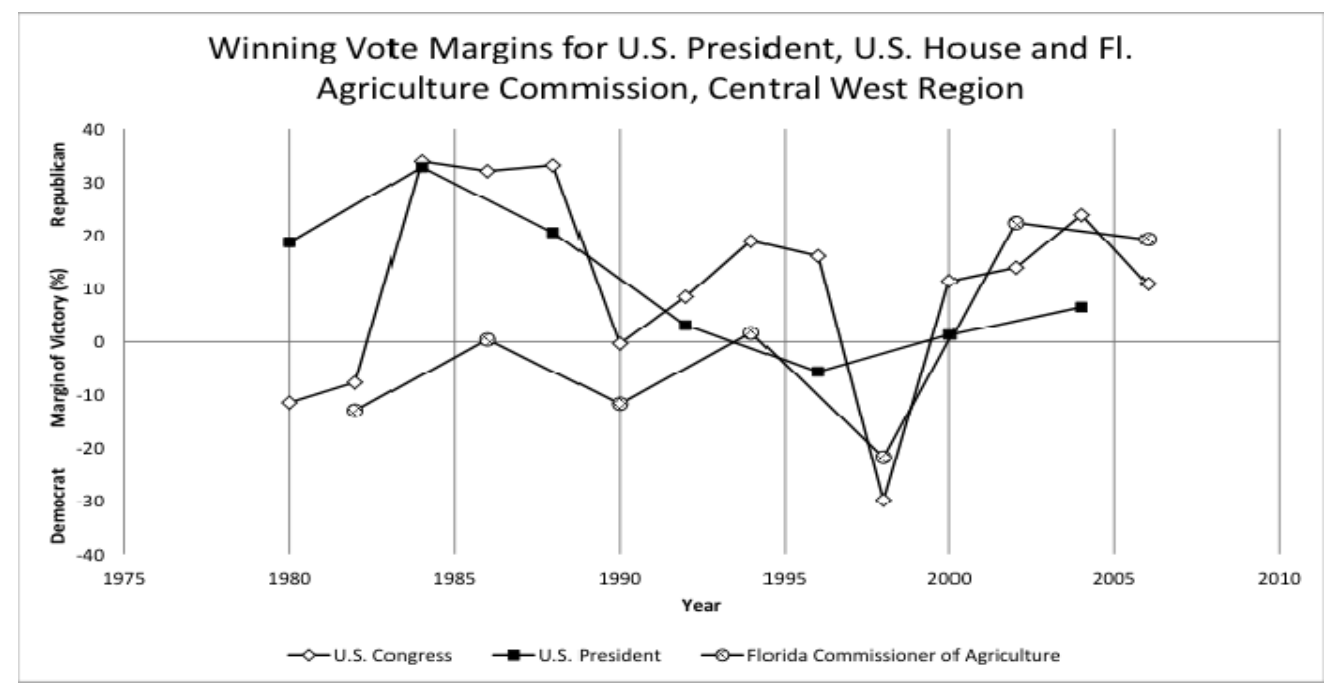

Winning Vote Margins for U.S. President, U.S. House and FI.

Agriculture Commission, South East Region

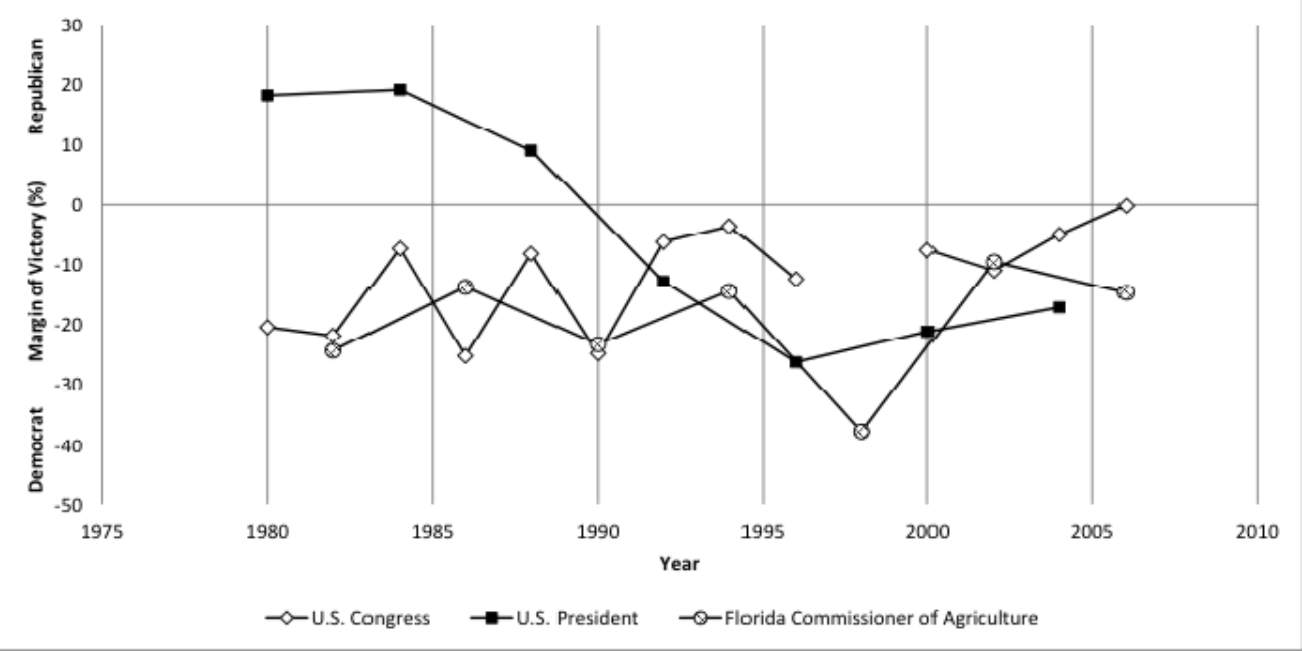




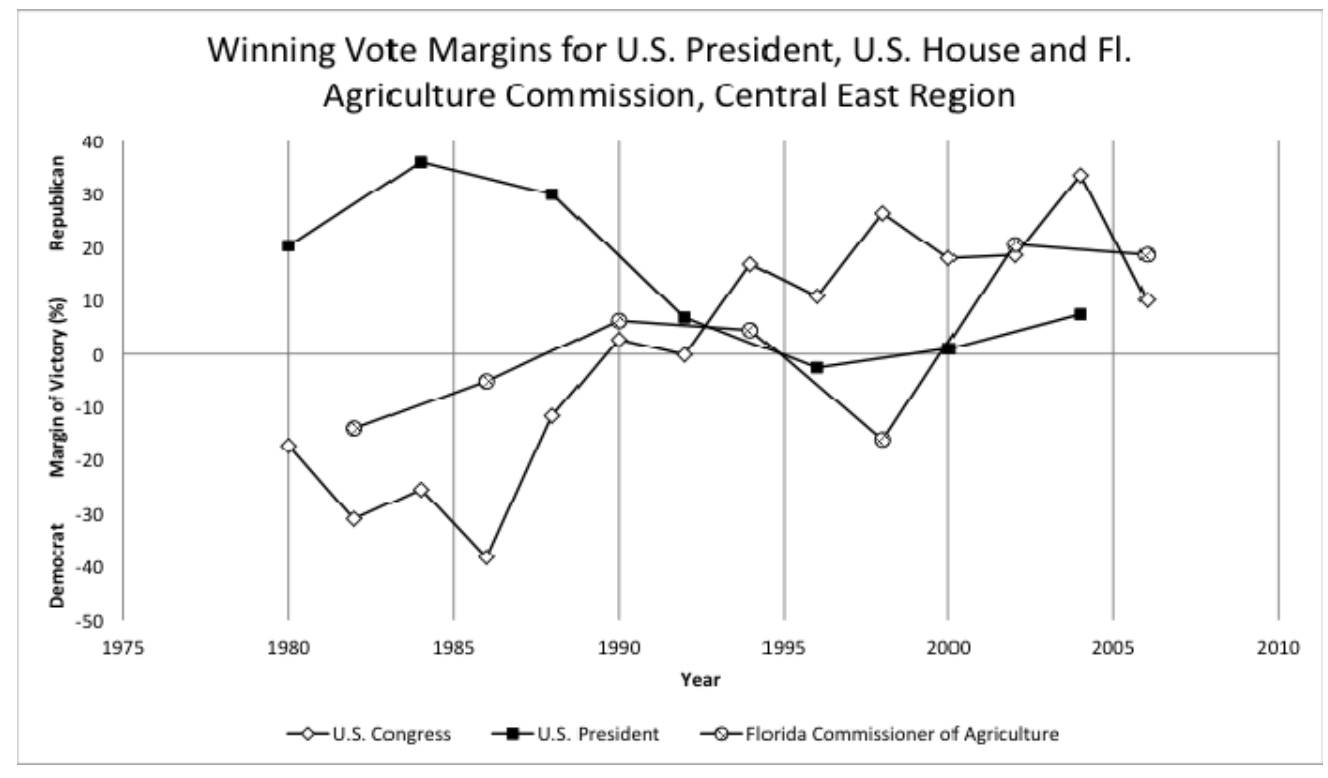

Winning Vote Margins for U.S. President, U.S. House and FI. Agriculture Commission, North West Region

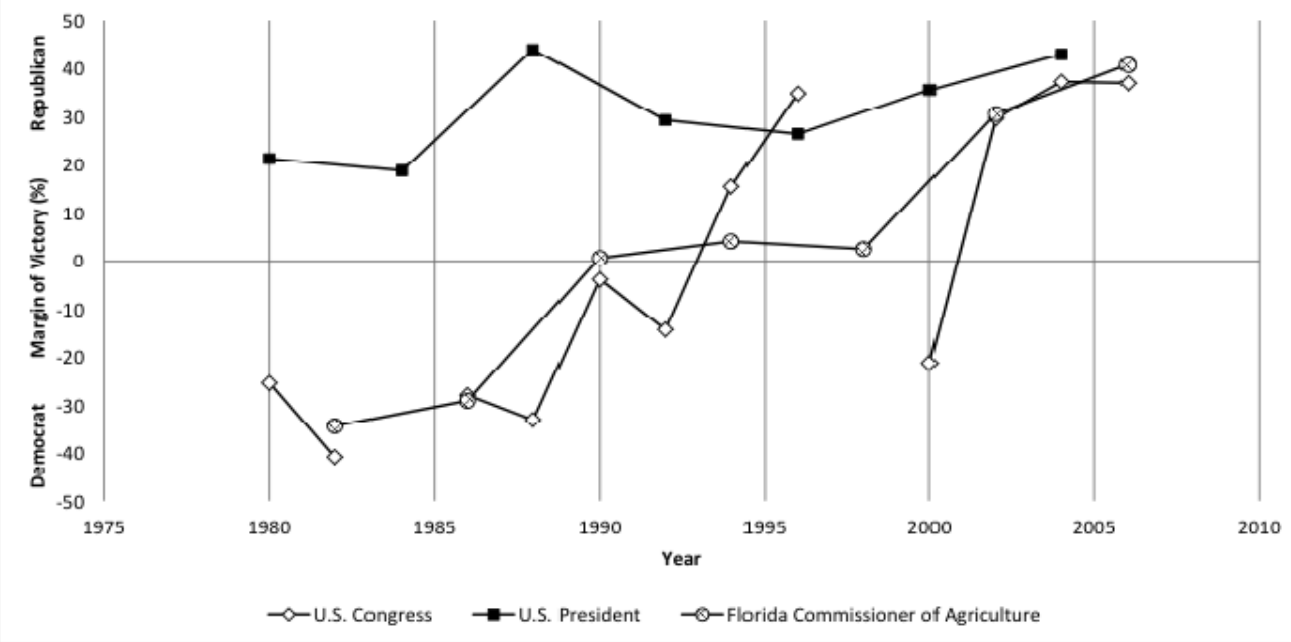



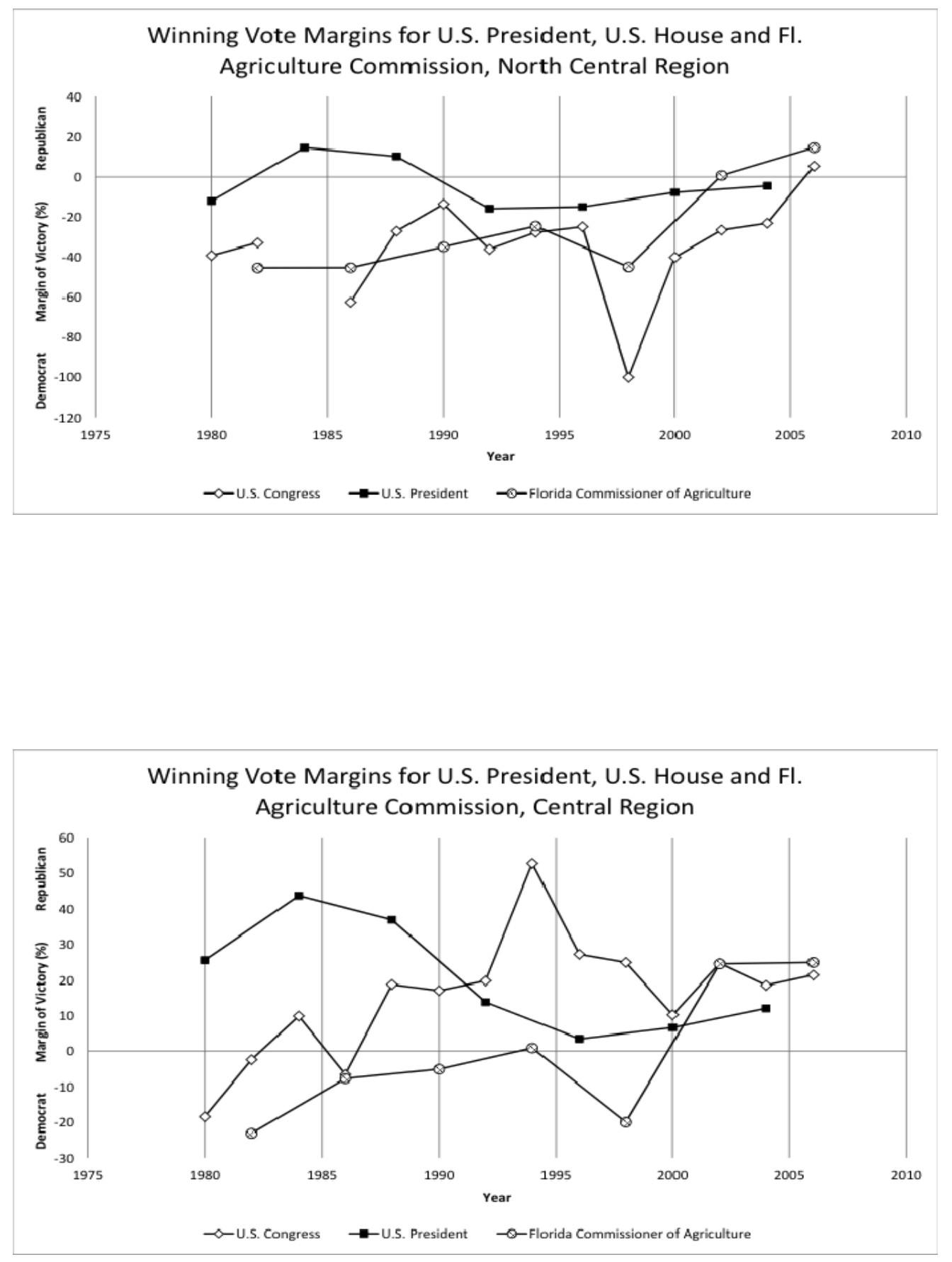


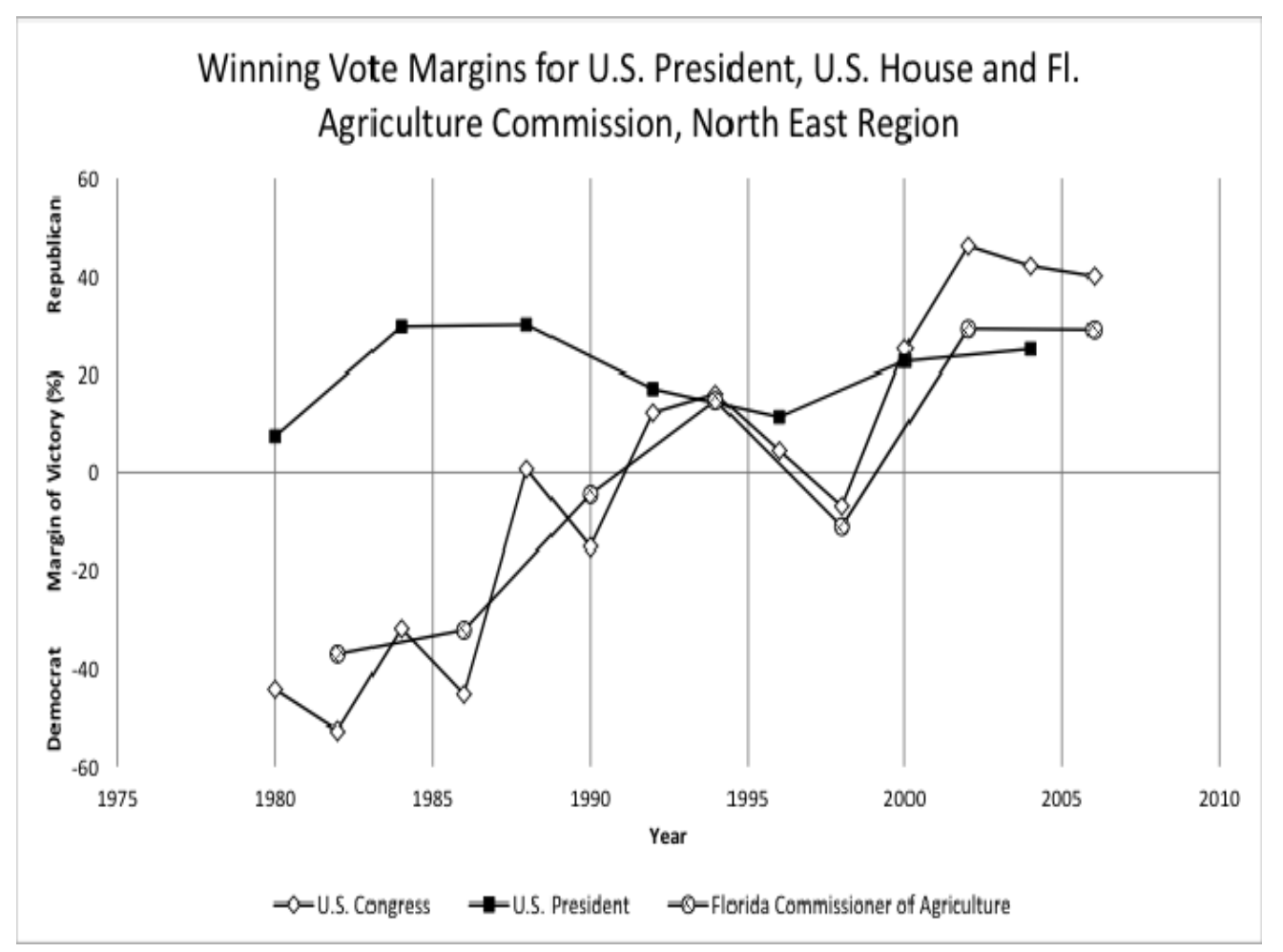

Source: Author Calculations, from Florida Division of Elections

The graphs in Figure 9 show that in every region, the election series have converged in some instances dramatically. Looking at the trend in the regions graphs over the twenty-five year time frame, we see that, from enormous divergence between presidential voting and voting for Congress and Agriculture Commissioner in the early 1980s, the series began to converge in the early 1990s, then widened over the course of the decade, perhaps reflecting divided government in Washington D.C., 
before converging again, more markedly, in the last decade. For some regions, such as Central, North Central and North West Florida, the time series for Congress and Agriculture Commissioner are almost coterminous in by 2006.

The region graphs illustrate the convergence in voting with more clarity than the county graphs. Overall, the graphs support the hypothesis that elections are increasingly driven by party identification on the part of voters.

\section{CONCLUSION}

In this chapter, I tested two hypotheses by comparing evidence against predictions implied by the hypotheses. First, the sectionalism hypotheses predicted that county election results form partisan sections. I tested this prediction with county level data, aggregated to region level, for elections for U.S. President and U.S. Congress between 1980 and 2006, and found clearly distinguishable partisan sections within Florida.

Second, the partisanship hypothesis predicted that election results for different offices over time would converge, as party eclipsed candidate or campaign as the determinant of voting. I tested this prediction with county level data, also aggregated to region level, for six different elections between 1980 and 2006, and found clear evidence of convergence of results for different elections. 
According to my theory, the two hypotheses are related because sections will contribute to party safe elections to the extent voters within a geographic section are partisans, meaning that they identify with either the Democratic or Republican or party, and take their cue regarding how to vote, in different elections, from that party identification.

My argument is that these sections explain party-safe elections, including elections for Congress. Institutional design, such as partisan redistricting, may play a part in party-safe Congressional elections, but it is not clear whether they make elections more or less competitive. It is likely that in some instances, as in Southwest Florida in the 1990s, gerrymandered districts complement sections. In other instances, gerrymandered districts appear to offset sections, as in Southeast Florida more recently. To make progress on this section-based, structural argument, I must provide an explanation of why these partisan sections exist. I turn to that task in chapter 6 . 
CHAPTER 6:

EXPLAINING PARTISAN SECTIONS IN FLORIDA 


\section{INTRODUCTION}

In the last chapter, I tested two hypotheses regarding the distribution of voters in Florida, and the role of party identification in how they vote. To describe the distribution I used election results by county and region, and I referred to these distinct and persistent distributions as sections. But how can I explain or account for these sections? That is the task I take up in this chapter. My hypothetical answer is that choices regarding where to live and the migration patterns that stem from these decision, create these sections. As in the previous chapter, I will test this theory by testing two hypotheses consistent with this claim.

I noted in chapter 2 that election scholars distinguish between short-term factors that may explain election results, such as economic conditions or campaign effects, and long-term factors, such as vote-maximizing behavior by elites, or institutional factors, such as redistricting. But it is difficult to see how short-term factors can be the cause of structures that persist across election cycles, or how elite behavior or district boundaries can account for sections that persist across over across almost a quarter century of election results, as I found in the previous chapter. My argument is that the explanation of these partisan sections, is to be found in structural feature of the electoral environment, not elites or institutions.

Of course, it is possible that the distribution of Florida voters into sections that are party-safe and sections that are competitive is merely the artifact of a random process. 
The premise of this dissertation, however, is that, these sections are not the product of chance, but that they are the product of social (structural) processes that can be identified and measured. In this chapter I seek to measure the effects of these processes using data from the decennial U.S. Census.

My strategy in this chapter, as in chapter 5, is to use empirical evidence to test certain predictions, or observable implications, that are implied by my hypotheses. In the previous chapter, my empirical data consisted of county and regional level election returns; in this chapter, the empirical data consists of U.S. census data, as well as election returns, usually calculated as an average over two or more election cycles. The analysis is this chapter constitutes one test of my proposed theory, since most hypotheses generate several possible predictions, implying several possible tests.

My emphasis on testing, as in the previous chapter, should not be viewed as an argument that testing theory is the only valid goal of social science. Much valuable scholarship is only concerned with developing and refining theory, rather than testing it. Nobel Prize winning political scientist Elinor Ostrom, for instance, is more interested in improving rational choice theories, and how they are specified, rather than for empirically testing them (Ostrom 1982, 1990). ${ }^{36}$ This study, on the other hand, takes its cue from the theoretical position that a theory that is tested is more useful than one that is not.

\footnotetext{
${ }^{36}$ This is, of course, precisely the critique of rational choice made by Green and Shapiro (2004) - that rational choice theorists do not test their theories.
} 
Having established what it is I want to test, the next question is how best to perform the test. Here the type of data that I have collected provides guidance; data that are measured quantitatively is well suited to statistical procedures. In chapter 5, I organized and presented my evidence graphically, and tested two hypotheses visually. In this chapter, I will test my hypotheses statistically, using regression analytics. Given the domain of my research question (elections for U.S. Congress), and the nature of my data (large-N, quantitative data, measured at the interval level), a statistical test is appropriate.

Statistical tests have several virtues. One virtue is that measurements made at the interval or ordinal level are likely to be less complex, less ambiguous and less contested than the categories that qualitative scholars typically seek to populate with observations (Geddes 2003). Another virtue is that quantitative researchers can often employ "off-the-shelf" indicators with which to collect observations on the variables of interest, rather than take on the burden of creating and justifying indicators $d e$ novo.

Nevertheless, statistical researchers must also address three operational issues. One is validity - are the interval or ratio level measures capturing the meaning of the concepts that are of interest? Here, the strategy of testing implications of the theory, rather than the theory itself, pays dividends. For since a theory has many implications, 
it has many possible valid variables, each representing different implications of the theory. Understood in this manner, "testing the theory" does not depend on the validity of any one variable (Geddes 2003). For instance, the dependent variable in this study can be measured as the ratio of the share of the two-party vote, or the percentage difference of the share of the total vote, and so on. The point is that more than one indicator of a concept may be valid.

A second issue in statistical tests involves the data set used for the analysis, and the possibility that the data is biased, meaning errors occur in a systematic, rather than random, manner. Bias in a data set typically results from measurement error, or from the manner in which data is sampled. In this study, I minimize the possibility of bias by gathering data for the entire population of my units of interest - Florida counties, rather than select certain counties. This avoids one source of bias, due to selection.

A third issue is spuriousness, also referred to as confounding: are the variables chosen the real cause of the outcome of interest, or is some other variable really the cause? Researchers who want to explain an outcome, as opposed to describing it, must account for alternative explanations, in some fashion. When a controlled experiment is not possible, researchers must find another means of control. This is the key challenge facing causal theories, such as this one, and thus deserves further comment. 


\subsection{Controlling for Alternative Explanations}

In the previous chapter, I noted that, to describe my domain of interest, I had to use simplifying assumptions, the inherent complexity of social reality. I did this by conceiving of elections as competition between only the two major parties, without regard to third parties, short-term electoral factors, or individual agency, creating a“ restrictive model" of elections. To explain my outcome of interest, the inherent complexity of social reality creates a different problem: any hypothesized cause may be spurious, meaning the outcome of interest may actually be caused by a different variable. The problem of spuriousness is perhaps the central theoretical challenge in constructing causal theories in social science.

If an experiment were possible, in which I randomly selected a thousand Floridians, so that various structural or demographic attributes were evenly distributed among this sample, and offered them the opportunity to move anywhere in Florida they chose, with all inducements necessary to make them do so, and observed both where they chose to live, and how they voted before and after the move, I would be able to draw conclusions about residential choice and partisanship, without recourse to multivariate statistics, or statistical controls. Obviously, such an experiment is impractical.

So in order to make the case for a certain variable as the cause of partisan sections, I need to account for alternative explanations in some other way. If researchers use 
statistical control to account for alternative explanations, they typically resort to regression analysis, a multivariate statistical method based on identifying correlations among variables of interest, where certain variables are adopted as "control variables". The logic of multiple regression is no different from the method used by qualitative researchers to control for alternative explanations: they compare units that are similar in as many respects as possible, the better to identify the variables that differ, and are thus likely to be the cause of the outcome of interest. Statistical control, however, derives from mathematical manipulation, rather than empirical observation (See Appendix C). In this chapter, I will test my theory by examining the influence of my key causal variables, ones that measure household migration, and other variables that logic or the scholarly literature indicates could influence my outcome of interest - the two-party vote breakdown.

Quantitative researchers using multivariate statistics seek to improve the accuracy of their results by expanding the number of independent variables. This makes it less likely that a possible causal variable has been omitted. But if the number of independent variables is increased, scholars must also increase the number of observations, not only because there are more variables on which values must be collected, but also because more observations increase the likelihood that any observed relationships between variables are a result of systematic relationships, rather chance or randomness. Expanding the set of observations without compromising data quality is thus a primary goal in quantitative research. 
In this section, I will specify the variables that I employ for my regression models. By specifying, I refer to theoretical definitions, which identify variables that, ideally, represent the concepts of interest, and operational definitions, which describe how the variables are measured, and where such measurements (or observations) are made. I will end the section with a brief discussion of the type of multiple regression that I will employ - ordinary least squares, or linear, regression, and the key assumptions that it makes.

\subsection{The Dependent Variables}

The purpose of my regression models is to measure how much different variables, measuring demographic features of the electorate, contribute to the two-party vote breakdown, at the county level, in election results for U.S. President and the U.S. House of Representatives. Specifically, I want to explain variation in the average winning margin, expressed as a percentage of the total votes received by the two parties, for the Republican or Democratic Party candidate, in elections measured a decade apart. Thus the dependent variable consists of interval level measures, expressed in percentages, and measured using the county as the unit of analysis. 
As in the previous chapter, I measure the dependent variable by taking the average value from two adjacent U.S. presidential elections, or from three successive U.S. House elections, rather than a single election. This averaging smoothes out period effects that might bias the results of any one election, such as the unusually high third party vote in the 1992 presidential election, or the unusually strong wave of support for the Republican Party in the 1994 mid-term elections, or for the Democratic Party in the 2006 mid-terms. For House election data, averaging also smoothes out the bias from the presidential coattails that favor the party of the winning presidential election years. Thus the average election result generates more reliable estimates of my dependent variable, of partisanship at the county level at a particular point during each decade. $^{37}$

I derive four averages that serve as the dependent variable (DV) in the four models in this section. The first two models examine voting for President. For the first model, the DV is the average of the winning margin of the two-party vote from the 1988 and 1992 presidential elections, calculated at the county level. For the second model, the DV is the average of the winning margin of the two-party vote from the 2000 and 2004 presidential elections. The next two models examine voting for the U.S. House of Representatives: for the third model, I the DV is the average of the winning margin from the House elections of 1988, 1990, and 1992, while for the fourth model, the DV is the average from the U.S. House elections of 1998, 2000, and 2002. In this chapter, the analysis only uses House election results from those elections in which

\footnotetext{
${ }^{37}$ Political analysts such as Charles Cook follow a similar procedure. Cook uses the average of the two trailing Presidential elections to calculate the ideology index for Congressional districts and states.
} 
both the Republican and Democratic Parties nominated a candidate, since the premise of my study is that voters identify with one of the two major parties, and that this stable, individual level partisan identification is the source of partisan sections at the aggregate level.

\subsection{The Independent Variables}

Recall that my theory is that residential choices are contributing to partisan sections, and that this sectionalism in turn contributes to the party-safe elections I described in the previous chapter. In order to test this theory, I need to identify variables that will represent migration patterns; in order to establish that migration patterns account for party-safe section, I need to control for alternative explanations. In the next subsection, I identify the variables that represent those alternative explanations. These migration variables and the control variables constitute, in toto, the independent variables that are employed in the statistical analysis in this chapter.

\section{Key Causal Variables}

Given my theory is that people moving into Florida from out of state are a cause of partisan sections, the key variables of interest involve measures of migration into and out of Florida counties. One observable implication, or prediction, from this theory, is that the more a county experiences in-migration, the more it is likely to change in partisan composition or profile, including becoming more party-safe for one or other 
of the two main parties. To represent migration patterns, variables are derived from items in the decennial U.S. Census, questions that ask respondents whether they lived in a different house five years earlier, and, if so, whether the previous residence was in the same state, or a different state. These are my key causal variables, and they are summarized in Table 1, which includes sample data for the variables from MiamiDade county and Escambia county.

Since constants cannot explain variation in the dependent variable, I need some indication that the values of my key causal variables do indeed vary, that measures of migration across the units of analysis (Florida counties) are not uniform. The values for Miami-Dade and Escambia Counties illustrate some of this variation. According to responses to the 1990 Census, approximately twice as many Escambia County residents lived in a different county five years earlier (24.5\%) as did Miami-Dade County residents (11.3\%), with similar difference for those living in a different state five years earlier (19.4\% to 9\%). Almost five times as many Miami-Dade County residents, however, lived in a different country five years earlier $(9.4 \%)$ than did Escambia County residents (2\%). A cursory examination of other counties displays similar variation. This gives me confidence that my variables do vary. 
Table 8 Residence of County Population, Five Years Earlier, as a Percentage of the County Population 5 yrs of Age and Older, in 1990.

\begin{tabular}{|c|c|c|}
\hline \multirow[t]{2}{*}{ Variable } & \multicolumn{2}{|c|}{ Percentage of County Population } \\
\hline & Miami-Dade & Escambia \\
\hline Same house 5 yrs ago & $45.8 \%$ & $47.9 \%$ \\
\hline Different house 5 yrs ago & $44.7 \%$ & $50.2 \%$ \\
\hline Same county & $33.5 \%$ & $25.7 \%$ \\
\hline Different county & $11.3 \%$ & $24.5 \%$ \\
\hline Same state & $2.3 \%$ & $5.0 \%$ \\
\hline Different state & $9.0 \%$ & $19.4 \%$ \\
\hline Outside U.S. & $9.4 \%$ & $2.0 \%$ \\
\hline
\end{tabular}

Source: 1990 U.S. Census

For the 1990 census, the U.S. Census Bureau also asked respondents who had migrated during the last five years from a different state, to identify whether they came from the Northeast, Midwest, South, or West region. These data were included in the two models using the 1990 Census data. Unfortunately this follow-up question was not asked in the 2000 Census, and thus cannot be included in the two models using the 2000 Census data.

\section{Control Variables}

A control variable is one that is associated with the DV but which we want to hold constant or "control" so we can examine the influence of the variables of greatest 
interest (in this instance, those that appear in Table 1 above). In this study, the control variables are chosen to represent racial, income, education, national origin, and occupation differences among the county populations, variables that many scholars believe affect and influence the vote choice and American elections. The values of all these variables were derived from decennial U.S. Census for 1990 and 2000.

One group of variables represents race. Here, I break down the population into three racial categories: white, black, and Hispanic. It is possible to drill down farther into the racial categories, but I do not disaggregate Hispanic into Cuban, Mexican or Puerto Rican, for two reasons. First, whereas such differentiation is relevant for some counties, such as Miami-Dade and Orange, it is not (yet) relevant for the vast majority of Florida counties, the high rates of immigration notwithstanding; these other racial and ethnic sub-divisions are not pervasive enough across the state to warrant further disaggregation. One reason for this is that many Florida counties are small in population. Second, this level of granularity is simply not necessary or relevant to my research question, or my theory. For the purposes of my regression analysis, I need variables that are significant across all units, not just variables relevant to a few.

A second group of variables represents class. As I have noted, class is a multidimensional concept, and political scientists typically use three indicators of class: income, education, and occupation. One strand in the political science literature suggests that more education is positively correlated with Democratic voting (Abramowitz 2008). In this education approach to class, possession of a four-year 
college degree is often considered a cut-off or standard for distinguishing working class from middle class. The variable "percentage of the population over 25 years of age with a college degree" is used to represent this class concept.

Another strand in the literature argues that income is the relevant dimension of class for electoral behavior; the hypothesis here is that higher income is positively correlated with Republican voting. I use the variable average household income to represent this concept. Yet a third approach states that occupation is the important dimension, partly because of the link between some occupations and level of education attained. To control for this interpretation of class, I include a group of variables that represent labor force characteristics: "the percentage of the labor force over 16 years of age employed in government sector", "the percentage in professional and managerial services, and the percentage in armed forces". The first variable addresses the public sector/private sector divide, the second address the white collar/blue collar divide, and the third addresses the military/civilian divide.

A third group of variables represents immigrants. Like class, this is not a straightforward concept. First, how will I define an immigrant? Those who are newly arrived cannot vote, so I need to be mindful of that, since I am interested in variables that affect election outcomes. In this study, I define immigrant in two ways: linguistically, to identify those of a different national origin, and birthplace, to identify those who moved to Florida from elsewhere, within the U.S. or without. Together, these two variables, operationalized in the U.S. Census as "the percentage 
who speak other than English at home" and "percentage of the total population born in Florida", represent the density of the non-native population.

Second, do immigrants behave in a distinctive manner when voting? If they do not, there is little value added by including them in the model. It is surely inaccurate to conceive of immigrants as a politically monolithic voting block within the American electorate, all preferring one specific party. Moreover, even immigrants who with the same national origin may vote differently: Cubans in Miami and Cubans in New Jersey do not necessarily vote the same way, and Mexicans in Texas do not necessarily vote the same way as Mexicans in California.

Nevertheless, it is a valid generalization that historically certain racial and ethnic groups have identified with one or other party, such as the Cubans and the Republican Party, and Puerto Ricans with the Democratic Party. As a consequence, it is prudent to control for immigration in some way, in case immigrant concentration has sectional consequences. Moreover, it is likely that immigrant status may be a proxy for certain values or policy preferences, especially regarding welfare. Then, since immigrants are not distributed evenly or randomly across the political landscape, but congregate in gateway cities and increasingly, gateway suburbs, there are grounds for controlling for the distribution of immigrants in examining the causes of sectionalism.

A fourth group of controls represent population density. As I noted in the literature review in chapter two, some scholars have found that the more densely populated 
areas, such as metropolitan population centers, tend to correlate with Democratic partisan strength, whereas less densely populated areas correlate with greater Republican Party voting (Lang and Sanchez 2008). It is plausible that density is a proxy for the demographic composition of the resident population: immigrants, for instance, are more likely to converge in crowded gateway cities, rather than in small towns or rural areas. Since this compaction may be due to necessity, rather than choice (immigrants who lack language skills require in-group immigrant networks for survival) I use the variable "mean travel time to work" to measure density, since this definition captures the intention or choice made by the native population, to live in a less dense area, as opposed to necessity imposed upon non-English speaking immigrants.

Two final control variables are county median age and the proportion of nontraditional households. I include median age of the county in my analysis because some researchers believe the elderly are more likely to turnout to vote, and thus if the elderly do identify with one specific party, then this higher elderly turnout will influence sectionalism; if they do not display any partisan bias, then their higher turnout will be a wash with respect to its impact on partisan sections. Although there is no consensus on partisan bias among the elderly in the literature (Kaufman et al. 2008), I control for this variable because of the high proportion of elderly and retired in the Florida population, which increases the possibility that this variable may matter for Florida election outcomes. 
A final control variable I include is the "proportion of households headed by females with children" (i.e. single mothers). This variable does double duty: it is one measure of the broad category of "non-traditional households", which also includes same sex couples, and it is also a measure of the "gender gap", which some observers claim to be a factor in American elections and partisan identification. Some scholars argue that non-traditional households tend to be Democratic in party orientation, whereas others argue that women are more likely to vote Democrat, although this gender gap, to the extent it exists, may be narrowing (Kaufman et al. 2008). In short, there is reason to include a measure of gender as a control variable. The full list of control variables used in the regression analysis is presented in Table 9.

\subsection{Transforming Non-linear Variables}

For linear regression, the fundamental assumption is that the values on the variables are normally distributed - that is, that the distribution of the variables, for different units, resembles a bell-curve shape. If a variable does not have this distribution or shape, the probability estimates generated by the ordinary least squares regression analysis are not accurate or trustworthy. So the first step is to check that variables are distributed in a manner appropriate for linear regression.

Two statistics are typically reviewed to determine whether data is normally distributed: skew and kurtosis. Skew is the degree to which the curve is symmetrical or not, while kurtosis is the degree to which the curve is either more pointed or flatter 
than the prefect normal distribution. Since many of the control variables are not normally distributed, they were transformed before being entered into the regression models. Transforming a variable makes its distribution more symmetrical, or "normal", and renders the variable more suitable for linear regression (See Appendix E). After transformation, skew and kurtosis values for all transformed variables were checked to ensure these values were within a range of -2 to +2 , which constitutes acceptable values for approximating normally distributed variables. ${ }^{38}$

\footnotetext{
${ }^{38}$ In general, the lower the absolute values of skew and kurtosis, the more effective the transformation. Values between -1 and +1 are excellent; values between -2 and +2 are good/acceptable. Values lower/higher than $-5 /+5$ are problematic.
} 
Table 9 Control Variables Deployed in OLS Regression Models

\begin{tabular}{|c|c|c|}
\hline Variable & Measurement Unit & Variable Type \\
\hline Total Population & Raw number & Continuous \\
\hline Percent White & Percentage & Continuous \\
\hline Percent Black & Percentage & Continuous \\
\hline Percent Hispanic & Percentage & Continuous \\
\hline Median Age & Raw number & Continuous \\
\hline Median $\mathrm{HH}$ income & U.S. Dollars & Continuous \\
\hline Percent Families below poverty level & Percentage of all families & Continuous \\
\hline Percent College degree or higher & Percent of pop 25 yr \& above & Continuous \\
\hline Persons in Labor Force & Percent of pop 16 yrs \& above & Continuous \\
\hline$\%$ in Gov't sector & $\%$ of lab force 16 yrs $\&$ above & Continuous \\
\hline$\%$ Prof. and Managerial sector & $\%$ of lab force 16 yrs $\&$ above & Continuous \\
\hline$\%$ in Service sector & $\%$ of lab force 16 yrs $\&$ above & Continuous \\
\hline$\%$ in Agricultural sector & $\%$ of lab force 16 yrs $\&$ above & Continuous \\
\hline \% in Manuf, Constr, Repair sector & $\%$ of lab force 16 yrs $\&$ above & Continuous \\
\hline Percent in Armed Forces & $\%$ of lab force 16 yrs $\&$ above & Continuous \\
\hline Percent Born in Florida & $\%$ of total county population & Continuous \\
\hline Percent Foreign Born & $\%$ of total county population & Continuous \\
\hline Percent Speak other than Eng. at Home & $\%$ of total county population & Continuous \\
\hline Population Density & Persons per square mile & Continuous \\
\hline Mean Travel Time to Work & Minutes & Continuous \\
\hline $\begin{array}{l}\text { Percent Female Head \& Children under } 18 \\
\text { yrs }\end{array}$ & $\%$ of total households & Continuous \\
\hline
\end{tabular}

Source: U.S. Census Bureau 
The first model, "Pres1990", uses the average winning margin of the two-party vote from the 1988 and 1992 U.S. presidential elections as the dependent variable, regressed against variables derived from the 1990 Census data. The second model, "Pres2000", uses the average winning margin of the two - party vote from the 2000 and 2004 U.S. presidential elections as the dependent variable, regressed against variables from the 2000 U.S. Census. The third model, "House1990", uses the average winning margin two-party vote share from the 1988, 1990, and 1992 U.S. House elections as the DV, regressed against variables from the 1990 U.S. Census. The fourth and last model, "House2000", uses the average two -party vote share from the 1998, 2000, and 2002 U.S. House elections as the DV, regressed against variables from the 2000 U.S. Census.

With four models, rather than one or two, I can compare the results for presidential voting with the results for U.S. House elections. This President/Congress vote comparison can shed light on the role of partisanship in Florida elections. In addition, repeated tests will generate a more precise estimate of the effect of my key causal variables on the DV. This iterative process, in which the same independent variables are regressed against different but related dependent variables, constitutes a sensitivity analysis, a method of enhancing confidence in the statistical estimates. ${ }^{39}$

\footnotetext{
${ }^{39}$ Sensitivity analysis involves re-classifying cases or re-scaling the dependent variable to see if it changes the result of the analysis. See, inter alia, Geddes (2003)
} 


\subsection{The Analytic Strategy: Correlation and Regression Coefficients}

My analytic goal is to build four parsimonious regression models, in which the DV is regressed against the fewest number of variables; the fewer the explanatory variables, the more powerful the theory. Thus my analytic strategy is winnow down the number of independent variables (key causal variables and control variables) such that the final model is spare and parsimonious, and explains as much variation in the outcome as possible with the fewest independent variables. ${ }^{40}$ The first step in this process of is to examine correlations between the independent variables and the dependent variable (the winning margin of victory at the county level) - to examine whether the control variables are actually related to the dependent variable. This is done using the Pearson correlation coefficient, a statistic that describes the degree to which two variables are related, without taking into account the influence of other variables.

If an independent variable is not correlated with the dependent variable, or outcome of interest, then it is very unlikely that the variable will predict variation in the outcome. Accordingly, including such uncorrelated variables in the regression model will not be useful, but will instead add to the "noise" in the model, and make it less parsimonious, and less powerful. ${ }^{41}$ If, however, the Pearson statistic showed that a

\footnotetext{
${ }^{40}$ Methodologists consider theories with fewer explanatory variables to be more "powerful" than a theory with more explanatory variables. See, inter alia, King et al. (1994).

${ }^{41}$ This assumes there are no interaction effects, and that there are no suppressor variables that are hiding the effect of one variable on another. But since a model should be no more complicated than it needs to be to answer the research question, I set aside such possibilities for the purposes of this study.
} 
variable was significantly correlated with the winning vote margin, then that variable was selected as a control variable.

In the next stage, the selected variables are entered into a multiple regression model, in order to identify those variables that are the best predictors of the winning vote margin. This is done using the regression coefficient, a statistic that describes the degree of association between two variables, taking into account ("controlling for") the influence of other variables included in the analysis. ${ }^{42}$ This approach allows me to select a parsimonious set of variables as control variables, and to build a regression model with fewer independent variables relative to the number of observations.

After identifying the most statistically significant control variables to be included in the final model, I repeat the process with the migration variables - my key causal variables. Those migration variables that are significantly correlated with the vote outcome are combined with the selected control variables to become the inputs for the final regression models. This process was repeated for each of the other three models: “Pres2000”, "House1990”, and "House2000”.

\footnotetext{
${ }^{42}$ A control variable is one that is related to the DV but which we want to hold constant or "control" in order to examine the effect of other variables.
} 


\subsection{Results for Model "Pres1990"}

First, Pearson correlation coefficients were generated to find the variables that were most closely associated with the two party vote break down. These correlations indicated that three variables - the percentage of population that was white, the county median income, and the percentage of the county labor force in the armed forces were positively correlated with increased Republican share of the average two-party presidential vote in 1988/1992. The reverse was true, however, for the percentage of population below the poverty line and the percentage of population that was black, which were associated with increased Democratic share of the two-party vote for president in 1988/1992.

In the second stage, these five statistically significant variables were entered into a multiple regression model to see which of these five variables best predicted the DVthe two-party vote breakdown. There were two such variables: the "percentage of population that is white", and the "percentage of labor force in the armed forces". These two variables were selected as the control variables to be entered into the final regression model, alongside the key causal variables.

Repeating the same steps with the key causal variables of interest - the residency variables, I identified the residency variables that are correlated with the two-party presidential vote breakdown in the county. There are two such variables: the percentage living in a different state five years earlier (in 1985), and the percentage 
living in the South or West regions of the U.S. These three migration variables were positively associated with the Republican share of the two-party vote. The two control variables and the three migration variables were then entered into the final regression model. The coefficients from the final model are displayed in Table 10 below.

Table 10 Results of OLS Regression of Republican Average Winning Margins from U.S. Presidential Elections of 1988 and 1992, by 1990 U.S. Census Variables

\begin{tabular}{lccc}
\hline \multicolumn{1}{c}{ Variable } & Beta $^{*}$ & Standard Error & p-value \\
\hline $\begin{array}{l}\text { \% of Pop. lived elsewhere in the } \\
\text { South, five years earlier }\end{array}$ & 2.73 & 1.02 & 0.001 \\
$\begin{array}{l}\text { \% of Pop. lived in Diff State, five } \\
\text { years earlier }\end{array}$ & -0.48 & 0.26 & 0.07 \\
$\begin{array}{l}\text { \% of Pop. White } \\
\text { \% of Labor Force in Armed Forces }\end{array}$ & 0.86 & 0.20 & $<0.001$ \\
\hline $\begin{array}{l}\text { \% of Pop. lived in Western U.S., five } \\
\text { years earlier }\end{array}$ & -3.33 & 3.29 & 0.29 \\
\hline
\end{tabular}

* Unstandardized coefficients

Source: Author Calculations, from 1990 U.S. Census and Florida Division of Elections Data

The test results from the model indicate that the two control variables (percent pop that is White, and \% Labor Force in Armed Forces) by themselves explained 37.2\% of the variation in the presidential vote breakdown, while the three migration variables explained a further $7.8 \%$ of the outcome. Together, these five variables explained $45 \%$ of the variability in the average two-party vote breakdown for the 
presidential elections of 1988 and 1992. Of these five variables, the two best predictors of increased Republican voting were increases in the white population, and increases in the proportion of the residents who were from out of state - particularly from other counties in the South. The remaining variables did not contribute individually in a significant manner to the variation in the dependent variable.

Substantively, the results support the hypothesis that migration patterns are contributing to political sectionalism and party-safe elections. The "Pres1990" model indicates that Florida counties with more in-migrants from other states, particularly from the Southern U.S., were more likely to vote Republican in the presidential elections of 1988 and 1992. If migration patterns into a Florida county explain approximately $8 \%$ of the vote, as this model suggests, then migration effectively made what would otherwise have been competitive elections at the county level into safe elections - boosting the winning margin to $10 \%$ or more. In short, the "Pres1990" model indicates that migration does influence county level voting for the two parties. To gain more leverage on this claim, I next repeat the modeling using data from the 2000 U.S. Census.

\subsection{Results for Model "Pres2000"}

By going through the same steps as before, I can build a second model, regressing the average of the winning margin for the presidential elections of 2000 and 20004 
against observed values from the 2000 U.S. Census. Unfortunately, region of origin was not available in this Census, unlike the 1990 Census, so the key causal variables of interest, the migration variables, do not have the same level of detail.

As before, I begin by examining statistical associations between potential control variables and my outcome of interest, the average county level two-party vote breakdown from the U.S. presidential elections held in Florida, using the Pearson correlation coefficients. This time, the variables that appear most statistically significant are the percentage of the county population that is white, and the percentage of county labor force in manufacturing, with increases in both these variables being associated with increased share of the two-party vote going to the Republican presidential candidate.

Negative correlations were found with the percent of the population that was black, the percent of the population that was Hispanic, the percent of the labor force that was professional/managerial, the population density, the percent of the population speaking a language other than English at home, and the percent of the population that was foreign-born. Increases in the values of these variables were associated with a lower county propensity to vote Republican for U.S. President in 2000 and 2004, and a higher share for the Democratic candidate.

As in the first model, stepwise regression was used to identify which among these variables were the best predictors of the vote outcome, the better to create the most 
parsimonious model. Three covariates that emerged as significant predictors of the two-party vote breakdown: the percentage of the population that was white, the percentage of the labor force in manufacturing, and the population density. These three variables were selected as the control variables for the final regression model.

The third, penultimate stage of the modeling process was to examine the Pearson correlations between the key causal variables, the residency variables, and the vote breakdown. These correlations showed that average winning margin from 2000/2004 U.S. presidential elections was negatively associated with the percentage of people living in a different house in the same county, and positively associated with the percentage of people living in a different house in a different county but within Florida. In other words, counties where voters had changed residence within the county in the last five years were more Democratic in presidential voting, whereas counties where voters moved from another county five years earlier were more Republican in presidential voting.

In the fourth and final step, the two migration variables were combined with the previously selected control variables, and enter the variables into the final regression model, to determine the independent effect of these variables on the average winning margin from the 2000/2004 presidential elections taken together. The regression coefficients are summarized in Table 11 below. 
The model indicates that the three control variables (percent white, percent in manufacturing, and population density) explain $42.7 \%$ of the variability in two-party vote margin. With respect to the direction of the effects, increases in the white population, a greater proportion of the labor force in manufacturing, and lower population density predicted greater Republican voting at the county level in elections for President in 2000/2004. The percent living in a different house within the same county, and different house in a different county in Florida, explained an additional $0.9 \%$ of variability - an increase that was not statistically significant. Thus the migration variables were redundant in this model, and did not contribute much individually to explaining the vote breakdown.

Table 11 Results of OLS Regression of Republican Average Winning Margins from U.S. President Elections of 2000 and 2004, by 2000 U.S. Census Variables

\begin{tabular}{lccc}
\hline \multicolumn{1}{c}{ Variable } & Beta* & Standard Error & p-value \\
\hline \% of Pop. White & 0.98 & 0.24 & $<0.001$ \\
\hline $\begin{array}{l}\text { \% of Labor Force in } \\
\text { Manufacturing }\end{array}$ & 1.14 & 0.48 & 0.02 \\
\hline $\begin{array}{l}\text { Population Density } \\
\text { \% of Pop. lived in diff. House, } \\
\text { same County, 5 years earlier }\end{array}$ & 0.77 & 0.35 & 0.02 \\
\hline $\begin{array}{l}\text { \% of Pop. lived in diff. House, } \\
\text { diff. Fl. County, 5 years earlier }\end{array}$ & 0.51 & 0.82 & 0.35 \\
\hline
\end{tabular}

* Unstandardized Coefficients

Source: Author Calculations, from 2000 U.S. Census and Florida Division of Elections Data 
So in sum, the percent of residents who are white, the percent of labor force in manufacturing, and population density were the only significant predictors of the county two-party winning margin in voting for U.S. President in Florida counties in 2000 and 2004. What were the differences between the two models, "Pres1990" and "Pres2000"? One difference is that labor force participation in the manufacturing sector, and population density, were not significant predictors in the 1990 model. The most significant difference, however, is that the migration variables are not significant predictors of the two-party vote in the "Pres2000" model.

Does this mean migration patterns had no influence on the vote breakdown? Not necessarily, for recall that whether a significant proportion of voters lived in another county or another home five years earlier was clearly associated with the vote breakdown in the 2000 model. This relationship between migration and voting is suppressed, however, once we control for the percent of the population that is white and population density. One possible explanation for this finding is statistical: county racial composition and county density are sufficiently correlated with the migration and residential patterns, and the association between residential mobility and voting in the 2000 model is so strongly associated with counties that are overwhelmingly white, and sparse, that these two variables predict both voting behavior and residential choice, rendering the residency variables redundant.

Another explanation is substantive, rather than statistical: Florida's partisan sections were essentially established by the 1990s, such that further migration no longer made 
a meaningful unique impact on these pre-existing sections, as expressed in the vote breakdown. Such a development would explain why the migration variables do not move the needle in the models using 2000 Census data. This explanation is supported by the distributions I described in the previous chapter. I will return to this issue in section.

Given that my hypothesis is that residential choice and migration patterns are creating sections that make elections party-safe, regardless of redistricting, I need to perform a similar analysis for elections for the U.S. House of Representatives. Here I will use average winning margins from successive House elections, reconstructed as county level results. This exercise will not only shed light on the relationship between migration and House elections, but also provide greater leverage on the research question, and depending on the results, either provide further empirical support for my theory, or disconfirm it.

\subsection{Results for Model "House1990"}

For the first model using House elections, "House1990", the dependent variable is the average of the winning vote margins, from each Florida Congressional district, for the 1988, 1990, and 1992 elections for U.S. House, reconstructed as county level results. As before, the first step is to examine correlations between my independent variables 
and the DV. This generates several statistically significant variables, which are summarized in Table 12.

Table 12 Correlations (r) between Republican Average Winning Margins from U.S. House Elections of 1988 - 1992, and 1990 U.S. Census Variables

\begin{tabular}{|c|c|c|}
\hline Variable & $\mathbf{r}$ & p-value \\
\hline Total Population & 0.27 & 0.045 \\
\hline White $\%(\mathrm{~T})$ & 0.51 & $<0.001$ \\
\hline Black \% (T) & -0.59 & $<0.001$ \\
\hline Hispanic (non-White) $\%(\mathrm{~T})$ & 0.37 & 0.002 \\
\hline Median Age & 0.52 & $<0.001$ \\
\hline Median Household Income & 0.37 & 0.003 \\
\hline$\%$ Below Poverty Level & -0.59 & $<0.001$ \\
\hline$\%$ College Educated & 0.14 & 0.26 \\
\hline Government \% & -0.65 & $<0.001$ \\
\hline Professional / Managerial \% & 0.06 & 0.64 \\
\hline Services $\%(T)$ & -0.22 & 0.07 \\
\hline Agricultural \% (T) & 0.02 & 0.89 \\
\hline Manufacturing \% & -0.13 & 0.29 \\
\hline Armed Forces \% $(\mathrm{T})$ & -0.13 & 0.29 \\
\hline Born in FL \% & -0.66 & $<0.001$ \\
\hline Foreign Born \% (T) & 0.46 & $<0.001$ \\
\hline Population Density (T) & 0.26 & 0.03 \\
\hline
\end{tabular}




\begin{tabular}{lcc}
\hline Travel Time to Work (min.) & -0.14 & 0.28 \\
Speak Other than English \% (T) & 0.41 & 0.001 \\
Female Head of Household with Children \% & -0.60 & $<0.001$ \\
\hline
\end{tabular}

$\mathrm{T}=$ transformed variable.

Source: Author Calculations, from 1990 U.S. Census and Florida Division of Elections Data

In the second step, I selected the variables most correlated with the vote breakdown, and regressed them against the county level vote outcome, to find the best predictors of the vote breakdown. Three variables best explained variability in the dependent variable: "the percentage born in Florida", "the percentage of the labor force working in government", and "the total county population"; the other variables were not significant predictors. These three significant covariates were selected to be control variables for the final regression model.

In the third step, correlations between my key causal variables of interest - the migration variables - and the election results were examined. The vote breakdown was significantly and positively associated with the percentage of people living in a different state five years earlier (in 1985), and the percentage living in the Northeast or Midwest in particular - meaning the greater the proportion of migrants in the county, the greater the Republican vote share. The vote breakdown was negatively associated with the percentage of people remaining in the same house or moving to a different county within Florida, meaning the more the county population was rooted, or consisted of internal migrants, the better the Democratic Party did. 
In the last step, the control variables and the migration variables were entered into the final regression model. When the three control variables were put in, they explained $58.3 \%$ of the variability in the county election results. Then the residency variables were introduced. First, the percent living in the Midwest five years earlier (in 1985) was added: this explained an additional $12.9 \%$ of the variability in the vote result. Then living in another state five years ago was entered, explaining a further $4 \%$ of the variability. The regression coefficients are summarized in Table 13 below.

Table 13 Results of OLS Regression of Republican Average Winning Margins from U.S. House Elections of 1988 - 1992, by 1990 U.S. Census Variables

\begin{tabular}{llcc}
\hline \multicolumn{1}{c}{ Variable } & Beta* & $\begin{array}{c}\text { Standard } \\
\text { Error }\end{array}$ & p-value \\
\hline $\begin{array}{l}\text { \% of Pop. lived in Midwest, five years } \\
\text { earlier }\end{array}$ & 0.64 & 1.56 & $<0.001$ \\
$\begin{array}{l}\text { \% of Pop. lived in Another State, five years } \\
\text { earlier }\end{array}$ & -0.54 & 0.69 & 0.006 \\
$\begin{array}{l}\text { \% Pop. born in Florida } \\
\text { \% Labor Force in Government }\end{array}$ & -0.55 & 0.42 & 0.046 \\
\hline County Population & -0.31 & 0.34 & 0.006 \\
\hline
\end{tabular}

* Unstandardized coefficient

Source: Author Calculations, from 1990 U.S. Census and Florida Division of Elections Data

Together, these five variables explained $75.1 \%$ of the variability in the dependent variable - a remarkably high proportion for a multiple regression model. By contrast, both the previous presidential voting models explained approximately $45 \%$ of the 
variability in the outcome. So the "House 1990" model is significantly more powerful when it comes to explaining the results of House elections than the same model built for presidential voting. Individually, all five variables were significant unique predictors of the county two-party vote margins; living in a Mid-western state has a positive association with the two party vote, whereas the other four variables are negatively associated with the election outcome.

\subsection{Results for Model "House2000"}

Finally, I examine the results from regressing independent variables against an average of the House election winning margins from the 1998, 2000, and 2002 elections. First, correlation analysis showed significant positive associations between election results and eight independent variables: the percent white, percent Hispanic, median household income, percent college educated, percent in armed Forces, population density, percent speaking language other than English, and percent foreign born. Significant negative associations were found with seven independent variables: percent black, percent below the poverty line, percent employed in government sector, percent employed in services sector, percent born in Florida, and percent of households with a female head of household with children. The correlations are summarized in Table 14 below. 
The next step is multiple regression, using stepwise entry of these independent variables. This indicated that four variables were predictors of the House vote breakdown at the county level: the percent born in Florida, the percent employed in the armed forces, the percent white, and the percent black. The other variables did not predict the county election results and were eliminated from further consideration in the analysis.

In the third step, correlation analysis between the migration variables and the vote breakdown indicated that all the migration variables (summarized in Table 12) were significant predictors of the dependent variable, with the exception of percent living outside the U.S. five years earlier. Negative associations were seen for the percent of people living in the same house, and the percent of people living in a different Florida county, meaning as those variables increased in value, the county House vote became less Republican and more Democratic. The other migration variables were positively associated with the vote breakdown, meaning the more that county voters lived in another state five years earlier, the more the House vote favored the Republican Party. 
Table 14 Correlations (r) between Republican Average Winning Margins from U.S. House Elections of 1998 - 2002, and 2000 U.S. Census Variables

\begin{tabular}{lcc}
\hline \multicolumn{1}{c}{ Variable } & r & p-value \\
\hline White (T) & 0.396 & 0.001 \\
Black (T) & -0.570 & $<0.001$ \\
Hispanic Non-White (T) & 0.245 & 0.05 \\
Median Age & 0.203 & 0.11 \\
Median Household Income & 0.497 & $<0.001$ \\
Below Poverty \% & -0.512 & $<0.001$ \\
\% College Educated & 0.394 & 0.001 \\
Government \% & -0.581 & $<0.001$ \\
Professional / Manager \% & 0.174 & 0.17 \\
Services \% & -0.390 & 0.001 \\
Agricultural (T) & -0.186 & 0.14 \\
Manufacturing \% & -0.196 & 0.12 \\
Armed Forces (T) & 0.361 & $<0.001$ \\
Population Density (T) & 0.0003 \\
Travel Time & -0.436 \\
Speak Other than English (T) & 0.286 & 0.048 \\
Female Head of Household with Children & & $<0.001$ \\
Born in FL & 0.001 \\
\hline
\end{tabular}

Source: Author Calculations, from 2000 U.S. Census and Florida Div. of Elections Data 
In the last stage, the four covariates (born in Florida, percent in armed forces, percent black, and percent white) were entered as the control variables in the regression model; they explained $58.3 \%$ of the variability in the county House vote outcome. The most significant variables were the percent of the labor force in the armed forces, which predicted greater Republican voting, and percent black, which predicted greater Democratic voting. Then the migration variables were entered, but they only explained an additional $3.0 \%$ of variability - an increase that was not substantively significant. As in the presidential election model using 2000 Census data, "Pres2000", only the control variables were significant predictors of the House vote; the migration variables did not explain House election results. The regression coefficient results are summarized in Table 15 below. 
Table 15 Results of OLS Regression of Republican Average Winning Margins from U.S. House Elections of 1998 - 2002, by 2000 U.S. Census Variables

\begin{tabular}{lccc}
\hline \multicolumn{1}{|c}{ Variable } & Beta* & Standard Error & p-value \\
\hline \% Labor Force in Armed Forces & 30.08 & 12.49 & 0.02 \\
\hline \% Pop. Black & -27.39 & 9.34 & 0.005 \\
\hline \% Pop. White & -2.90 & 1.2 & 0.02 \\
\hline \% Pop. Born in Florida & -0.96 & 0.62 & 0.13 \\
\hline \% Same House 5 yrs ago & 2.81 & 2.03 & 0.17 \\
\hline \% Diff House, Same County & & & 0.80 \\
\hline \% Diff House, Diff Fl. County & 1.37 & 4.03 & 0.88 \\
\hline \% Different State & 0.31 & 2.06 & 0.44 \\
\hline
\end{tabular}

* Unstandardized coefficients

Source: Author Calculations, from 2000 U.S. Census, Florida Division of Elections Data

\subsection{Conclusion}

My key causal variables, measures of the proportion of a county that lived elsewhere five years earlier, emerge as significant predictors of election results in the late 1980s and early 1990s. In the 1988 and 1992 U.S. presidential elections, the percent of the 
residents who were from out of state, particularly from other counties in the South, was one of the best predictors of the two-party vote breakdown at the county level, while the percent of the population that was white was an important control variable. In House elections over the same period, the percent of the county population that lived in another state five years earlier was one of the best predictors of the two-party vote breakdown; here important control variables were the percentage born in Florida, the percentage of the labor force working in government, and the total county population. In short, migration from out of state clearly and favorably influenced the share of the vote won by the Republican Party within Florida counties entering the last decade of the twentieth century.

This migration effect, however, became less important ten years later. In the models built using the 2000 Census data, the migration variables are not significant predictors of the two-party vote result. The best predictors of presidential voting in the 2000 and 2004 elections in Florida counties were the percent of the population that was white, the percent of the labor force in manufacturing, and population density; the best predictors of voting in House elections between 1998 and 2002 were the percent born in Florida, the percent of the labor force in the armed forces, and the percent black. It appears that the migration effect had played itself out by the turn of the century.

So both presidential and House elections display similar results and similar trends with respect to the influence of migration variables in Florida elections in the last two decades of the twentieth century. The regression models indicate that migration 
patterns had lesser impact at the end of the decade of the 1990s than they did at the beginning. One possibility, as I noted, is because sections were no longer statistically significant factors since they were established structural features, reflected in the racial and economic composition of counties; this would explain why race and occupation variables remain significant. Yet another possibility is that the model specification could be the cause of the differences between the 1990 models and the 2000 models. Since model specification can bias statistical results, in the next section I offer a different test of my theory, using a different data set.

\section{RELIGIOSITY AND PARTISAN SECTIONS}

To test the religiosity hypothesis I compare the prediction that religiosity is associated with the two-party vote with empirical data, and the greater the proportion of the county population that is religiously observant, the greater the Republican Party vote share. As the indicator of religiosity, I use the proportion of the county that is Evangelical Protestant, because regular church attendance is a basic tenet of this denomination, and scholars typically use church attendance as a measure of religiosity. Note that the measure of Evangelicals that I use excludes black Protestant denominations. The source of this data is the Association for Religion Data Archives (ARDA), which calculates raw number of adherents of different religious denominations, at state and county level. To obtain the proportion that is Evangelical 
Protestant, I divide this raw number by the state population. (Appendix F provides further details about this measure).

For the other independent variables, I use demographic data from the American Community Survey (ACS), a survey conducted by the U. S. Census Bureau in middecade, similar to the decennial Census in form and purpose, but administered to a sample, rather than the entire population. In the model that follows, I use ACS data for collected in 2006, which includes data for 2005 for those variables that involve the "year earlier" status, such as migration variables.

\subsection{Independent and Dependent Variables}

The model is similar to the models developed in the previous section, except that the time period is longer, and the variables include "the proportion of the county population that is evangelical Christian". I take two measures of this variable: the percentage of the county population that is Evangelical Christian in 1980, and twenty years later, in 2000. As before, my key causal variable of interest is the migration variable: the percentage of the population that lived in another county in the previous year, in this instance 2005. Using the filtering process as before, the control variables are ones that are correlated with the DV: the average county household income in 2005 , the percent of the county population that was non-white in 2005 ; the mean 
commute time in 2005 , county population size, and county median earnings for those with a post-graduate degree.

In this model, the dependent variable is the winning margin of the two-party vote, at the county level, in the 2004 presidential election. The margin is calculated in the same way as previously - as the percentage difference between the Democratic and the Republican vote share of the total two-party vote, with all third parties excluded. Here, unlike in the previous section, a positive number indicates a Democratic winning margin in the two party vote breakdown. Using these variables, I build two models: a simultaneous model, and a stepwise, or hierarchic model, in which variables are entered into the model in succession.

\subsection{A Simultaneous Regression Model using Religiosity as Predictor}

In this model, there are two analytics stages: first, examining correlations between independent variables and the vote outcome, to identifying statistically significant correlates, and second, entering these variables into the regression model. Examining the Pearson correlations between the independent variables and the outcome of interest, I obtain the results in Table 14, which displays significantly correlated variables shaded in grey. 
Correlation analysis indicates that three variables are correlated to a statistically significant degree with the DV, which is the percent voting Democrat in Florida counties in the presidential election of 2004: the size of the county, the percent nonwhite, and the percent of the population that is evangelical Christian. The first two correlations are positive, meaning the bigger and more racially diverse the county, the higher the Democrat share of the two-party vote for U.S. President in 2004; the last variable is negative, meaning the higher the proportion of evangelical Christians in the county population, the higher the Republican share of the vote for President tends to be.

I also examined the Pearson correlation between migration variables and the twoparty vote share, and found that the percent living in another county the previous year (2005), and the percent moving from elsewhere within Florida since the previous year, were statistically significant correlates. Finally, mean commute time in 2006 was also correlated with the two-party vote share, indicating that the longer the commute, the lower the Democratic presidential vote in 2004. This last correlation is consistent with the "exurban" voting pattern that political observers commented on after the 2004 election, where Republican voting increases with distance from the urban center, burgeoning in concentric circles through the exurban, small-town and rural population belts.

The second step is to regress these six covariates against the winning margins in the county level vote for U.S. President in 2004, to see how well they predict the vote 
outcome. One way is to enter all the variables at the same time, in a simultaneous regression. These variables are: county population in 2005 , percent evangelicals in 2000 , the mean commute time in 2005 , percent who lived in another county in the previous year (2005), percent moving into the county from in-state, and percent of the county population that was non-white in 2005. Entering them at the same time, I obtain the results summarized in Table 16. 
Table 16 Correlations (r) between Democratic Winning Margins from 2004 U.S. Presidential Election, and 2006 American Community Survey Variables

\begin{tabular}{|c|c|c|}
\hline Variable & $\mathbf{r}$ & p-value \\
\hline Population (2006) & 0.432 & $<0.001$ \\
\hline Pct Evangelical Protestant (2000) & -0.575 & $<0.001$ \\
\hline Median HH income 2006 & 0.047 & 0.712 \\
\hline Median with Bach. degree 2006 & 0.036 & 0.796 \\
\hline Median Earn. Postgrad/Prof degree 2006 & -0.039 & 0.780 \\
\hline Mean Commute Time (min) & -0.247 & 0.047 \\
\hline Pct lived in Other County yr ago & -0.253 & 0.042 \\
\hline Pct from In-State & -0.263 & 0.034 \\
\hline Pct from Out of State & -0.066 & 0.600 \\
\hline Pct from Abroad & 0.034 & 0.789 \\
\hline Pct leaving County in 2006 & -0.149 & 0.235 \\
\hline Pct Moving In-State & -0.131 & 0.300 \\
\hline Pct Moving Out of State & -0.036 & 0.778 \\
\hline Domestic net Migration 2000-2005 & 0.206 & 0.100 \\
\hline Average $\mathrm{HH}$ size & -0.220 & 0.078 \\
\hline Pct Evangelical Protestant 1980 & -0.546 & $<0.001$ \\
\hline Pct Non-white & 0.484 & $<0.001$ \\
\hline
\end{tabular}

Source: Author Calculations, from 2006 American Community Survey and Florida Division of Elections Data 
These six variables together account for $57 \%$ of the variability of the DV, or the Democratic share of the two-party vote in 2004, and five of the six variables are significant predictors of Democratic voting for President. The model indicates that the Democratic share of the vote in the county increases with the percent that moved into a county from another county within Florida, with the percent of the county population that is non-white. Thus if a Florida county that experiences in-migration and becomes a more Democratic county, then those migrants tend to come from within Florida, whereas if a county experiences in-migration and becomes a more Republican county, then those migrants tend to arrive from out of state. The regression coefficients are summarized in Table 17 below.

Table 17 Results of Simultaneous OLS Regression of Democratic Winning Margins from 2004 U.S. President Elections, by 2006 American Community Survey Variables

\begin{tabular}{llcc|}
\hline \multicolumn{1}{|c}{ Variable } & Beta* & Standard Error & p-value \\
County Population & $4.407 \mathrm{E}-6$ & 0.00 & 0.093 \\
\% Pop. Evangelical in 2000 & -0.51 & 0.10 & $<0.001$ \\
Mean Commute Time & -0.71 & 0.34 & 0.038 \\
\% Diff. County Year ago & -1.79 & 0.59 & 0.004 \\
\% From In-state & 2.27 & 0.91 & 0.015 \\
\% Non-white & 0.30 & 0.11 & 0.006 \\
\hline * Unstandardized Coefficients & & & \\
Source: Author Calculations, from 2006 American Community Survey and Florida Division of \\
Elections Data
\end{tabular}


The results in Table 17 support the finding from the previous models: migrants into Florida from out of state are moving to specific counties, rather than randomly, and contributing to the Republican sections I described in the previous chapter. In short, internal migration contributes to partisan sections in Florida. On the other hand, the Democratic share decreases as the percent of the county population that is evangelical increases, and as the mean commute time increases. In other words, sparsely populated counties with significant in-migration from elsewhere, with a large proportion of religiously observant Christians, tend to be electorally favorable to the Republican Party.

\subsection{Hierarchical Regression Model using Religiosity as Predictor}

An alternative way to construct the final regression model is to enter the variables stepwise, rather than all at once. In this step-wise, or hierarchical approach, I use two logical decision rules. First, I consider chronology. So that the first step is to enter the variables measuring variables that pre-date the 2004 election, and then introduce the variables that occur later. So step 1 is to introduce the percent evangelicals in 2000, step 2 is to introduce percentage non-white and mean commute time in 2006, step 3 is to introduce the percent of the population who are new to the county from the previous year, either from abroad or from another county in-state, and step 4 is to enter county population in 2006. 
The second decision rule is to consider model fit. This is a measure of how much of the variation in the dependent variable a given independent variable accounts for, when independent variables are regressed against it. The statistic used to measure goodness of fit is R-squared. Examining R-squared for the independent variables, I find that three variables "fit" the model well; the rest do not. The results are summarized in Table 18 below.

Table 18 Results of Hierarchical Regression of Democratic Winning Margins from 2004 U.S. Presidential Election, by 2006 American Community Survey Variables

\begin{tabular}{|c|c|c|c|c|c|c|}
\hline Step & Variable & $\mathbf{R}$ & R-sq. & R-sq. chg & F chg & $\begin{array}{c}\text { Sig. F } \\
\text { Change }\end{array}$ \\
\hline 1 & \% Evangelical 2000 & 0.57 & 0.33 & 0.33 & 30.68 & $<0.001$ \\
\hline 2 & \% Non-white 2006 & 0.68 & 0.46 & 0.13 & 14.67 & $<0.001$ \\
\hline 3 & $\%$ Other County 2005 & 0.72 & 0.51 & 0.05 & 7.28 & 0.009 \\
\hline
\end{tabular}

Source: Author Calculations, from 2006 American Community Survey and Florida Division of Elections Data

After step 1, entering the percent of Evangelicals, the model explained $32.7 \%$ of the variability in the percent of the two-party vote share won by the Democratic presidential candidate in 2004. After step 2, entering the percent non-white, the model accounted for an additional $12.9 \%$ of the variability. After step 3, percent living in another county, the model accounted for an additional 5.8\% of the variability. Together, these three steps accounted for $71.7 \%$ of the variability in percent voting 
Democrat. I leave out the remaining variables, since they are redundant and barely explain any additional variability in the outcome.

Next, I examined the coefficients for the direction and size of the effect that these variables have on the outcome or dependent variable. The model indicates that the higher the proportion of evangelical Christians in the county population, and the higher the proportion of recent migrants from another county, the lower the predicted Democratic vote share. On the other hand, the higher the non-white share of the county population, the larger the Democratic vote share. The results for the effect of Evangelical Protestants are particularly robust, with a low standard error, and high statistical significance (less than $0.1 \%$ likelihood that the results are due to chance). On the other hand, the size of the effect is greatest for the proportion that lived in another county a year ago, with $1 \%$ change in that proportion inducing more than a $1 \%$ change in the two-party vote share. The results are summarized in Table 19. 
Table 19 Results of Hierarchical Regression of Democratic Winning Margins from 2004 U.S. Presidential Election, by 2006 American Community Survey Variables

\begin{tabular}{|l|c|c|c|}
\hline \multicolumn{1}{|c|}{ Variable } & Beta* & Standard Error & p-value \\
\hline \% Pop. Evangelical Prot. 2000 & -0.51 & 0.09 & $<0.001$ \\
\hline \% Pop. Non-white in 2006 & 0.35 & 0.11 & 0.002 \\
\hline \% Lived in Other County in 2005 & -1.14 & 0.42 & 0.009 \\
\hline
\end{tabular}

*The coefficients are unstandardized.

Source: Author Calculations, from 2006 American Community Survey and Florida Division of Elections Data

In sum, religiosity and racial breakdown are significant predictors of county-level presidential voting in Florida. The residency choices made by the more religiously observant predicts greater Republican voting, and this migration and partisanship combine to contribute to partisan sections within the state. The effect of these two variables is reinforced by patterns of migration that are systematically biased: migrants into Florida from out-of-state are contributing to Republican sections, and in-state migrants within Florida are contributing to Democratic sections

\section{CONCLUSION}

In this chapter, my objective was to test the hypothesis that residential choice and migration patterns are contributing to the partisan sections uncovered in chapter five. 
Specifically, I tested the prediction that patterns of migration would contribute to winning vote margins in presidential and House elections. To compare the prediction against evidence, I used data from the decennial U.S. Census, including a battery of questions on where the respondent lived five years ago.

The models provide reasonable support for the theory that migration patterns are contributing to sectionalism and party-safe elections. The findings from the Census data are stronger for the period circa 1990 than for the period circa 2000, but a different model using 2006 ACS, a mid-decade sample, and a religiosity variable, finds strong evidence for the hypothesis that observant white households tend to migrate in ways that perpetuate and consolidate partisan sections in Florida. 


\section{CHAPTER 7:}

BUILDING A GENERAL THEORY OF ELECTIONS 


\section{PARTISAN SECTIONS IN FLORIDA, REVISITED}

In this dissertation, I have argued that party-safe elections are the result of migration patterns and residential choices made by American voters. My argument is not that these decisions regarding where to live are driven by partisanship, but that the social preferences that do drive these decisions are correlated with partisanship. The residential choices made by American voters sort them into counties and regions that form distinct and observable partisan sections. These partisan sections account for the underlying partisan composition of electoral districts. The result of this underlying composition is to create persistent partisan balance favoring one of the two parties, or "red and blue" electoral districts.

I have presented this explanation as a structural theory of party safe elections, one that emphasizes the social preferences and attributes of voters, rather than their rational responses to economic incentives or conditions, the behavior of elites, or the design of institutions, such as electoral districts. In focusing on attributes of voters, I emphasized partisan identification, rather than ideology or issue attitudes: I assumed that voters are stable partisans, and that this partisanship can be observed and inferred, at the aggregate level, from election results. Such an approach avoids the problems associated with measuring ideology, or issue attitudes, at the individual level, and the problems inherent in theoretically or empirically linking such measures to behavior. 
This emphasis on behavior rather than attitudes informs my research design, which emphasizes concrete empirical evidence, collected from secondary sources maintained by state and Federal agencies, to build and test research a falsifiable, empirical (or non-tautological) theory. To test the theory, I employed a large-N research design, and gathered aggregate-level data that recorded votes and demographic features of population sub-groups at the county level, such as race, ethnicity, religion, and residential mobility, using indicators that can provide quantifiable measures of the these variables. Since different procedures for measuring variables may produce different results from the same hypotheses, I have specified the operational definitions for the variables I employed, and I have described how observations were made. My objective is to ensure that the study is replicable.

These activities occupied chapters 2 through 4 of my dissertation. In chapters 5 and 6 , I used the empirical evidence I collected to test four observable implications, or hypotheses, of my theory. I did this by comparing the evidence with the predictions suggested by the hypotheses. These four related hypotheses constitute the empirical, non-tautological core of my theory of district competiveness and party-safe elections. 


\section{$1.1 \quad$ Four Hypothesis, Revisited}

First, I tested the hypothesis that Florida exhibits clearly distinguishable geographic areas, characterized by distinctively and persistently partisan voting behavior, or sections. I found that it does. The distribution of voters gives the Republican Party resounding majorities in elections in Northwest, Northeast and Southwest Florida, whereas the distribution of voters gives the Democratic Party a decisive advantage in elections in North Central and Southeast Florida.

Second, I tested the hypothesis that Florida voters exhibit increasing party line voting. I found that they do. Over a twenty-six year period, from 1980 to 2006, the results for a variety of elections, for national and state office, in all regions of the state, converged considerably along party lines. The patterns were far too striking to be random, and suggest that Florida voters, in the aggregate, are increasingly voting along party lines.

Given that elections at the county and regional level are evidently party-safe, my claim is that we should expect Congressional districts to be largely party-safe, regardless of how or why they are drawn. My conclusion is that county-level results are sufficient to explain party-safe House elections, and that designing districts along partisan lines is redundant: the distribution of voters is sufficient to explain party-safe Congressional elections. 
The relationship between Congressional districts and partisan sections is displayed in the maps in Figures 1 and 2. We see from these maps that House elections in Florida had a distinct sectional pattern in the 1990s, with Democratic strength in the North Central Florida, and the ribbon along the East coast from Southeast Florida into East Central Florida, and Republican strength elsewhere. This sectionalism continued into the next decade, with essentially the same pattern. My argument is that it is these persistent sections, not redistricting, that creates party-safe House elections in Florida. 
Figure 10 Florida's Partisan Sections, by Average Winning Margins from U.S. House Elections of 1992-1996

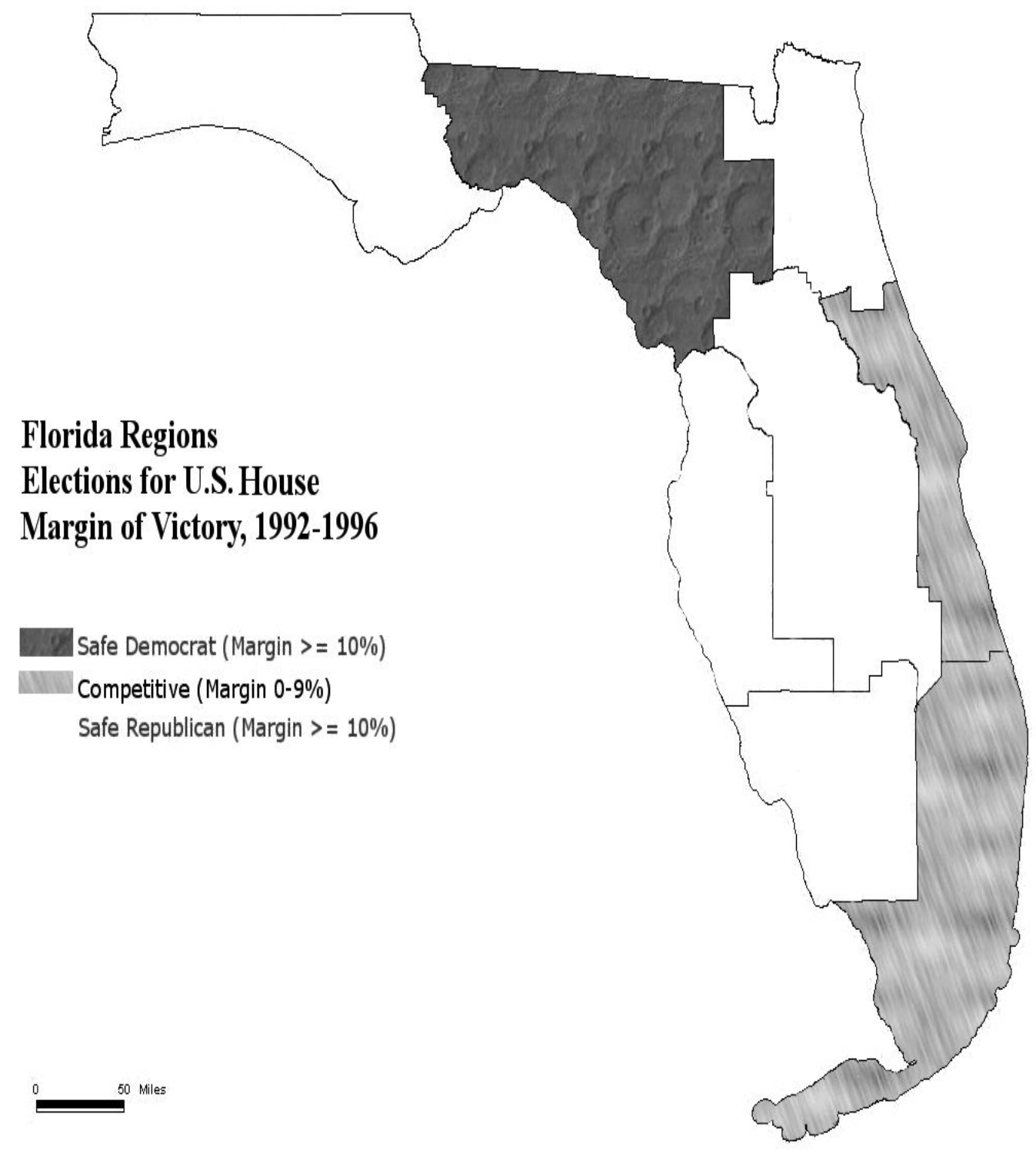

Source: Author Calculations, from Florida Division of Elections Data 
Figure 11 Florida's Partisan Sections, by Average Winning Margins from U.S. House Elections of 2002-2006

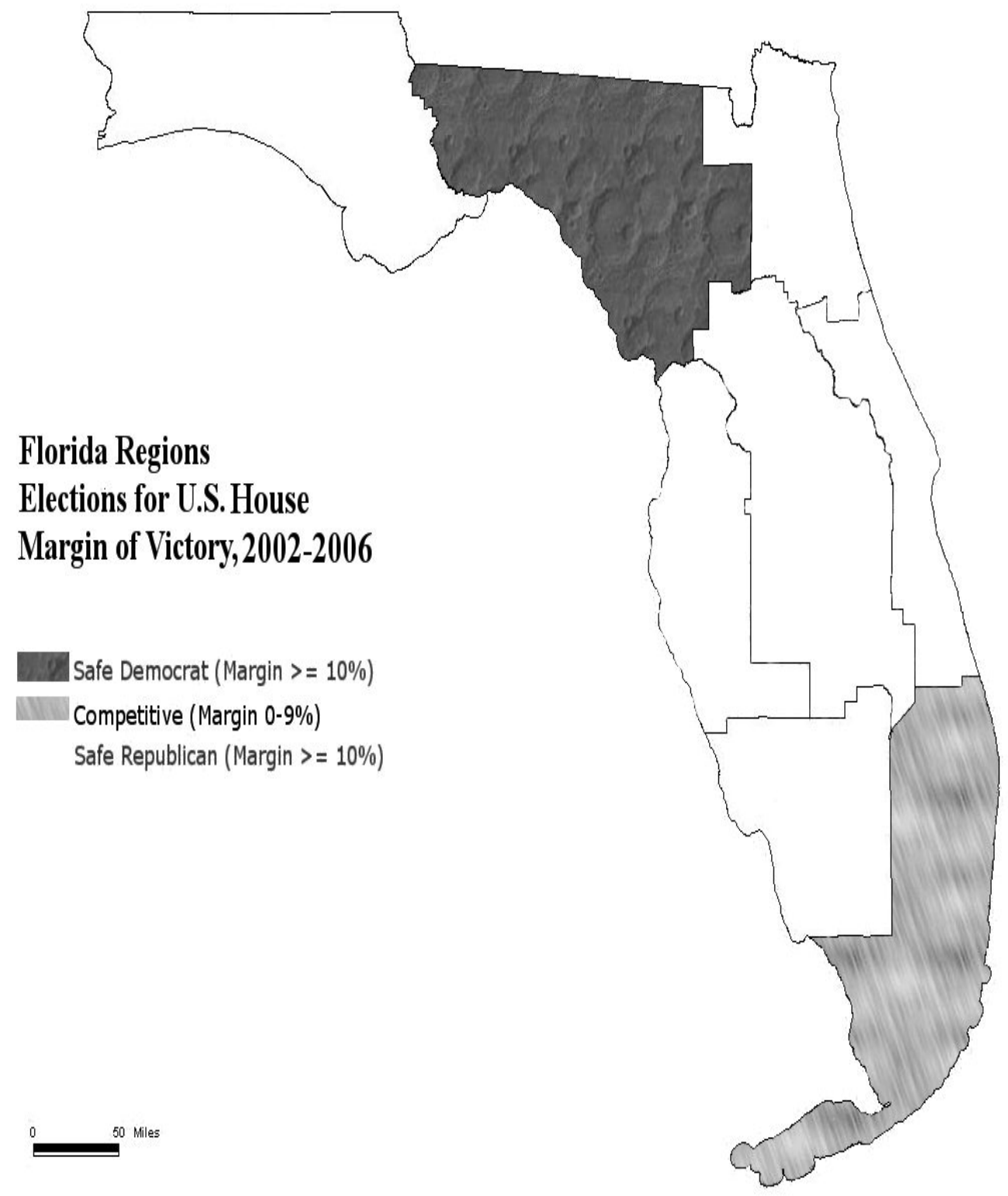

Source: Author Calculations, from Florida Division of Elections Data 
Third, I tested the hypothesis that these sections are caused by residential choices and migration patterns made by American households moving into and within Florida. I predicted that patterns of migration correlate with party-safe presidential and House elections. I then compared this prediction against evidence, using data from the decennial U.S. Census, including a battery of questions on where the respondent lived five years ago, and some control variables. I found that residency variables did help to explain partisan sections in the early 1990s, but not in the early 2000's. I speculated that this might be because the sections had already formed, or perhaps because of multicollinearity, a statistical problem with aggregate data. I suggested that testing hypotheses with individual level data might help to shed light on the results.

Fourth, I investigated the finding that the racial make-up of the county mattered for political sectionalism. I theorized that this might originate in one of two important cleavages in American politics - income and religiosity. Since income did not appear as a particularly significant variable in the regression models, I hypothesized that the "race effect" originated in religiosity, and that the migration and settlement patterns of church-going evangelical Protestants, who tend to live in exurban or rural communities with less minority representation, explained the correlation between race and partisanship. I tested this hypothesis with the prediction that the proportion of a county that is evangelical Protestant will be Republican party-safe, and found confirmation for the prediction. 
On the whole, the models offer significant support for my broad claim that migration patterns are contributing to sectionalism and party-safe elections in Florida. The findings from the Census data are stronger for the period circa 1990 than for the period circa 2000, but a different model using mid-decade sample data, and a religiosity variable, finds strong evidence for the hypothesis that church-going, or observant, Protestant households tend to migrate in ways that perpetuate and consolidate partisan sections in Florida.

There is some evidence that redistricting, the most popular explanation of party-safe elections, may contribute to party-safe elections, but the evidence is patchy and inconclusive. It appears that redistricting may enhance competitiveness, or suppress it; its effect is not systematic or predictable. Such indeterminacy regarding the consequences of redistricting reinforces my thesis that structural factors offer a more convincing explanation of party-safe elections than the "district gerrymandering" explanation.

\section{EXTENDING THE RESEARCH}

Like any social science explanation, my theory is a partial one; it explores only the influence of structural variables on the outcome of interest. But every study has limitations; they simply serve as motivation to find ways to improve a theory. In the remainder of this concluding chapter, I will discuss how I can build on the research 
done so far to advance our understanding of American elections. One option is to broaden the study methodologically, by including a qualitative component, thus creating a quantitative-qualitative, "mixed method" research design.

A quantitative explanation that defines explanation using the causal weight of different variables on the outcome of interest, such as this one, cannot explain how the different variables lead to the outcome of interest; it does not describe the process by which partisan sections come to be formed. What are the motivations of American households who move home? Why did they choose to move to a certain county? What factors were uppermost in their minds? My data set cannot answer these questions; instead, I have bracketed them, make assumptions about motives, and moved on. Any research into complex social outcomes must make assumptions in order to move forward to test the hypotheses that form the core of this theory.

But a mixed-method design may choose to treat the questions that I have bracketed as the outcomes to be explained, developing propositions or hypotheses about motivations that can be tested with empirical data. In that case, a qualitative case study using methods such as interviews, focus groups, or participant observation is a more suitable research design. If this were combined with quantitative research presented here, the result would be a methodologically broader, quantitativequalitative (or mixed) research design. With this approach, I could analyze the motivations behind the residential and voting choices I have referred to in this dissertation. 
This mixed method approach is one way to develop and expand on this research. Another way is to explore the individual choices that lie underneath the aggregatelevel outcomes such as partisan sections, without recourse to qualitative methods, is to conduct individual level survey research. The latter approach is also more theoretically elegant. To clarify this claim, I return to the concept of a general explanation.

\section{A GENERAL EXPLANATION OF ELECTIONS}

My theory states that migration and settlement choices create partisan sections, and these sections shape the underlying partisan balance of electoral districts, contributing to party-safe elections. Such an explanation identifies a pre-existing structure as the cause (the composition of the community in which the election is held) rather than events that occurred on election day or in the campaign in the weeks or months leading up to the election. As I noted in chapter three, explanations that emphasize constraints on choice and action that pre-date the actor in question or the situation at hand, can be defined as a general explanation (Parsons 2008).

The Michigan school "social-psychological" concept of partisanship, a combination of political socialization experienced in childhood and adolescence, and political orientations that emerge in adulthood - ostensibly as a result of this socialization- is a general explanation (Campbell et al. 1960). Family socialization and the workings of 
the human mind are enduring constraints to behavior that exist prior to the decision of who to vote for, and they are phenomena experienced by everyone; they are not choices or historical contingencies. The virtue of general explanations is that they can be applied across time and space, to a variety of different domains, during a variety of different time periods.

Redistricting, by contrast, is a particular explanation, one where the outcome is explained not by a universal process or structural constraints, but by historical contingency, by choices made in a particular manner, at a particular time, by specific groups or individuals. Not all states redesign Congressional districts every ten years, and if they do, the process is specific to each state, and the decisions ultimately depend on choices made by specific groups and individuals that emerge in a specific context - redistricting commissions, legislators, or judges. In a particular explanation, the outcome is explained by choice, not structure.

\subsection{Individual Level General Explanations}

The distinction between general and particular matters because I need criteria for making research decisions: what direction should I take to further pursue this research agenda? What explanatory logic that will complement the aggregate level, structural, general theory I have presented here? In fact, two theoretical possibilities present themselves: rational choice and psychology. These two explanatory logics 
complement my study for two reasons. First, they are both general explanations: their casual logic relies on pre-existing structures, which in this instance take the form of individual attributes or relationships that are presumed to prevail everywhere, such as instrumental rationality, or the desire for security, that are presumed to explain behavior. In that sense, they well serve the general explanation offered here. Second, both these approaches adopt the individual as the unit of analysis, rather than an aggregate such as the underlying partisan composition of a county or electoral district. In that sense, they complement the aggregate level research I have pursued here.

Rational choice is a familiar individual level approach to most social scientists. Such theories combine universalistic assumptions about instrumental rationality and agency with the influence of context, typically conceived as institutions, or the "rules of the game", to generate predictions about behavior. Psychological explanations, for their part, concentrate on preferences that stem from individual-level characteristics and relationships, which may or may not be rational, to generate predictions about behavior (t'Hart 2010). Which of these two approaches is the best choice? Here, I refer to the criterion of empiricism.

In the psychological approach, behavior is explained by certain drives and motivations that are common to all individuals across space and time. Unlike rational choice explanations, the psychological approach does not simply assume that individual preferences exist, but instead, seeks to identify and confirm their existence, 
empirically. And unlike rational choice explanations, psychological explanations do not require empirically questionable assumptions about "rationality". Rather, a psychological approach would seek evidence that certain motivations are in play (such as security, solidarity, community, or identity) in the population being studied, examine individual level characteristics that might drive these motivations generate certain preferences, and link these characteristics and preferences to the outcome of interest - which happen to be partisanship and sectionalism in this study.

The theory I have presented in this dissertation has one central assumption: that partisanship is a stable social identity, and that this partisanship is linked in straightforward manner to voting behavior. Rather than delve into the concept empirically, I have assumed that this partisan identification is partly social, and partly psychological - or "social-psychological", as theorized by Converse and the Michigan School (Campbell et al. 1960). It follows that one avenue for further exploration is to seek empirical verification of this psychological conceptualization of partisanship; that is, to take my assumption that partisanship is a social-psychological phenomenon, and examine it empirically.

\subsection{Testing Psychological Hypotheses}

To test individual level hypotheses on the relationship between psychological variables and partisan identification and sectionalism, I will need a set of observations 
that takes the individual as the unit of analysis, and that offers information on psychological motivations and partisanship at the individual level, and from there to partisanship at the aggregate level, which I have referred to as partisan sections. To collect individual-level cross-sectional observations on my variables of interest, a standard approach is to create a questionnaire composed of closed-ended questions that can be used to examine correlations between psychological orientations, political orientations such as partisanship, and residential preference. One way to conceive of and operationalize psychological variables is to employ the concept of personality, as employed by Hetherington and Weiler (2009) in their analysis of the relationship between the "authoritarian personality" and voting behavior. Taking this approach, I can test hypotheses relating personality with partisanship, with moral orientations, or values (defined as attitudes toward cultural practices and institutions), as intervening variables.

To operationalize values, as well as political orientations such as partisanship, the National Election Studies (NES) offers questions that I can use as "off-the-shelf" indicators. The NES question prompts regarding values ("the newer lifestyles are contributing to the breakdown of our society", and "the world is always changing and we should adjust our view of moral behavior to those changes") partisanship, (asking the respondent to self-identify their intensity of partisan or ideological orientation on a seven-point scale) and a host of other political orientations can be simply adopted verbatim for the survey; this will minimize bias or ambiguity stemming from question wording. These prompts can be combined with a set of questions designed to measure 
individual residential preferences, and a battery of questions to measure values for control variables, such as race, sex, and income. To control for possible regional or geographic bias in the survey responses, observations can be collected from different regions of Florida, and, ideally, from a control group outside of Florida, one with a demonstrably different demographic profile.

If social identity is psychological in nature, then, since individual psychology, unlike personal financial circumstances, or hairstyles, tends not to vary over time for most of the electorate, the responses to these questions from a random sample of the votingage population should have the same distribution as the population at large, and any selection bias from the sample should be nonsystematic rather than systematic (King et al. 1994). However, selection bias would not be non-random would not be true if the hypotheses involved contingent variables that would be expected to differ systematically from one group to another; in that case, observations would need to be drawn from a controlled experiment in which the researcher randomly assigned values of the explanatory variable.

If I can collect data that measures the psychological attributes and motivations that contributes to a social identification such as partisanship, and identify the link between partisanship and residential choice, then these psychological motivations will be another set of structural variables I can add to the aggregate structural variables I have measured in this study to craft a more comprehensive, general explanation of sectionalism and party-safe elections. Such a research proposal has the virtue that it 
dovetails with the burgeoning scholarly interest in the psychological element of mass politics, and in particular, the processes of group identification and intergroup relations that lead to political outcomes, such as election results.

All social science explanations are partial explanations: no one theory can credibly seek to fully and comprehensively account for complex social outcomes such as election results and voting behavior. Some of the variation in electoral outcomes cannot be explained by the variables in my theoretical model. So the structural, migration-driven theory of elections presented here is a partial explanation; various institutional, rational and cultural factors will also play a part in contributing to the outcome, albeit some more than others. My objective is not to supplant other explanations or approaches, but to complement them. The structural theory presented here seeks to recover some of the theoretical ground in a topic that has been dominated by institutional and elite-centric explanations. The debate over the current polarization in American politics is large enough in scope and important enough in its consequences for democratic representation to benefit from different perspectives. 


\section{BIBLIOGRAPHY}

Abramowitz, Alan I. 1994. "Issue Evolution Reconsidered: Racial Attitudes and Partisanship in the U.S. Electorate." American Journal of Political Science 38 (February): 1-24.

Abramowitz, Alan I. and Kyle L. Saunders. 1998. "Ideological Realignment in the U.S. Electorate.” Journal of Politics 60 (May): 634-52.

Abramowitz, Alan I., Brad Alexander and Matthew Gunning. 2006. "Incumbency, Redistricting, and the Decline of Competition in the U.S. House Races." Journal of Politics 68 (1): 75-88.

Abramowitz, Alan I. 2006. "Disconnected, or Joined at the Hip?" In Red and Blue Nation? ed. Pietro S. Nivola and David W. Brady. Washington, DC: Brookings Institution.

Abramowitz, Alan I. and Kyle L. Saunders. 2008. "Is Polarization a Myth?” Journal of Politics 70 (April): 542-555.

Aldrich, John H. 1995. Why Parties? The Origin and Transformation of Party Politics in America. Chicago: University of Chicago Press.

Allison, Paul. 1999. Multiple Regression: A Primer. Thousand Oaks: Pine Forge Press.

Ansolabehere, Stephen and James M. Snyder Jr. 2000. "Money and Office: The Sources of the Incumbency Advantage in Congressional Campaign Finance." In Continuity and Change in House Elections, ed. David W. Brady, John F. Cogan, and Morris P. Fiorina. Stanford: Stanford University Press.

Ansolabehere, Stephen and James M. Snyder Jr. 2002. "The Incumbency Advantage in U.S. Elections: An Analysis of State and Federal Offices, 1942-2000." Election Law Journal 1 (3): 315-38.

Snyder, James M., Stephen Ansolabehere and Erik. C. Snowberg. 2006. "Television and the Incumbency Advantage in U.S. Elections." Legislative Studies Quarterly 31 (November): 469-490.

Ansolabehere, Stephen, John Mark Hansen, Shigeo Hirano, and James M. Snyder Jr. 2006. "The Decline of Competition in U.S. House Elections." In The Marketplace of Democracy, ed. Michael P. McDonald and John Samples. Washington, DC: Brookings Institution.

Baker, Stephen. 2008. The Numerati. Boston: Houghton Mifflin. 
Baker, Wayne. 2005. America's Crisis of Values: Reality and Perception. Princeton University Press.

Bartels, Larry M. 1992. “The American Public's Defense Spending Preferences in the Post-Cold War Era. Public Opinion Quarterly 58: 479-508.

Bartels, Larry M. 2000. "Partisanship and Voting Behavior, 1952-1996." American Journal of Political Science 44 (January): 35-50.

Bartels, Larry M. 2006. "What's the Matter with What's the Matter with Kansas?" Quarterly Journal of Political Science 1: 201-226.

Bartels, Larry M. 2008. Unequal Democracy. The Political Economy of the New Gilded Age. Princeton: Princeton University Press.

Bennet, Andrew, Aharon Barth and Ken Rutherford. 2003. "Do We Preach What we Practice? A Survey of Methods in Political Science Journals and Curricula." PS: Political Science and Politics 36 (July): 373-378.

Bensel, Richard F. 1984. Sectionalism and American Political Development. Madison: University of Wisconsin Press.

Black, Merle. 2004. "The Transformation of the Southern Democratic Party." Journal of Politics 66 (November): 1001-1017.

Black, Earle, and Merle Black. 1987. Politics and Society in the South. Cambridge: Harvard University Press.

Black, Earle, and Merle Black. 2002. The Rise of Southern Republicans. Cambridge: Harvard University Press.

Black, Earle, and Merle Black. 2007. Divided America: The Ferocious Power Struggle in American Politics. New York: Simon and Schuster.

Booth, Wayne C., Gregory G. Colomb, and Joseph M. Williams. 2008. The Craft of Research. Chicago: University of Chicago Press.

Brady, David W., Robert D'Onofrio and Morris P. Fiorina. 2000. "The Nationalization of Electoral Forces Revisited." In Continuity and Change in House Elections, ed. David W. Brady, John F. Cogan, and Morris P. Fiorina. Stanford: Stanford University Press.

Brady, David W., and Craig Volden. 2006. Revolving Gridlock: Politics and Policy from Jimmy Carter to George W. Bush. Boulder: Westview Press. 
Brady, David W., and Hahrie Hahn. 2007. "Primary Elections and Candidate Ideology: Out of Step with Primary Electorate?" Legislative Studies Quarterly 32 (February): 79-105.

Brewer, Mark D., and Jeffrey M. Stonecash. 2006. Split: Class and Cultural Divides in American Politics. Washington, DC: CQ Press.

Brody, Richard A. 1991. Assessing the President. Stanford: Stanford University Press.

Brunell, Thomas L. 2008. Redistricting and Representation: Why Competitive Elections are Bad for America. New York: Routledge.

Burden, Barry C., and David C. Kimball. 1999. "A New Approach to the Study of Ticket-Splitting.” American Political Science Review 92 (September): 533-44.

Burden, Barry C. 2001. "The Polarizing Effects of Congressional Primaries." In Congressional Primaries and the Politics of Representation, ed. Michael Galderisi, Marni Ezra, and Michael Lyons. Lanham, MD: Rowman and Littlefield.

Burnham, Walter Dean. 1970. Critical Elections and the Mainsprings of American Politics. New York: Norton.

Bishop, Bill. 2008. The Big Sort: Why the Clustering of Like-Minded America is Tearing Us Apart. Boston: Houghton Mifflin.

Cain, Bruce E. 1984. The Reapportionment Puzzle. Berkeley: University of California Press.

Cain, Bruce E., Karin MacDonald, and Michael McDonald. 2005. "From Equality to Fairness: The Path of Political Reform since Baker v. Carr." In Party Lines: Competition, Partisanship and Congressional Redistricting, ed. Thomas E. Mann, and Bruce E. Cain. Washington, DC: Brookings Institution Press.

Campbell, Angus, Phillip E. Converse, Warren E. Miller, and Donald E. Stokes. 1960. The American Voter. New York: Wiley.

Carmines, Edward G., and Geoffrey C. Layman. 1997. "Issue Evolution in Postwar American Politics: Old Certainties and Fresh Tensions." In Present Discontents: American Politics in the Very Late Twentieth Century, ed. Byron E. Shafer. Chatham, NJ: Chatham House.

Carmines, Edward G. and James A. Stimson. 1989. Issue Evolution: Race and the Transformation of American Politics. Princeton, NJ: Princeton University Press. 
Carson, Jamie L., Erik J. Engstrom and Jason M. Roberts. 2006. "Redistricting, Candidate Entry, and the Politics of Nineteenth-Century U.S. House Elections." American Journal of Political Science 50 (April): 283-93.

Carsey, Thomas M., and Geoffrey C. Layman. 2006. "Changing Sides or Changing Minds? Party Identification and Policy Preferences in the American Electorate." American Journal of Political Science 50 (April): 464-477.

Cleveland, William. 1994. The Elements Of Graphing Data. New Jersey: AT\&T Labs.

Converse, Philip E. 1964. "The Nature of Belief Systems in Mass Publics." In Ideology and Discontent, ed. David E, Apter. New York: Free Press.

Cox, Gary W., and Johnathan N. Katz. 2002. Ellbridge Gerry's Salamander: The Electoral Consequences of the Reapportionment Revolution. New York: Cambridge University Press.

Dalton, Russell J., Scott Flanagan, and Paul Allen Beck. 1984. Electoral Change in Advanced Industrial Countries: Realignment or Dealignment? Princeton: Princeton University Press.

Davis, Nancy J. and Robinson, Robert V. 1996. "Are the Rumors of War Exaggerated? Religious Orthodoxy and Moral Progressivism in America." American Journal of Sociology 102 (November): 756-787.

Delli Carpini, Michael X. and Scott Keeter. 1996. What Americans Know about Politics and Why It Matters. New Haven, CT: Yale University Press.

Desposato, Scott W., and John R. Petrocik. 2003. "The Variable Incumbency Advantage: New Voters, Redistricting and the Personal Vote." American Journal of Political Science 47 (January): 18-43.

DiMaggio, Paul, John Evans, and Bethany Bryson. 1998. "Have Americans' Social Attitudes Become More Polarized?" American Journal of Sociology 102 (November): $690-755$

Downs, Anthony. 1957. An Economic Theory of Democracy. New York: Harper.

Erikson, Robert S. 1972. "Malapportionment, Gerrymandering, and Party Fortunes in Congressional Elections." American Political Science Review 66 (December): 123445.

Evans, John H., Bethany Bryson, and Paul DiMaggio. 2001. Opinion Polarization: Important Contributions, Necessary Limitations." American Journal of Sociology 106 (January): 944-59. 
Fenno, Richard F. 1978. Home Style: House Members in their Districts. Boston: Little, Brown.

Fiorina, Morris P. 1977. Congress: Keystone of the Washington Establishment. New Haven: Yale University Press.

Fiorina, Morris P. 1996. Divided Government. 2d ed. Needham Heights, MA: Allyn \& Bacon.

Fiorina, Morris P. 2002. "Parties, Participation, and Representation in America: Old Theories Face New Realities." In Political Science: The State of the Discipline, ed. Ira Katznelson and Helen V. Milner. New York: W.W. Norton.

Fiorina, Morris P. Keystone Reconsidered. In Congress Reconsidered, ed. Lawrence C. Dodd and Bruce I. Oppenheimer. Washington, DC: CQ Press.

Fiorina, Morris P., with Samuel J. Abrams and Jeremy C. Pope. 2006. Culture War? The Myth of Polarized America. New York: Longman.

Fiorina, Morris P. and Matthew S. Levendusky. 2006. "Disconnected: The Political Class versus the People." In Red and Blue Nation? ed. Pietro S. Nivola and David W. Brady. Washington, DC: Brookings Institution.

Fleisher, Richard and Jon R. Bond. 2000. "Congress and the President in a Partisan Era." In Polarized Politics: Congress and the President in a Partisan Era, ed. Richard Fleisher, and Jon R. Bond. Washington, DC: CQ Press.

Fox, John. 1997. Applied Regression Analysis, Linear Models, and Related Methods. Thousand Oaks: Sage.

Frank, Thomas. 2004. What's the Matter with Kansas? How Conservatives Won the Heart of America. New York: Metropolitan Books.

Frankfort-Nachmias, Chava. 2006. Research Methods in the Social Sciences. New Jersey: Worth Publishers.

Gelman, Andrew, and Gary King. 1990. "Estimating the Incumbency Advantage without Bias." American Journal of Political Science 34: 1142-1164.

Gelman, Andrew and Gary King. 1993. "Why are American Presidential Campaign Polls so Variable When Votes Are so Predictable? British Journal of Political Science 23 (October): 409-451.

Gelman, Andrew. 2006. Red State, Blue State, Rich State, Poor State: Why Americans Vote The Way They Do. Princeton: Princeton University Press. 
Gimpel, James G. 1999. Separate Destinations: Migration, Immigration, and the Politics of Places. Ann Arbor: University of Michigan.

Gimpel, James G. and Jason E. Schuknecht. 2004. Patchwork Nation: Sectionalism and Political Change in America. Ann Arbor: University of Michigan Press.

Glaeser, Edward L. and Bryce A. Ward. 2006. "Myths and Realities of American Political Geography." Journal of Economic Perspectives 20 (Spring): 119-144.

Gerber, Elisabeth R., and Rebecca B. Morton. 1998. "Primary Election Systems and Representation." Journal of Law, Economics, and Organization 14 (August): 304324.

Hetherington, Marc J. 2001. "Resurgent Mass Partisanship: The Role of Elite Polarization.” American Political Science Review 45 (September): 619-631.

Hetherington, M. J., \& Johnathan Weiler. 2009. Authoritarianism and Polarization in American Politics. New York: Cambridge University Press.

Hunter, James Davison. 1991. Culture Wars: The Struggle to Define America. New York: Basic Books.

Inglehart, Ronald. 1997. Modernization and Postmaterialism: Cultural, Economic, and Political Change in 43 Societies. Princeton: Princeton University Press.

Inglehart, Ronald, and Christian Welzel. 2005. Modernization, Cultural Change and Democracy: The Human Development Sequence. New York: Cambridge University Press.

Jacobson, Gary C. 1978. "The Effects of Campaign Spending in Congressional Elections. American Political Science Review 72: 469-91.

Jacobson, Gary C. 1989. "Strategic Politicians and the Dynamics of House Elections, 1946-86.” American Political Science Review 83 (September): 773-793.

Jacobson, Gary C. 2000a. "Party Polarization in National Politics: The Electoral Connection." In Polarized Politics: Congress and the President in a Partisan Era, ed. Richard Fleisher, and Jon R. Bond. Washington, DC: CQ Press.

Jacobson, Gary C. 2000b. "Reversal of Fortune: The Transformation of U.S. House Elections in the 1990s." In Continuity and Change in House Elections, ed. David W. Brady, john F. Cogan, and Morris P. Fiorina. Stanford: Stanford University Press.

Jacobson, Gary C. 2004. "Explaining the Ideological Polarization of the Political Parties since the 1970s." Paper prepared for the annual meeting of the Midwest Political Science Association, Chicago, April 15-18. 
Jacobson, Gary C. 2006. "Competition in U.S. House Elections." In The Marketplace of Democracy, ed. Michael P. McDonald and John Samples. Washington, DC: Brookings Institution.

Jacobson, Gary C. 2006. "Why Other Sources of Polarization Matter More." In Red and Blue Nation: Characteristics and Causes of America's Polarized Politics, ed. Pietro S. Nivola, and David W. Brady. Washington, DC: Brookings Institution Press.

Jacobson, Gary C. 2007. George Bush: A Divider, Not a Uniter. New York: Longman.

Jacobson, Gary C. 2009. The Politics of Congressional Elections. New York: Longman.

Jacobson, Gary C. and Samuel Kernell. 1983. Strategy and Choice in Congressional Elections, $2^{\text {nd }}$ ed. New Haven: Yale University Press.

Jacoby, William G. 1997. Statistical Graphics for Univariate and Bivariate Data. Thousand Oaks: Sage Publications, Inc.

Keith, Bruce E., David B. Magleby, Candice J. Nelson, Elizabeth Orr, Mark C. Westlye, and Raymond Wolfinger. 1992. The Myth of the Independent Voter. Berkeley: University of California Press.

Key, V. O., Jr. 1955. “A Theory of Critical Elections.” Journal of Politics 17: 3-18

Key, V. O., Jr. 1959. "Secular Realignment and the Party System.” Journal of Politics 21: $198-210$.

Key, V. O., Jr. 1961. Public Opinion and American Democracy. New York: Knopf.

Kimball, David C., and Cassie A. Gross. 2006. "The Growing Polarization of American Voters." In The State of the Parties, ed. John C. Green. Boulder: Rowman and Littlefield.

King, David C. 2003. "Congress, Polarization, and Fidelity to the Median Voter." Harvard University, Kennedy School of Government Working Paper, March 10.

King, Gary, Robert O. Keohane and Sidney Verba. 1994. Designing Social Inquiry. Princeton: Princeton University Press.

Kruse, Kevin. 2007. White Flight: Atlanta and the Making of Modern Conservatism. Princeton: Princeton University Press.

Layman, Geoffrey. 2001. The Great Divide: Religious and Cultural Conflict in American Politics. New York: Columbia University Press. 
Layman, Geoffrey C. and Edward G. Carmines. 1997. "Cultural Conflict in American Politics: Religious Traditionalism, Post-Materialism, and U.S. Political Behavior." Journal of Politics 59 (August): 751-777.

Layman, Geoffrey C., and Thomas M. Carsey. 2002. "Party Polarization and 'Conflict Extension' in the American Electorate." American Journal of Political Science 46 (October): 786-802.

Levitt, Steven D., and Catherine Wolfram. 1997. "Decomposing the Sources of Incumbency Advantage in the U.S. House." Legislative Studies Quarterly 22 (Feb): 45-60.

MacDonald, Michael P. 2006. "Redistricting and Competitive Districts." In The Marketplace of Democracy, ed. Michael P. McDonald and John Samples. Washington, DC: Brookings Institution.

Mann, Thomas E. 2006. "Polarizing the House of Representatives: How Much Does Gerrymandering Matter?" In Red and Blue Nation? ed. Pietro S. Nivola and David W. Brady. Washington, DC: Brookings Institution.

Mann, Thomas E. 2006. "Polarizing the House of Representatives: How Much Does Gerrymandering Matter?" In Red and Blue Nation: Characteristics and Causes of America's Polarized Politics, ed. Pietro S. Nivola, and David W. Brady. Washington, DC: Brookings Institution Press.

Marsh, David and Gerry Stoker. 2010. "Introduction”. In Theory and Methods in Political Science, $3^{\text {rd }}$ ed. New York: Palgrave MacMillan.

Musket, Seth. 2009. No Middle Ground: How Informal Party Organizations Control Nominations and Polarize Legislatures. Ann Arbor: University of Michigan Press.

Mayhew, David. 1973. "Congressional Elections: The Case of the Vanishing Marginals.” Polity 6 (Spring): 295-318.

Mayhew, David. 1974. Congress: The Electoral Connection. New Haven: Yale University Press.

McCarty, Nolan, Keith T. Poole, and Howard Rosenthal. 2006. Polarized America: The Dance of Ideology and Unequal Riches. Cambridge: The MIT Press.

Miller, Jane E. 2005. Writing About Multivariate Analysis. Chicago: University of Chicago Press.

Miller, Warren E. 1991. "Party Identification, Realignment and Party Voting: Back to Basics." American Political Science Review (85): 557-68. 
Mondak, Jeffery J. 2010. Personality and the Foundations of Political Behavior. Cambridge: Cambridge University Press.

Mouw, Ted, and Michael E. Sobel. 2001. "Culture Wars and Opinion Polarization: The Case of Abortion." American Journal of Sociology 4 (January): 913-43.

Norris, Pippa, and Ronald Inglehart. 2004. Sacred and Secular: Religion and Politics Worldwide. Cambridge: Cambridge University Press.

Oppenheimer, Bruce I. 2005. "Deep Red and Blue Congressional Districts: The Causes and Consequences of Declining Party Competitiveness." In Red and Blue Nation? ed. Pietro S. Nivola and David W. Brady. Washington, DC: Brookings Institution.

Orren, Karen, and Stephen Skowronek. 2004. The Search for American Political Development. New York: Cambridge University Press.

Parsons, Craig. 2008. How to Map Arguments in Political Science. New York: Oxford University Press.

Patterson, Thomas E. 1993. Out of Order. New York: Alfred Knopf.

Phillips, Kevin. 1969. The Emerging Republican Majority. New York: Arlington House.

Page, Benjamin I. and Robert Y. Shapiro. 1992. The Rational Public. Chicago: University of Chicago Press.

Persily, Nathaniel. 2005. "Forty Years in the Political Thicket: Judicial Review of the Redistricting Process since Reynolds v. Sims." In Party Lines: Competition, Partisanship and Congressional Redistricting, ed. Thomas E. Mann, and Bruce E. Cain. Washington, DC: Brookings Institution Press.

Petrocik, John R. 1981. Party Coalitions and the Decline of the New Deal Party System. Chicago: University of Chicago Press.

Polsby, Nelson W. 2004. How Congress Evolves: Social Bases of Institutional Change. New York: Oxford University Press.

Poole, Keith T., and Howard Rosenthal. 1997. Congress: A Political-Economic History of Roll Call Voting. New York: Oxford University Press.

Poole, Keith T. and Howard Rosenthal. 1984. "The Polarization of American Politics." Journal of Politics 46: 1061-1079. 
Putnam, Robert D. 2007. "E Pluribus Unum: Diversity and Community in the Twenty-first Century: The 2006 Johan Skytte Prize Lecture." Scandinavian Political Studies 30 (June): 137-174.

Rae, Nicol C. 1998. Conservative Reformers: The Republican Freshmen and the Lessons of the 104th Congress. New York: M.E. Sharpe.

Rhode, David W. 1991. Parties and Leaders in the Postreform House. Chicago: University of Chicago Press.

Reynolds, Paul Davidson. 1971. A Primer in Theory Construction. New York: Allyn and Bacon.

Schachter, Jason. 2001. "Why People Move: Exploring the March 2000 Current Population Survey." Current Population Reports (May). Washington D.C.: U.S. Census Bureau.

Shoemaker, Pamela, James William Tankard, and Dominic L. Lasorsa. 2003. How to Build Social Science Theories. Thousand Oaks: SAGE Publications, Inc.

Sinclair, Barbara. 1995. Legislators, Leaders, and Lawmaking. Baltimore: johns Hopkins.

Sinclair, Barbra. 2005. "The New World of U.S. Senators." In Congress Reconsidered, ed. Lawrence C. Dodd and Bruce I. Oppenheimer. Washington, DC: CQ Press.

Skowronek, Stephen. 1982. Building a New American State: The Expansion of National Administrative Capacities, 1877-1920. New York: Cambridge University Press.

Skocpol, Theda. 1995. Protecting Soldiers and Mothers: The Political Origins of Social Policy in the United States. Cambridge: Harvard University Press.

Sorauf, Frank J. 1992. Inside Campaign Finance. New Haven: Yale University Press.

Stonecash, Jeffrey M., Mark D. Brewer, and Mack D. Mariani. 2003. Diverting Parties: Social Change, Realignment, and Political Polarization. Boulder, CO: Westview Press.

Stonecash, Jeffrey M. 2006: Political Parties Matter: Realignment and the Return of Partisan Voting. Boulder, CO: Lynn Riener.

Sundquist, J. L. 1983. Dynamics of the Party System: Alignment and Realignment of Political Parties in the United States. Rev. ed. Washington, DC: Brookings Institution. 
Sunstein, Cass. 2001. Republic.com. Princeton: Princeton University Press.

t'Hart, Paul. 2010. "Political Psychology: Exploring the Human Factor in Political Life." In Theory and Methods in Political Science, ed. David Marsh and Gerry Stoker. Basingstoke: Palgrave.

Teaford, Jon C. 1996. Post-Suburbia: Government and Politics in the Edge Cities. Baltimore: The Johns Hopkins University Press.

Teaford, Jon C. 2006. The Metropolitan Revolution: The Rise of Post-Urban America. New York: Columbia University Press.

Tukey, John W. 1977. Exploratory Data Analysis. Boston: Addison Wesley.

Wuthnow, Robert. 1988. The Restructuring of American Religion: Society and Faith Since World War II. Princeton: Princeton University Press.

Zaller, John. 1992. The Nature and Origins of Mass Opinion. New York: Cambridge University Press. 


\section{APPENDICES}

\section{APPENDIX A}

The distributions and differences discussed in this chapter are calculated using what I term the "winning vote margin", which is a relative value, or ratio, that expresses the difference between the Republican candidate's share of the total vote gained by the two parties in that election, minus the Democratic candidate's share of that total, in relation to the two-party vote total. The alternative approach would be to simply calculate the ratio directly, without recourse to differences, by taking the Republican share of the two-party vote and dividing by the Democratic share of the two-party vote.

The required election results were downloaded from the online archives of the Florida Division of Elections into an Excel file, and then manipulated using Excel formulas to produce the percentages and differences necessary to calculate the "winning vote margin" for each election. These final values were then used as inputs in Excel charting functions to produce the dot plots and bar charts reproduced in chapters 5, 6 and 7. 


\section{APPENDIX B}

The Congressional election results at the county level were calculated from elections data downloaded from the online archives of the Florida Division of Elections, available at: https://doe.dos.state.fl.us/elections/resultsarchive/index.asp

The data was downloaded into an Excel file, and sorted by office. For U.S. President, U.S. Senate, Governor, Attorney General, and Agriculture Commissioner, the values for the Republican candidate and the Democratic candidate were selected, and all votes for other candidates were removed. Thus there were two values for each county, which were then allocated to each county as the Republican or Democratic vote.

For the United States Representative (USR) were extracted from the file, and exported into a different spreadsheet. This sheet was then sorted by county, and then by Congressional district (CD) for each county.

For counties were each Congressional district within that county offered a choice between a Republican and a Democrat candidate, the vote totals were extracted and used to calculate the "winning vote margin" as explained in Appendix A. If a race within the county involved a member of either the Republican or Democratic parties running unopposed, or against a write-in (WI) candidate, that race and all the votes accruing to that race was eliminated from the calculation for "winning vote margin". This procedure created the Congressional results by county that are used in this chapter. 


\section{APPENDIX C}

Statistical control can be conceived in terms of the processes of "partialing", or "residualization". Partial coefficients represent residuals, are a value attributed to the relationship between a concept or variable and the outcome of interest, in this instance the two-party vote share, as if that relationship that were unaffected by the effect of the other variables in the model. This statistical artifice is the essential meaning behind "controlling" for other variables in multiple regression. Consequently, statistical control obtained in this manner is also referred to as partialing or residualizing. Other cognate terms are controlling for, holding constant, and covarying (Licht 1995).

Thus, for instance, the partial coefficient, or residual for " $\%$ white" in the model, reflects the relationship between the proportion of a county population that is white, and the two party vote share, In real life, of course, the proportion of a county that is "white", is related to other variables, reflecting the existing demographic and economic profile of the county. Thus statistical control is a mathematical artifice, and less straightforward and intuitive than experimental control. Unfortunately, experimental control is often neither feasible nor ethical. 


\section{APPENDIX D}

In this dissertation, I divide Florida into eight regions, with each Florida county allocated to one and only one region, as described in the table below.

\begin{tabular}{|c|c|c|c|c|c|c|c|}
\hline Northwest & $\begin{array}{l}\text { North } \\
\text { Central }\end{array}$ & Northeast & $\begin{array}{c}\text { Central } \\
\text { West }\end{array}$ & Central & $\begin{array}{c}\text { Central } \\
\text { East }\end{array}$ & Southwest & Southeast \\
\hline Escambia & Gadsden & Baker & Citrus & Marion & Volusia & Charlotte & Martin \\
\hline Santa Rosa & Leon & Nassau & Hernando & Sumter & Brevard & Glades & Palm Beach \\
\hline Okaloosa & Wakulla & Duval & Pasco & Lake & Indian River & Lee & Broward \\
\hline Walton & Jefferson & Clay & Pinellas & Seminole & Okeechobee & Hendry & $\begin{array}{l}\text { Miami } \\
\text { Dade }\end{array}$ \\
\hline Holmes & Madison & St. John's & Hillsborough & Orange & St. Lucie & Collier & Monroe \\
\hline Washington & Taylor & Putnam & Manatee & Osceola & & & \\
\hline Bay & Hamilton & Flagler & Sarasota & Polk & & & \\
\hline Jackson & Suwanne & & DeSoto & Hardee & & & \\
\hline Calhoun & Lafayette & & & Highlands & & & \\
\hline Liberty & Dixie & & & & & & \\
\hline Gulf & Columbia & & & & & & \\
\hline \multirow[t]{5}{*}{ Franklin } & Union & & & & & & \\
\hline & Bradford & & & & & & \\
\hline & Gilchrist & & & & & & \\
\hline & Alachua & & & & & & \\
\hline & Levy & & & & & & \\
\hline
\end{tabular}




\begin{abstract}
APPENDIX E
Variables that had skew or kurtosis values above 2.0 were identified for transformed. Two types of transformations were used. One was to take the square root of every value of a variable. This brings the larger values closer to the lower values and makes the data less spread out, thus correcting the degree of skewness in the data. In some instances, this square root transformation was not sufficient, especially when there were extreme values in a variable; these extreme cases were recoded to an appropriate unit of measure from their nearest neighbor.
\end{abstract}

For example, the percentage of Hispanic residents in 1990 had an extreme outlier-Miami Dade county with $49.03 \%$. The next nearest neighboring data point was Hardee county with $22.99 \%$. Miami Dade was recoded to $30.99 \%$. This preserves the order of the values - for example, the highest is still the highest — but reduces the skew of the variable. These variables were then transformed using the square root transformation. Once this was completed, all variables were sufficiently normal to meet the condition for multiple regression. 


\section{APPENDIX F}

The data on Evangelical Christians is obtained from the data sets of the Association on Religion Data Archives (ARDA), maintained and updated by Pennsylvania State University, State College, PA, and archived and accessible online at http://www.thearda.com.

The data on Evangelical Christians used in the analysis in this study is drawn from the records archived at:

http://www.thearda.com/mapsReports/reports/selectCounty.asp.

The ARDA divides each county population into six categories: Evangelical Protestant, Mainline Protestant, Orthodox, Catholic, Other, and Unclaimed. To calculate the percentage Evangelical, I took the raw number, and divided by the county population. I repeated this process for data for 1980 and 2000.

The ARDA defines "Evangelical Protestant" in terms of adherence to one of several Christian sects or denominations. This list can be viewed here: http://www.thearda.com/mapsReports/reports/evangelical.asp. The definition of "adherent" includes full members, their family members, and others who attend regularly. Note that the ARDA definition of "Evangelical Protestant" does not include historically black churches or denomination families. 
In popular use, the term "Evangelical" has variations, but most Evangelical Protestant leaders identify the term with two main tenets (in addition to the basic Christian creed that Jesus Christ as the Son of God). One is that the Bible is authoritative, or the Word of God. More conservative evangelicals construe this as literal inerrancy. More liberal evangelicals construe this to mean that the Bible is a mix of literal and allegorical statements. The second tenet is an obligation to share the faith in some way, either through regular church attendance with like-minded believers, or the more expansive obligation to simply share the "good news" with, or seek to persuade, nonbelievers. 
VITA

\section{REZWAN HUSSAIN}

1991

1994

1994-1998

1998-2000

2001-2002

2003-2004

2004-2011

2004-2006

2007-2010

2010-2011
B.A., Political Science

Swarthmore College

Swarthmore, Pennsylvania

M.A., Government

University of Texas at Austin

Austin, Texas

Research Analyst

Greenwich Partners

Greenwich, Connecticut

Assistant Vice-President

Greenwich Natwest

London, UK

Portfolio Manager

Von Kohorn Research Associates

Westport, Connecticut

Travel in South America and Asia

Doctoral Candidate

Department of Politics and International Relations

Florida International University

Miami, Florida

Teaching Assistant

Department of Politics and International Relations

Florida International University

Miami, Florida

Instructor, American Politics, International

Politics, and Comparative Politics

Department of Politics and International Relations

Florida International University

Miami, Florida

Instructor, English Composition

Writing Program

Florida International University, Miami, Florida 